Generation Interconnection Policies and Wind Power: A Discussion of Issues, Problems, and Potential Solutions

K. Porter, S. Fink, C. Mudd, and J. DeCesaro Exeter Associates, Inc.

Columbia, Maryland
Subcontract Report NREL/SR-550-44508 January 2009 


\section{Generation Interconnection Policies and Wind Power: A Discussion of Issues, Problems, and Potential Solutions}

K. Porter, S. Fink, C. Mudd, and J. DeCesaro Exeter Associates, Inc.

Columbia, Maryland

NREL Technical Monitor: D. Corbus

Prepared under Subcontract No. LAM-8-77548-01

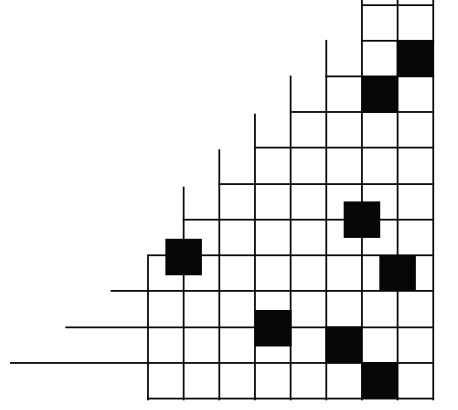




\section{NOTICE}

This report was prepared as an account of work sponsored by an agency of the United States government. Neither the United States government nor any agency thereof, nor any of their employees, makes any warranty, express or implied, or assumes any legal liability or responsibility for the accuracy, completeness, or usefulness of any information, apparatus, product, or process disclosed, or represents that its use would not infringe privately owned rights. Reference herein to any specific commercial product, process, or service by trade name, trademark, manufacturer, or otherwise does not necessarily constitute or imply its endorsement, recommendation, or favoring by the United States government or any agency thereof. The views and opinions of authors expressed herein do not necessarily state or reflect those of the United States government or any agency thereof.

Available electronically at http://www.osti.gov/bridge

Available for a processing fee to U.S. Department of Energy and its contractors, in paper, from:

U.S. Department of Energy

Office of Scientific and Technical Information

P.O. Box 62

Oak Ridge, TN 37831-0062

phone: 865.576 .8401

fax: 865.576 .5728

email: mailto:reports@adonis.osti.gov

Available for sale to the public, in paper, from:

U.S. Department of Commerce

National Technical Information Service

5285 Port Royal Road

Springfield, VA 22161

phone: 800.553 .6847

fax: 703.605.6900

email: orders@ntis.fedworld.gov

online ordering: http://www.ntis.gov/ordering.htm

This publication received minimal editorial review at NREL 


\section{Acknowledgments}

The National Renewable Energy Laboratory's Wind Technologies Program funded the research that went into this project. The authors thank Brian Parsons and David Corbus of the National Renewable Energy Laboratory for supporting this work.

We also thank Lynn Coles of the National Renewable Energy Laboratory; Mark Bolinger and Ryan Wiser of the Ernest Orlando Lawrence Berkeley National Laboratory; Eric Laverty of the Midwest ISO; Natalie McIntire, a consultant to Wind on the Wires and the American Wind Energy Association; Brendan Kirby, a consultant to the National Renewable Energy Laboratory; and Matt Schuerger of Energy Systems Consulting LLC for their review comments. The authors also thank Mr. Laverty of the Midwest ISO, Dottie Roark of ERCOT, Ed Weber of the Western Area Power Administration, Monica Gonzalez of ISO New England, Sean Egusa of the Bonneville Power Administration, and Ken Mancini of PJM for providing review comments on the appendix. Finally, the authors thank Bruce Green of the National Renewable Energy Laboratory for his editorial assistance. 


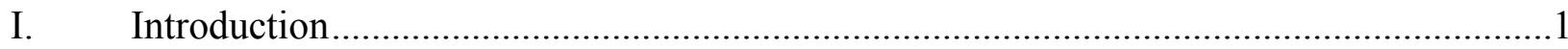

II. Basics of Large-Scale Generator Interconnection .......................................................

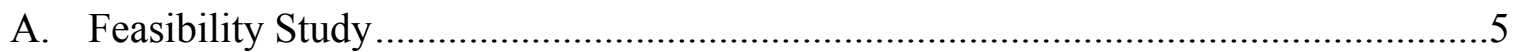

B. Interconnection System Impact Study .................................................................

C. Interconnection Facilities Study …………………..........................................

D. Large Generator Interconnection Agreement..........................................................

E. Orders 661 and 661-A: Interconnection for Wind Energy ………………………....13

III. Generator Interconnection Requests in the Queues ......................................................

IV. Factors Contributing to the Surge in Interconnection Requests …………......................24

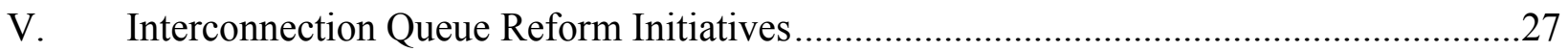

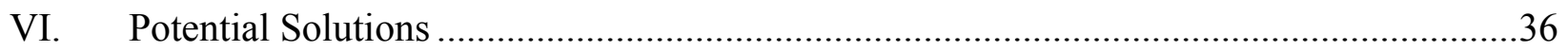

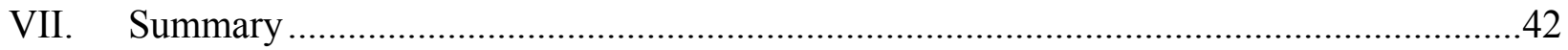

\section{LIST OF TABLES}

PAGE

$1 \quad$ Summary of Queue Procedures versus Order 2003 ......................................................... 11

2 Status of Queues as of July 2008, 2000 - 2007 by Number of Requests ........................ 23

3 Status of Queues as of July 2008, $2000-2007$ by MW of Capacity …………................ 23

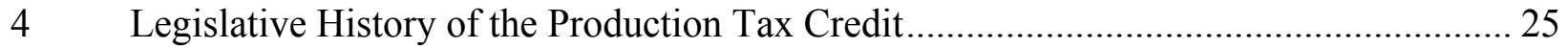

$5 \quad$ RTO and ISO Generation Queue Reform Proposals (as of December 2008)................... 33 


\section{LIST OF FIGURES}

PAGE

1 FERC Order 2003 Timeline for Basic Interconnection Studies .........................................4

2 Flow Chart of the Large Generating Facility Interconnection Process................................8

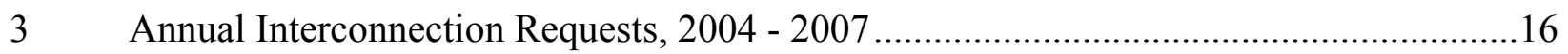

$4 \quad$ MW of Annual Interconnection Requests, 2006 and 2007...........................................17

$5 \quad$ Generator Interconnection Requests by Fuel Source, 2007...........................................18

6 Capacity of Interconnection Requests Compared to Installed Capacity

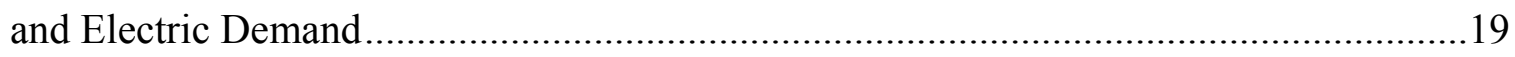

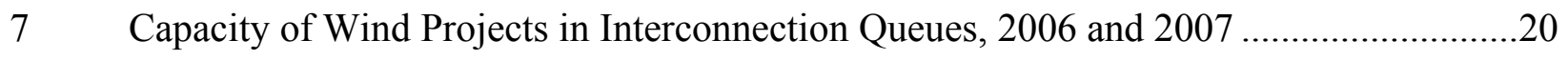

$8 \quad$ Number of Interconnection Requests for 2008 through October 20, 2008.....................21

$9 \quad$ Number of Interconnection Requests by Fuel Type for 2008 through

October 20, 2008

10 Capacity of Interconnection Requests for 2008 through October 20, 2008 .....................22

11 Capacity of Interconnection Requests by Fuel Source for 2008 through

October 20, 2008

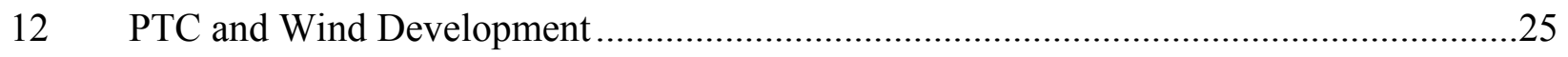

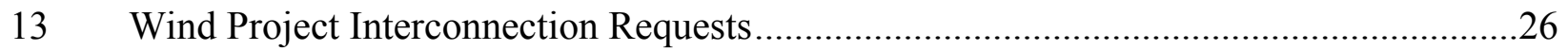

14 Potential Estimated Deposits for a 100-MW Project by RTO or ISO ………....................37 


\section{APPENDICES}

PAGE

A. Bonneville Power Administration................................................................................. A-1

B. California Independent System Operator.....................................................................

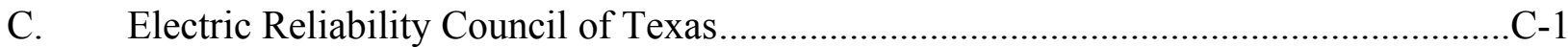

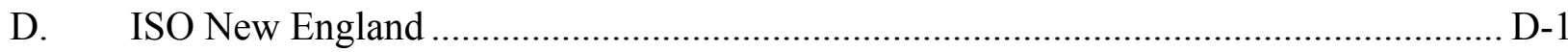

E. The Midwest Independent System Operator...................................................................

F. New York Independent System Operator ...................................................................

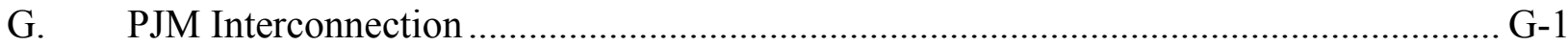

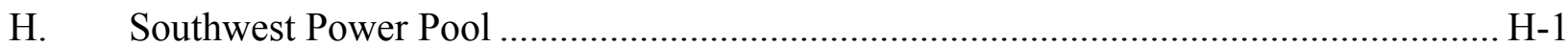

I. Western Area Power Administration........................................................................... 


\section{Introduction}

On July 24, 2003, the Federal Energy Regulatory Commission (FERC) issued Order 2003 governing large generator interconnection procedures, defined as those encompassing generation facilities with a nameplate capacity of $20 \mathrm{MW}$ or greater. ${ }^{1}$ Order 2003 directed transmission providers to file revised open access transmission tariffs (OATT) adding the standardized Large Generator Interconnection Procedures (LGIP) contained in the Order. The procedures and rules were subsequently reaffirmed and clarified under Orders 2003-A in March 2004, 2003-B in December 2004, and 2003-C in June 2005. ${ }^{2}$ FERC-jurisdictional transmission providers (i.e., an entity that engages in the generation or transmission of energy at the wholesale level) can either follow the standard interconnection agreement and procedures set out in Order 2003, or file variances as long as they are equal to or superior to the standard interconnection agreement FERC included in Order 2003. FERC gave greater flexibility to regional transmission organizations (RTOs) and independent system operators (ISOs) in complying with Order 2003, stating that as independent entities, RTOs and ISOs will be less likely to discriminate against other market participants.

FERC issued Order 2003 out of concern that the interconnection process at the time was characterized by delays and a lack of standardization and therefore was discouraging generators from participating in the electricity market. FERC determined that such delays and lack of standardization gave a competitive advantage to utilities that owned both transmission and generation facilities and was therefore inconsistent with FERC Order 888, which required transmission providers to offer open access to transmission facilities. FERC determined that a single set of interconnection procedures and agreements was necessary. FERC's intent was to reduce the opportunities for undue discrimination and accelerate the development of new generation, while maintaining reliability and ensuring that rates are just and reasonable.

Since the adoption of Order 2003, a large number of generator interconnection applications have been filed. From 2004 through 2007, the number of interconnection queue applications more than tripled amongst Bonneville Power Administration (BPA), the Western Area Power Administration (WAPA), and RTOs and ISOs. As a result, generation interconnection queues across the country are clogged with proposed generating projects, which in turn has increased processing time for interconnection studies and contributed to significant delays for generating projects. Consequently, both transmission providers and generators are

\footnotetext{
${ }^{1}$ FERC has a related policy governing small generator interconnection procedures for generators less than $20 \mathrm{MW}$. This report is primarily focused on interconnection policies for large generators over $20 \mathrm{MW}$. Standardization of Small Generator Interconnection Agreements and Procedures, Order No. 2006, FERC Stats. \& Regs. ๆ 31,180, order on reh'g, Order No. 2006-A, FERC Stats. \& Regs. ๆ 31,196 (2005), order granting clarification, Order No. 2006-B, FERC Stats. \& Regs. ๆ 31,221 (2006), appeal pending sub nom. Consol. Edison Co. of N.Y., Inc. v. FERC, Nos. 06-1275, et al., (D.C. Cir. filed July 14, 2006).

${ }^{2}$ Federal Energy Regulatory Commission, Standardization of Generator Interconnection Agreements and Procedures, Order No. 2003, 68 FR 49845 (Aug. 19, 2003), FERC Stats. \& Regs. ๆ 31,146 (2003) (Order No. 2003), order on reh'g, Order No. 2003-A, 69 FR 15932 (Mar. 26, 2004), FERC Stats. \& Regs. ๆ 31,160 (2004) (Order No. 2003-A), order on reh'g, Order No. 2003-B, 70 FR 265 (Jan. 4, 2005), FERC Stats. \& Regs. $\mid 31,171$ (2005) (Order No. 2003-B). See also Notice Clarifying Compliance Procedures, 106 FERC 91,009 (2004), Order No. 2003-C, 111 FERC 91,401 (June 16, 2005), aff'd sub nom. Nat'l Ass'n of Regulatory Util. Comm'rs v. FERC, 475 F.3d 1277 (D.C. Cir. 2007).
} 
frustrated. Transmission providers contend that the low entry requirements and the ease of suspending applications leads to a congested interconnection queue; generators complain about uncertain transmission cost allocation, delays in processing interconnection applications, potential lost market opportunities, and multiple studies and restudies, among other things.

FERC held a technical conference on generator interconnection queues in December 2007, and issued an order in March 2008 directing RTOs and ISOs to file a status report on their interconnection queues and queue reform initiatives (if any) by April 2008. ${ }^{3}$ FERC focused on RTOs and ISOs as the size of the interconnection queue backlog seemed more prominent with them. The RTOs and ISOs were directed to file status reports on the size of their interconnection queue, the expected timetable for processing pending interconnection requests, the contributors to the queue backlog and whether clustering has helped or not helped minimize the clogging of the interconnection queue, and the status and schedule of any stakeholder processes on interconnection queue reform. It also directed the RTOs and ISOs to address the impacts of any potential reforms on smaller customers or other classes of interconnection customers. ${ }^{4}$

All of the RTOs and ISOs filed their status reports with FERC in April 2008, and the RTOs and ISOs are following up the status reports with reform proposals. FERC approved the Midwest Independent Transmission System Operator's (Midwest ISO) generator interconnection queue reform initiative in August 2008, and the California ISO's (CAISO) reform proposal in September 2008. PJM Interconnection has already implemented several initial reforms and more are being discussed, and ISO New England filed its proposal with FERC in October 2008. Another generation interconnection queue reform proposal is being prepared by the Southwest Power Pool (SPP). The New York ISO is beginning its stakeholder process to consider possible interconnection queue reforms.

This report describes the adoption and implementation of FERC Order 2003 and the reasons for the sharp rise in generation interconnection filings in recent years. After an introduction, Section II explains the basics of large-scale generator interconnection. Section III summarizes the number of generator interconnection filings at BPA, WAPA, and the RTOs and ISOs across the country. Section IV documents the reasons for these sharp increases in generator interconnection filings. Section V explains the interconnection queue reform initiatives that have been approved, proposed, or are under consideration. A review of potential solutions to the problem of clogged generator interconnection queues is provided in Section VI. The report closes with a summary in Section VII.

\section{Basics of Large-Scale Generator Interconnection}

The central feature of the generation interconnection procedure is the interconnection queue, effectively the waiting line for connecting to the grid. To date, the queue has been established on a first-come first-served basis, where the transmission provider assigns a sequential position to interconnection customers as they first file their interconnection request. The review of generator interconnection requests is conducted in phases with a series of studies,

\footnotetext{
${ }^{3}$ Federal Energy Regulatory Commission, Interconnection Queuing Practices, Order on Technical Conference, 122 FERC $\uparrow 61,252(2008)$.

${ }^{4}$ Federal Energy Regulatory Commission, Order on Technical Conference. 122 FERC $\uparrow$ 61,252, March 20, 2008.
} 
each involving more detail and financial commitment. Each of the interconnection studies must take into account all other projects ahead of the proposed project in the generation interconnection queue.

Generators can request energy-only interconnection, whereby the generator can connect to the transmission grid and deliver energy on an as-available basis. The interconnection study for an energy-only interconnection request consists of stability and steady state analysis that would identify the network upgrades necessary to interconnect the facility to the grid without negatively affecting reliability. Alternatively, a network interconnection request requires the transmission provider to assess what transmission network upgrades are needed in order to integrate the generating facility into the grid in the same manner as the transmission provider would integrate its own facilities to serve native load. Among other things, the studies for a network interconnection request include analysis of the transmission provider's system at peak load and under a variety of severely stressed conditions to determine whether the aggregate of all generation in the area can be delivered to the aggregate of all load in the area when the interconnection customer's generating facility is at full output, consistent with reliability criteria and procedures. Typically, a network interconnection is required to participate in capacity markets or to be counted as a capacity resource. For either energy-only or network interconnection service, transmission service must be arranged separately under the transmission provider's open access transmission tariff.

Order 2003 stipulates that interconnection customers must submit separate requests for each project site, but are able to submit multiple requests for a single site, something done by interconnection customers that want to examine the feasibility of different points of interconnection for a single project. With each request, interconnection customers must also provide an expected in-service date. The projected in-service date must be the lesser of seven years, or the planning window for the regional or transmission provider's expansion planning period. The expected in-service date can exceed this time period (up to a maximum of 10 years) if the interconnection customer can demonstrate that a large project will require a longer lead time, or can be even longer if the transmission provider and interconnection customer mutually agree to an extension.

Transmission providers assign queue positions according to the date and time that they receive a valid interconnection request. The position then determines the order in which the series of interconnection studies are conducted, and interconnection construction costs are allocated. A queue position can only be transferred to another interconnection customer with the transfer of the specific generating facility identified in the initial queue request. It is not possible to transfer the position in the queue to a new or materially different project. Interconnection customers may withdraw their requests at any time, but are liable for all costs incurred up to that point. Order 2003 also contains a provision for suspension of a project without loss of queue position. An interconnection customer can, at any time, request that a project be suspended for a cumulative period of up to three years. Suspension does not result in loss of queue position, and the transmission provider is still obligated to treat the project as a legitimate facility in studies conducted for other projects with lower queue positions.

The generator interconnection process leading up to a Large Generator Interconnection Agreement (LGIA) consists of three studies - feasibility study, system impact study, and interconnection facilities study - that are done sequentially while taking into account all other 
interconnection requests higher up in the queue. The three studies consist of increasingly more detailed engineering assessments that examine the technical considerations of interconnecting the particular project onto the grid at a certain point, while maintaining system balance and not exceeding the operating limits of the grid. Figure 1 provides an expected timeline for these three studies, outlined in more detail below. ${ }^{5}$

\section{Figure 1}

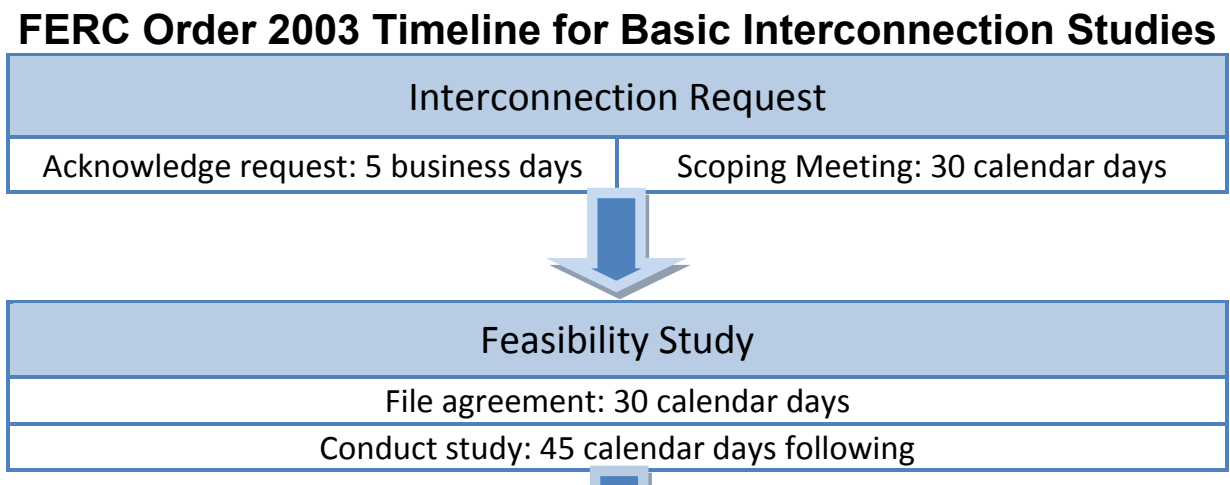

\begin{tabular}{|c|}
\hline Feasibility Study Results \\
\hline Results meeting: 10 business days \\
\hline Provide System Impact Study Agreement: 3 business days following \\
\hline
\end{tabular}

\begin{tabular}{|c|}
\hline System Impact Study \\
\hline File agreement: 30 calendar days \\
\hline Conduct study: 90 calendar days following \\
\hline
\end{tabular}

\begin{tabular}{|c|}
\hline System Impact Study Results \\
\hline Meeting: 10 business days \\
\hline Provide Interconnection Facilities Study Agreement: 3 business days following \\
\hline
\end{tabular}

\begin{tabular}{|c|}
\hline Interconnection Facilities Study \\
\hline Plus/minus $20 \%$ of cost: 90 calendar days \\
\hline Plus/minus $10 \%$ of cost: 180 calendar days \\
\hline
\end{tabular}

Order 2003 sets these study time requirements on a 'best effort' basis and hence, they are not considered legally binding deadlines. The timeline above includes the basic study phases only

\footnotetext{
${ }^{5}$ Information on studies taken from: FERC, "Docket No. RM02-1-001; Order No. 2003-A, Appendix B, Standard Large Generator Interconnection Procedures (LGIP) including Standard Large Generator Interconnection Agreement (LGIA)," March 3, 2004.
} 
and does not include any optional studies that may need to be performed. Also, additional time following the facilities study is required for negotiating and filing the LGIA.

\section{A. Feasibility Study}

The interconnection study process begins with an interconnection feasibility study agreement that specifies that the interconnection customer is responsible for study costs. The transmission provider and interconnection customer then conduct a scoping meeting after which the interconnection customer has five days to provide an attachment to the study agreement outlining the desired point(s) of interconnection and any alternative points. The transmission provider then has five days to sign and return the study agreement with a cost estimate for completing the study. Within 30 days, the interconnection customer executes the agreement and provides a $\$ 10,000$ deposit, which then reserves the interconnection customer's place in the interconnection queue. The initial feasibility study consists of a high-level look at whether the project is feasible at that particular point of entry into the grid. The feasibility study considers the base case with all generating facilities that are currently, or may be in the near future, connected to the grid. ${ }^{6}$ This includes:

- All existing generating facilities;

- All proposed generating facilities interconnected to affected systems that may have an impact on the current request; ${ }^{7}$

- All proposed generating facilities that have a pending higher queued interconnection request; and

- All proposed generating facilities that do not have a queue position, but have executed an LGIA or requested that their LGIA be filed with FERC. ${ }^{8}$

FERC directs transmission providers to make an effort to complete the initial feasibility study within 45 days. The feasibility study results include a list of facilities needed to construct the interconnection and a non-binding good-faith estimate of the costs and time required to complete the construction. The transmission provider then meets with the interconnection customer within ten days to discuss the results. Sometimes the need for a re-study is identified due to some significant change in circumstances. This could include:

- A higher-queued project withdrawing from the queue;

- Substantial modifications being made to a higher-queued project; or

- A re-designation of the point of interconnection.

Regardless of the reason, if a re-study is required, the cost is borne by the interconnection customer. The need for a re-study, however, does not affect the interconnection customer's queue position.

\footnotetext{
${ }^{6}$ The base case refers to the base-case power flow, short circuit, and stability data for interconnecting that particular facility to that point on the existing grid.

${ }^{7}$ Affected system refers to an electric system other than that particular transmission provider's system that may be affected by the proposed interconnection.

${ }^{8}$ For example, this may be the case if a generator already had an LGIA with a transmission provider prior to the implementation of Order 2003.
} 
Order 2003 allows transmission providers to forego the initial feasibility study and move straight to the interconnection system impact study. In this case, the $\$ 10,000$ deposit is applied to the cost of the interconnection system impact study. The interconnection customer must still meet all the conditions required to conduct an impact study (discussed below).

\section{B. Interconnection System Impact Study}

Following the meeting to discuss the feasibility study, and assuming a re-study is not required, the transmission provider has three days to provide a non-binding, good-faith cost and timeframe estimate for completing the interconnection system impact study. If the interconnection customer wishes to move forward with the project, it must execute the study agreement, provide documentation of project site control, and submit a $\$ 50,000$ deposit to the transmission provider within 30 days. The system impact study is a more detailed version of the feasibility study and evaluates the impact of the proposed project on system reliability. The transmission provider is obliged to try to complete the study within 90 days and if unable to do so, it must notify the interconnection customer of an updated estimated completion date. Within ten days following completion of the system impact study, the parties will meet to discuss the results and determine if a re-study is required. Any required re-study must be done within 60 days and does not result in a loss of queue position.

\section{Interconnection Facilities Study}

The final phase consists of the interconnection facilities study. The interconnection facilities study is a detailed study that identifies what equipment, engineering, procurement, and construction work will be required to connect the proposed generating project to the grid, including all transformer configurations, switchgear, meters, and any other equipment. The study includes estimates of the full interconnection cost and the time required to complete the construction. The transmission provider has three days to provide an interconnection facilities study agreement along with an estimate of the cost and time required to complete the interconnection facilities study. The interconnection customer then has 30 days to execute the agreement, provide the necessary technical data, and pay either $\$ 100,000$ or the interconnection customer's portion of the estimated monthly cost of conducting the interconnection facilities study, whichever is greater.

The transmission provider has 90 days to provide a draft report with a good faith cost estimate that is within 20 percent of the actual costs, or 180 days to provide a draft report with a good- faith cost estimate within 10 percent of actual costs. If the transmission provider cannot meet these deadlines, it must notify the interconnection customer of the delay and provide an updated timeframe and an explanation. Following receipt of the draft interconnection facilities study, the interconnection customer has 30 days to provide written comments that are to be included in the finalized facilities study. The transmission provider and interconnection customer will meet to discuss the results within 10 days to determine if a re-study is required.

Following the successful conclusion of the studies and agreement on the results, the transmission provider may provide an engineering and procurement agreement. This is an optional agreement that allows the transmission provider to begin engineering and procurement of any items that may have long acquisition lead-times. The interconnection customer can also 
request a series of optional interconnection studies. The optional studies are for informational purposes only, and the interconnection customer must bear the full study costs.

\section{Large Generator Interconnection Agreement}

The result of the studies and negotiations is the LGIA. It includes a set of appendices that the interconnection customer must fill out containing the detailed technical specification for the project. The interconnection customer may also request negotiations with the transmission provider regarding any disputed provisions in the technical requirements. Unless an agreement is made to the contrary, an interconnection customer has 60 days to execute the LGIA, request filing of an unexecuted LGIA to FERC, or initiate the dispute resolution process at FERC. Otherwise, the interconnection customer will lose its position in the queue and its interconnection request is considered withdrawn. Following the filing of the final LGIA with FERC, the interconnection customer must provide evidence of continued site control or a nonrefundable $\$ 250,000$ deposit that will later be applied towards the construction costs of any necessary facilities to interconnect the generation project. Additionally, the interconnection customer must demonstrate that it is meeting certain project milestones, which include one or more of the following:

- A fuel supply contract (if applicable);

- A cooling water supply contract (if applicable);

- Contracts for engineering, major equipment, or construction for the project;

- Contracts for the sale of energy or capacity from the project; and

- Application for an air, water, or land use permit.

Once all conditions are met and agreements in place, then the next step consists of gaining approval from FERC before proceeding with design, procurement, and construction of the facilities and upgrades agreed to in the LGIA.

Figure 2 provides a graphical representation of the large-scale generator interconnection process, as just described. 


\section{Figure 2}

\section{Flow Chart of the \\ Large Generating Facility Interconnection Process}

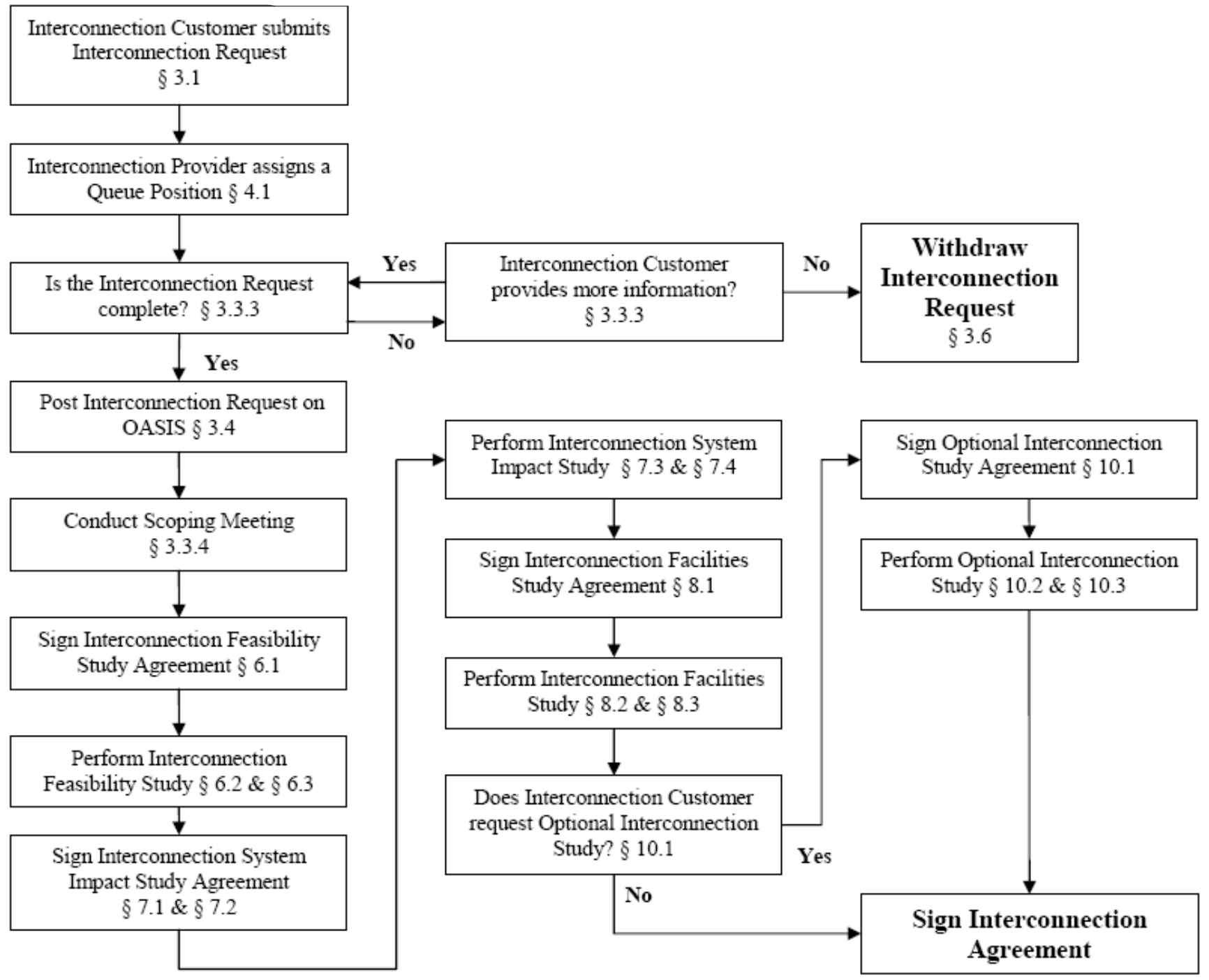

Source: FERC Order 2003, Appendix A. 


\section{Clustering}

Order 2003 also contains provisions for giving transmission providers the option to study interconnection requests as a group, also known as "clustering." Clustering must be implemented on the basis of queue position and within a fixed-time window based on pre-determined opening and closing dates. The start and end dates of the cluster window are of the transmission provider's choosing, but the duration of the window is not to exceed 180 days. A transmission provider can then allocate the costs of the common network upgrades for the clustered projects in proportion to each project's system impact, without regard to queue position.

\section{Cost Allocation}

Order 2003 outlines how interconnection and grid reinforcement costs should be allocated, and the interconnection studies help assign cost responsibilities between transmission providers and generation developers, and among generation projects. Two types of construction costs are defined: direct connection facilities and network upgrades. Direct connection facilities consist of all equipment and construction required to connect the new generating facility to the first point of interconnection with the transmission grid. Network upgrades consist of equipment and construction required to reinforce the existing transmission system in order to accommodate the new generation project. Generators are responsible for the costs of all interconnection studies and the cost of all direct connection facilities between the generator and the transmission grid. Generators also pay for the up-front costs of network upgrades and new additions to the transmission network that are required because of generator interconnections. Over time, the project owners are reimbursed for the network upgrade costs by transmission providers, with interest, via credits against the costs of transmission service to the interconnecting generator or, if available, financial transmission rights (FTRs). The costs for constructing network upgrades is allocated according to queue position and hence, is paid initially by the first interconnection customer that requires them, unless the transmission provider elects to cover the costs itself. Transmission providers have the option of fully reimbursing generators for the network upgrade portion within five years from when the generating facility comes on-line, or until the total of the transmission credits equals the generator's upfront payments plus interest.

Order 2003 allows RTOs and ISOs, defined as "independent entities," to propose alternative variations on the Order 2003 pro forma interconnection provisions. FERC stated that an RTO or ISO has "different operating characteristics depending on [its] size and location and is less likely to act in an unduly discriminatory manner than a Transmission Provider that is a market participant." As such, FERC's "independent entity" standard allows RTOs and ISOs to propose variations to Order 2003 that are "just and reasonable and not unduly discriminatory and would accomplish the purposes of Order 2003."10

RTOs and ISOs have used the independent entity variation to propose alternatives to the Order 2003 pro forma tariff on interconnection procedures and pricing of network upgrades. For example, the Midwest ISO allocates 50 percent of generator-related network upgrade costs directly to the generators, and 50 percent to load in the Midwest ISO. For transmission network upgrades above $345-\mathrm{kV}$ needed to maintain reliability, the Midwest ISO allocates 20 percent of

\footnotetext{
${ }^{9}$ FERC Order 2003, p. 827.

${ }^{10}$ Federal Energy Regulatory Commission, Interconnection Queuing Practices, Order on Technical Conference, 122 FERC 961,252 (2008), p. 13, note 10.
} 
the costs to all customers and 80 percent to beneficiaries as identified through modeling. For network upgrade costs over $\$ 100,000$, SPP allocates one-third of the upgrade costs to all transmission customers in the SPP region and two-thirds are allocated to an affected zone on a megawatt-mile basis. More recently, the RTO's and ISO's queue reform proposals are also being filed under the independent entity standard variation. Table 1 on the next page compares the different RTO and ISO pre-reform procedures versus those prescribed in Order 2003. 
Table 1

Summary of Queue Procedures versus Order 2003

\begin{tabular}{|c|c|c|c|c|c|c|c|c|}
\hline & Order 2003 & PJM $^{1}$ & $\begin{array}{l}\text { Midwest } \\
\text { ISO }^{2}\end{array}$ & NYISO & ISO-NE & SPP & CAISO $^{3}$ & ERCOT \\
\hline $\begin{array}{l}\text { Interconnection } \\
\text { Request Deposit }\end{array}$ & $\$ 10,000$ & $\$ 10,000$ & $\$ 10,000$ & $\$ 10,000$ & $\$ 10,000$ & $\$ 10,000$ & $\$ 10,000$ & $\begin{array}{l}\$ 1,000 \text { to } \\
\$ 5,000\end{array}$ \\
\hline Site Control/Deposit & $\begin{array}{c}\text { SC or } \\
\$ 10,000\end{array}$ & None & $\begin{array}{c}\text { SC or } \\
\$ 10,000\end{array}$ & $\begin{array}{c}\text { SC or } \\
\$ 10,000\end{array}$ & SC or $\$ 10,000$ & $\begin{array}{c}\text { SC or } \\
\$ 10,000\end{array}$ & $\begin{array}{c}\text { SC or } \\
\$ 10,000\end{array}$ & None \\
\hline $\begin{array}{c}\text { Third Party Feasibility } \\
\text { Study }\end{array}$ & No rule & Yes & Yes & Yes & No & No & Yes & No \\
\hline Waive Feasibility Study & Yes & No & Yes & Yes & No & Yes & Yes & No \\
\hline $\begin{array}{c}\text { Feasibility Study } \\
\text { Timeline }\end{array}$ & 45 days & 90 days & 45 days & 45 days & 45 days & 45 days & 45 days & 90 days \\
\hline Cluster Studies & Optional & Conducts & Optional & Optional & Optional & Optional & Optional & Optional \\
\hline $\begin{array}{c}\text { System Impact Study } \\
\text { Deposit }\end{array}$ & $\$ 50,000$ & $\$ 50,000$ & $\$ 50,000$ & $\$ 50,000$ & $\begin{array}{c}\$ 50,000 \text { or } \\
\text { estimated cost }\end{array}$ & $\$ 50,000$ & $\$ 50,000$ & $\begin{array}{c}\text { Based on } \\
\text { project size }\end{array}$ \\
\hline $\begin{array}{l}\text { Permit Applications/ } \\
\text { Site Control/Deposit }\end{array}$ & Site Control & Permits & Site Control & Site Control & Site Control & Site Control & Site Control & Site Control \\
\hline $\begin{array}{c}\text { System Impact Study } \\
\text { Timeline }\end{array}$ & 90 days & 120 days & 90 days & 90 days & 90 days & 90 days & 90 days & $\begin{array}{l}\text { Up to } 210 \\
\text { days }\end{array}$ \\
\hline
\end{tabular}

${ }^{1}$ Some of PJM's generator interconnection reforms have been approved and implemented.

2 The Midwest ISO has a new FERC-approved generator interconnection system in place as of August 2008.

${ }^{3}$ CAISO's new generator interconnection process was approved by FERC in September 2008.

${ }^{4}$ Some RTOs and ISOs hire their own consultants at times. Third party consultants refer to those hired by generation developers. 
Table 1

Summary of Queue Procedures versus Order 2003 (continued)

\begin{tabular}{|c|c|c|c|c|c|c|c|c|}
\hline & Order 2003 & PJM & Midwest ISO & NYISO & ISO-NE & SPP & CAISO & ERCOT \\
\hline $\begin{array}{l}\text { Interconnection } \\
\text { Facilities Study Deposit }\end{array}$ & $\begin{array}{l}\$ 100,000 \text { or } \\
\text { share of } \\
\text { costs }\end{array}$ & $\begin{array}{l}\$ 100,000 \text { or } \\
\text { 3-month } \\
\text { costs }\end{array}$ & $\begin{array}{l}\$ 100,000 \text { or } \\
\text { estimated } \\
\text { monthly cost }\end{array}$ & $\begin{array}{l}\$ 100,000 \text { or } \\
\text { estimated } \\
\text { monthly cost }\end{array}$ & $\begin{array}{l}\$ 100,000 \text { or } \\
\text { estimated } \\
\text { monthly cost }\end{array}$ & $\begin{array}{l}\$ 100,000 \text { or } \\
\text { estimated } \\
\text { monthly cost }\end{array}$ & $\begin{array}{l}\$ 100,000 \text { or } \\
\text { estimated } \\
\text { monthly cost }\end{array}$ & $\begin{array}{l}\text { Combined } \\
\text { with SIS }\end{array}$ \\
\hline $\begin{array}{c}\text { Optional Sensitivity } \\
\text { Analysis Study }\end{array}$ & $\begin{array}{l}\text { Yes, } \$ 10,000 \\
\text { deposit }\end{array}$ & No & Yes & $\begin{array}{c}\text { Yes, } \\
\text { estimated } \\
\text { cost deposit }\end{array}$ & $\begin{array}{l}\text { Yes, } \$ 10,000 \\
\text { deposit }\end{array}$ & No & Yes & No \\
\hline Suspend Projects & Up to 3 years & Up to 3 years & Up to 3 years & $\begin{array}{l}\text { Up to } 3 \text { years } \\
\text { but only } \\
\text { after signing } \\
\text { the } \text { LGIA }^{5}\end{array}$ & $\begin{array}{c}\text { Up to } 3 \text { years } \\
\text { but only after } \\
\text { signing the } \\
\text { LGIA }\end{array}$ & Up to 3 years & $\begin{array}{l}\text { Up to } 3 \text { years } \\
\text { but only } \\
\text { after signing } \\
\text { the LGIA }\end{array}$ & No \\
\hline $\begin{array}{c}\text { Engineering \& } \\
\text { Procurement } \\
\text { Agreement }\end{array}$ & Optional & Required $^{6}$ & Optional & Optional & Optional & Optional & Optional & No \\
\hline $\begin{array}{l}\text { Large Generator } \\
\text { Interconnection } \\
\text { Agreement Timeline }\end{array}$ & $\begin{array}{l}60 \text { days to } \\
\text { file }\end{array}$ & 60 days & $\begin{array}{l}60 \text { days to } \\
\text { file }\end{array}$ & $\begin{array}{l}60 \text { days to } \\
\text { file }\end{array}$ & 75 days & $\begin{array}{l}60 \text { days to } \\
\text { file }\end{array}$ & $\begin{array}{l}60 \text { days to } \\
\text { file }\end{array}$ & 180 days \\
\hline $\begin{array}{l}\text { Large Generator } \\
\text { Interconnection } \\
\text { Agreement Deposit }\end{array}$ & $\$ 250,000$ & $\begin{array}{l}\text { Estimated } \\
\text { costs }\end{array}$ & $\$ 250,000$ & $\$ 250,000$ & $\$ 250,000$ & $\$ 250,000$ & $\$ 250,000$ & None \\
\hline
\end{tabular}

${ }^{5}$ Does not allow projects to enter suspended status during study phase. Once an LGIA is executed, construction activity can be suspended for up to 3 years.

${ }^{6}$ Customers must sign a construction agreement, but they have an option for self-building interconnection facilities. 


\section{E. Orders 661 and 661-A: Interconnection for Wind Energy}

\section{Order 661}

In Order No. 2003-A, FERC noted that the procedures and agreements laid out in Order 2003 were based on the needs of traditional generation facilities, and that non-synchronous generators, such as wind plants, might benefit from a different approach. A blank Appendix $G$ was added to the standard LGIA for the future adoption of requirements specific to nonsynchronous technologies. ${ }^{11}$

In a Notice of Proposed Rulemaking (NOPR) issued in 2004, FERC proposed technical standards for the interconnection of large wind generating plants to be included in Appendix $G$ of the LGIA. ${ }^{12}$ The NOPR attempted to recognize the unique characteristics of wind plants, specifically that they use induction generators, consisting of several small generators connected to a collector system, and do not respond to grid disturbances in the same manner as large conventional generators.

On June 2, 2005, FERC issued Order No. 661 requiring public utilities to add standard procedures and technical requirements for the interconnection of large wind generation units to their standard LGIPs and LGIAs in their OATTs.

The technical requirements for wind generation facilities outlined in the NOPR were adopted in Order No. 661. The requirements address low-voltage ride-through capability, supervisory control and data acquisition (SCADA) capability, and power factor design criteria, among others.

- Low-Voltage Ride-Through (LVRT) Standard. The NOPR required wind generators to stay connected to the grid for voltage drops of 15 percent of nominal network voltage levels; however, it is not required unless the system impact study shows that it is needed. As a result, a wind plant is only required to satisfy the LVRT standard if the transmission provider illustrates, through the system impact study, that such capability is necessary to ensure safety or reliability. The point of interconnection, rather than at the high side of the wind plant substation transformers, was designated as the point of measurement for the LVRT.

- Power Factor Design Criteria (Reactive Power). A power factor range of $+/-0.95$ was adopted for large wind generating plants. The wind plant is only required to maintain the required power factor range if the transmission provider shows, through the system impact study, that this capability is required of the plant to ensure safety or reliability. The onus is on the transmission provider to show that reactive power capability is needed for each individual wind plant interconnection customer. If it is required to provide reactive power capability, the wind plant should be able to operate anywhere in the $+/-0.95$ power factor range.

\footnotetext{
${ }^{11}$ FERC Order 2003, Appendix G, Requirements of Generators Relying on Newer Technologies.

${ }^{12}$ Federal Energy Regulatory Commission, Interconnection for Wind Energy and Other Alternative Technologies, Notice of Proposed Rulemaking, 110 FERC $\uparrow$ 61,036 (2004) (NOPR).
} 
- SCADA Capability. The SCADA requirement adopted under the Order requires the wind interconnection customer to provide SCADA capability with the specific SCADA information and control capability required to be agreed to by the wind plant interconnection customer and the transmission provider. Wind plants are only required to have the capability to receive instructions; transmission providers are not authorized to control a wind plant in any way. The requirement is flexible enough that the customer and the provider can negotiate the specific SCADA capability that meets the needs of the transmission system at the specific location of the wind plant. In addition, the parties have the flexibility to decide what information should be provided and what equipment should be installed at the site.

- Self-Study of Interconnection Feasibility. The wind developer is permitted to satisfy the requirements of the interconnection request by providing a set of preliminary electrical design specifications depicting the wind plant as a single equivalent generator after which the plant may enter the queue and receive the base case data as is provided for all large generators in Order No. 2003. No more than six months following the submittal, the wind plant is required to submit completed detailed design specifications and other data needed to allow the transmission provider to complete its system impact study.

The initial application for the LVRT, SCADA, and power factor design criteria requirements was for LGIAs signed on or after January 1, 2006. The procedure permitting the wind plant interconnection customer to complete the interconnection request with singlegenerator equivalent design specifications went into effect immediately after the Final Order was published.

\section{Order 661-A}

On December 12, 2005, FERC issued Order No. 661-A making changes to certain provisions included in Order No. 661. While no changes were made to the power factor provisions or the self-study of interconnection feasibility, significant changes were made to the LVRT standard.

The North American Electric Reliability Corporation (NERC) and the American Wind Energy Association (AWEA) submitted joint recommendations for proposed changes to the LVRT standard, which were adopted by FERC. The changes also included a transition period that has since expired. The changes include the following:

- Wind plants (following the transition period) are required to ride through low voltage events down to a zero voltage level for "location specific" clearing times up to a maximum of nine cycles. ${ }^{13}$ If the fault on the transmission system remains after the clearing time, the wind plant is permitted to disconnect from the system.

\footnotetext{
${ }^{13} \mathrm{~A}$ cycle is equal to $1 / 60^{\text {th }}$ of a second.
} 
- LVRT capability is required for all new wind plant interconnections, not just those flagged by the system impact study. The point of measurement for the requirement is at the high side of the wind plant step-up transformer and no longer at the point of interconnection.

- Variations to the LVRT provisions are only permitted on an interconnection-wide basis. Limiting variations does not restrict the ability of any party to request a deviation in a specific non-conforming agreement filed with the FERC (as opposed to a variation built into a pro forma tariff).

\section{RTO and ISO Compliance with Orders 661 and 661-A}

In accordance with Order 661 and 661-A, RTOs and ISOs created separate attachments to their open access transmission tariffs regarding wind interconnection criteria. The Midwest ISO, SPP, PJM, ISO-NE, CAISO, and NYISO all follow Order 661-A for low-voltage ride-through requirements. They also follow the Order 661 rule for meeting power factor capability as only being required if so shown in the System Impact Study. The Midwest ISO, SPP, PJM, ISO-NE, and NYISO grant wind developers six months to provide detailed technical data following the interconnection request, though both SPP and PJM have had working group discussions examining this issue. The new CAISO generator interconnection procedures remove this sixmonth exemption for wind projects and require all generators to provide all detailed technical data along with their interconnection request.

The RTOs and ISOs differ in whether they regard a change of wind turbine type as a material change requiring a re-study. SPP and PJM both require a re-study. The Midwest ISO, ISO-NE, CAISO, and NYISO examine each on a case-by-case basis to determine whether it is a large enough variation to be considered a material change. A material change would lead to a restudy, while a non-material change would not. 


\section{Generator Interconnection Requests in the Queues}

The number of generator interconnection requests received by the various RTOs and ISOs has ballooned in recent years, partially driven by state renewable portfolio standard (RPS) requirements that have led to a significant increase in interconnection requests for wind power projects. At the end of 2007, the Midwest ISO estimated that at the current rate and under the current system, they would succeed in completing the processing of the projects in their queue by about $2050 .{ }^{14}$ For this report, data was compiled on the number of generation interconnection requests filed at the seven RTOs and ISOs, as well as at two power marketing administrations with high quality wind resources-BPA and WAPA. The number of generator interconnection requests received by the various RTOs started to increase dramatically in 2005. Figure 3 below shows the number of requests received annually for the years 2004 to 2007. As indicated, the number of interconnection requests has at least doubled for each RTO, and in many cases, more than tripled since 2004.

Figure 3

\section{Annual Interconnection Requests, 2004 - 2007}

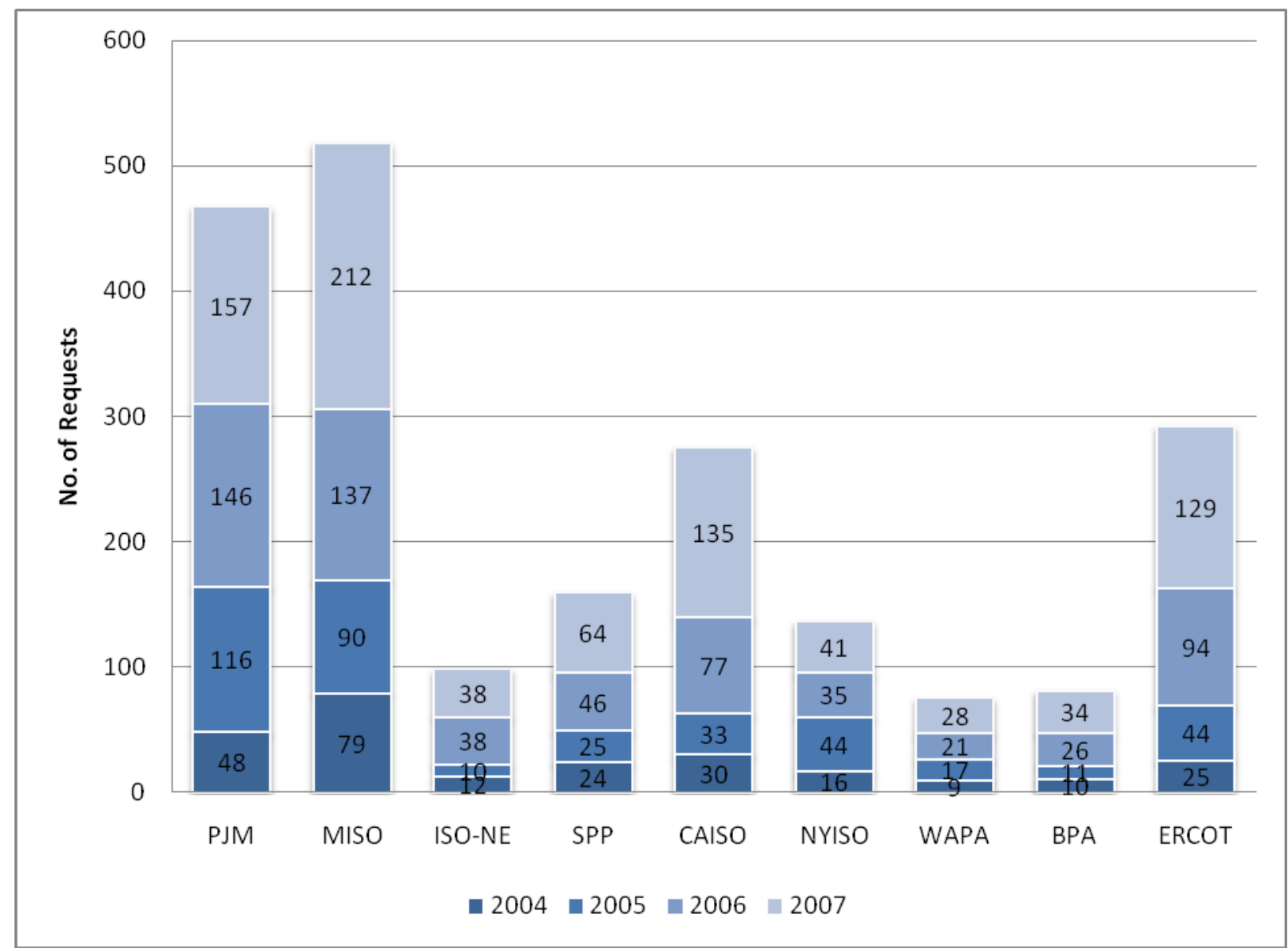

Source: Exeter Associates, Inc., based on data from BPA, WAPA, and the RTOs and ISOs.

\footnotetext{
${ }^{14}$ Midwest ISO, "Prepared Remarks of Clair J. Moeller, Vice President of Transmission Asset Management, Midwest Independent Transmission System Operator, Inc.," FERC Docket No. AD08-2-000, December 11, 2007.
} 
Caution should be exercised in interpreting the data as some interconnection customers may have several different interconnection points evaluated for the same project and must submit a separate request for each point of connection. Some of the requests are ultimately withdrawn, as project owners elect not to continue with the project at that site or encounter difficulties with procuring equipment or securing site control. Nevertheless, each request often requires at least the completion of an initial feasibility study. Figure 4 shows the amount of megawatts (MW) represented by the requests that were made in 2006 and 2007. The amount of capacity requested for interconnection more than doubled in the Midwest ISO and CAISO between 2006 and 2007, and significant increases were also seen in PJM and ERCOT.

Figure 4

MW of Annual Interconnection Requests, 2006 and 2007

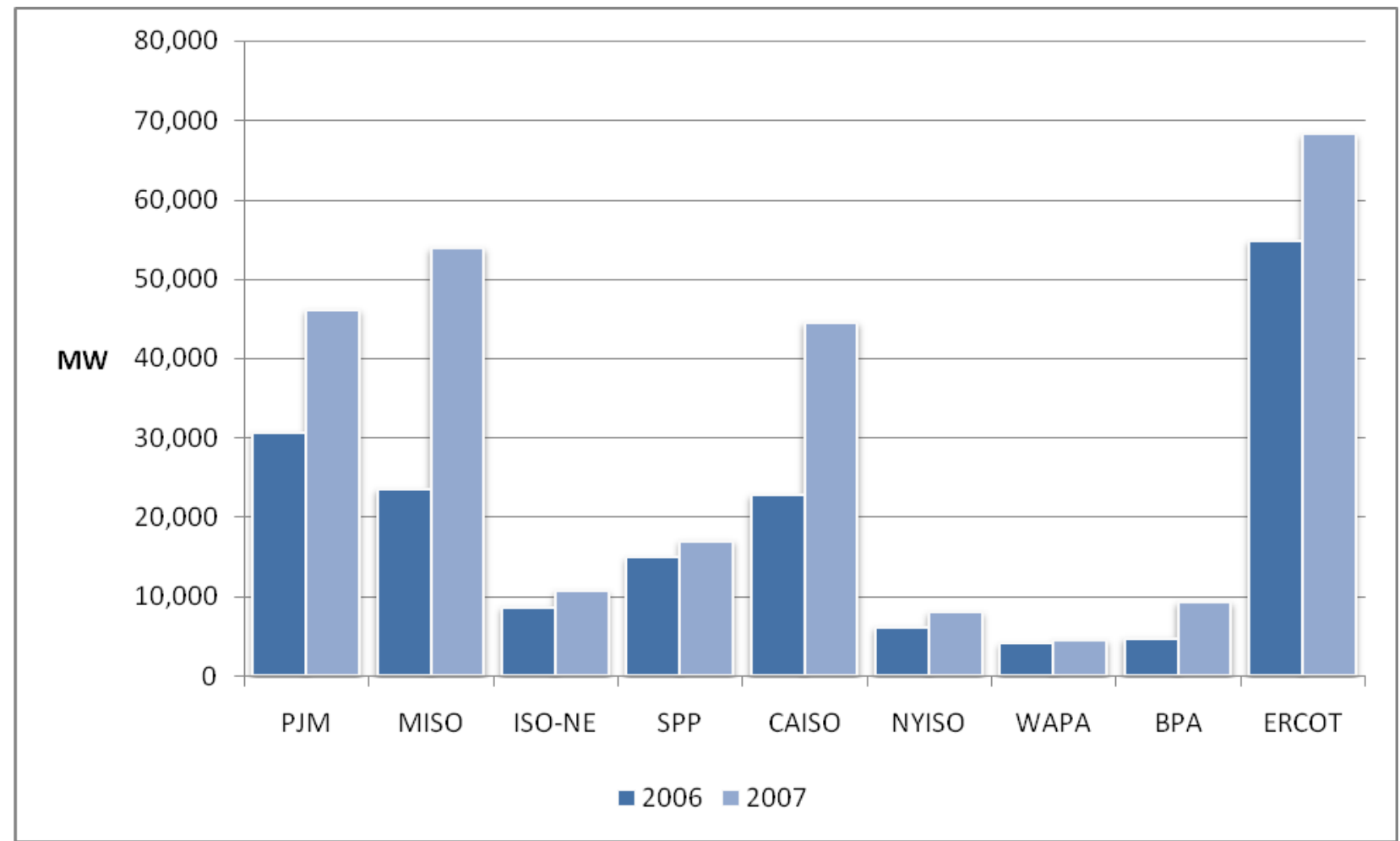

Source: Exeter Associates, Inc., based on data from BPA, WAPA, and the RTOs and ISOs. 
Figure 5 represents the gigawatts of capacity in the interconnection queues at the same transmission providers, by fuel source in 2007. Only projects active in the interconnection queue, but not placed in-service are included in Figure 5-suspended projects are not included. There were 225 gigawatts $(\mathrm{GW})$ of wind capacity in the interconnection queue, more than twice as much as natural gas, the next largest fuel resource in the interconnection queue. Moreover, 64 percent of the wind capacity entered the interconnection queues in $2007 .^{15}$

Figure 5

Generator Interconnection Requests by Fuel Source, 2007

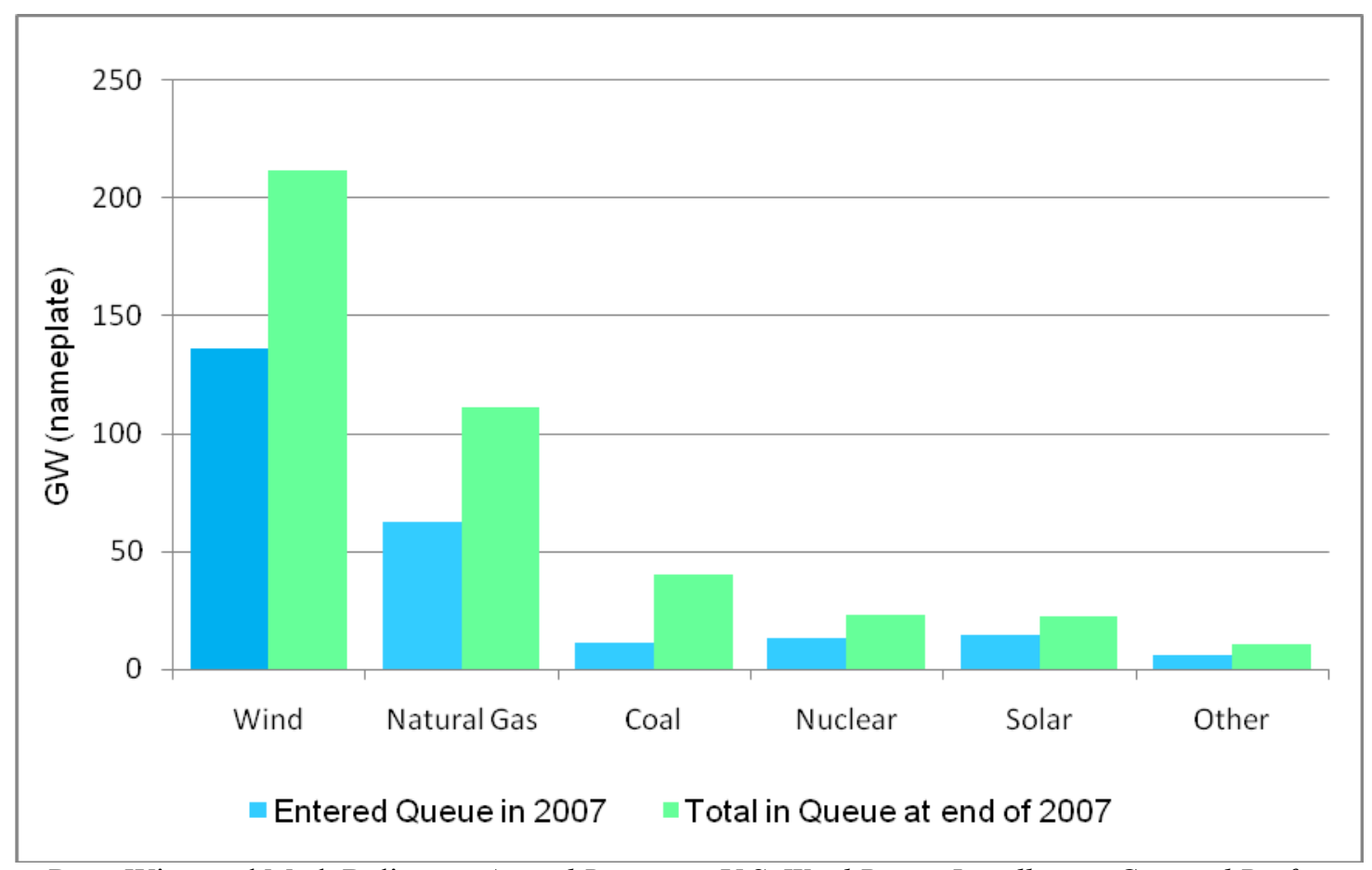

Source: Ryan Wiser and Mark Bolinger. Annual Report on U.S. Wind Power Installation, Cost and Performance 2007. U.S. Department of Energy, May 2008. http://eetd.lbl.gov/EA/EMP/reports/lbnl-275e.pdf. (Accessed September 5, 2008). Based on data compiled by Exeter Associates, Inc.

\footnotetext{
${ }^{15}$ Ryan Wiser and Mark Bolinger, Annual Report on U.S. Wind Power Installation, Cost and Performance 2007. U.S. Department of Energy, May 2008. http://eetd.lbl.gov/EA/EMP/reports/lbnl-275e.pdf. (Accessed September 5, 2008).
} 
Figure 6 presents the capacity of interconnection requests through 2007 by ISO or RTO and BPA and WAPA. For CAISO, ERCOT, and WAPA, the capacity of interconnection requests is more than the total installed generating capacity and, in CAISO's and ERCOT's case, peak electricity demand as well.

Figure 6

Capacity of Interconnection Requests Compared to Installed Capacity and Electric Demand

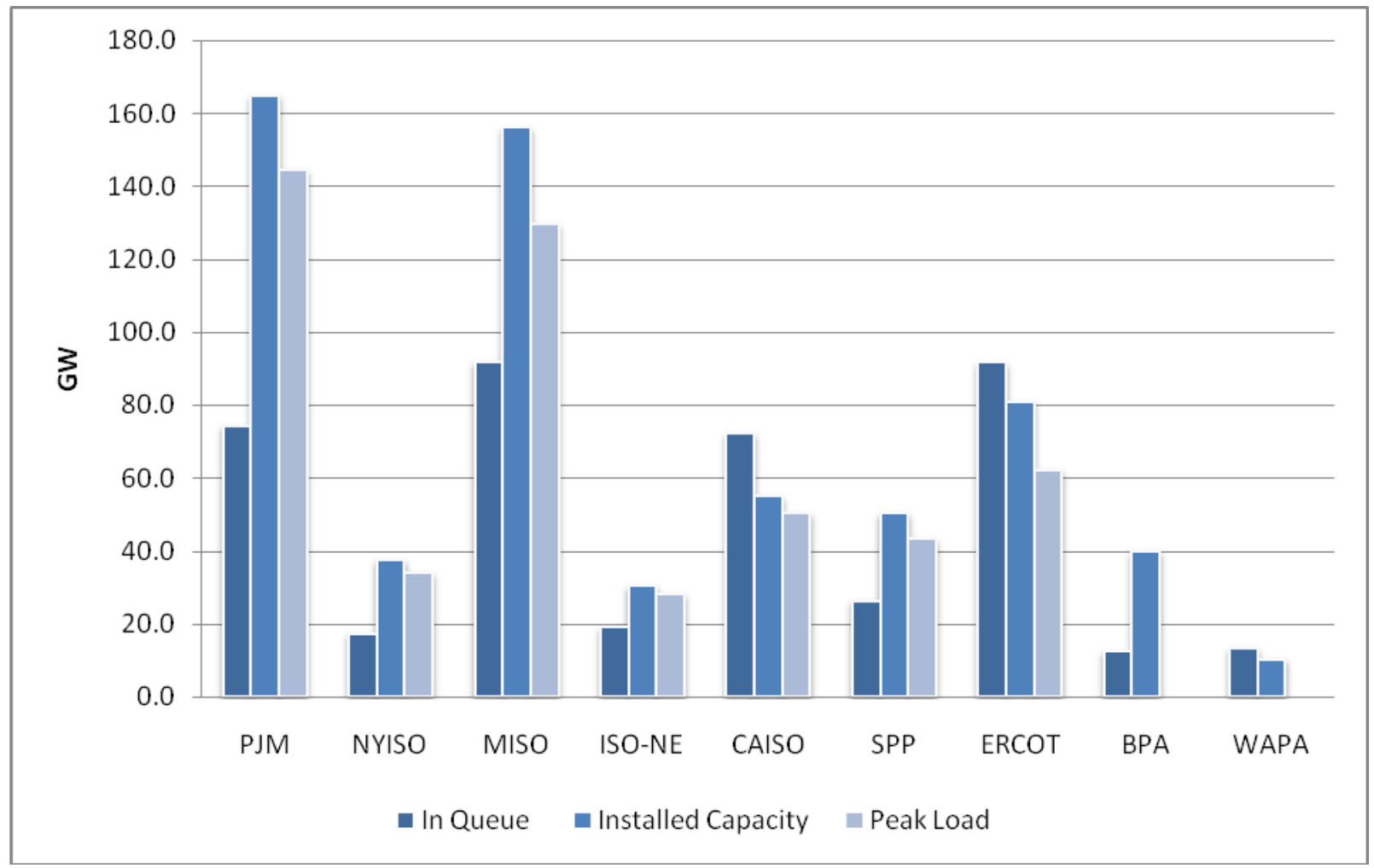

Source: Exeter Associates, Inc., based on data from BPA, WAPA, and the RTOs and ISOs. 
Figure 7 below shows the cumulative capacity of wind power projects in the interconnection queues at the end of 2007. This graph does not include projects that have been suspended or withdrawn.

Figure 7

Capacity of Wind Projects in Interconnection Queues, 2006 and 2007

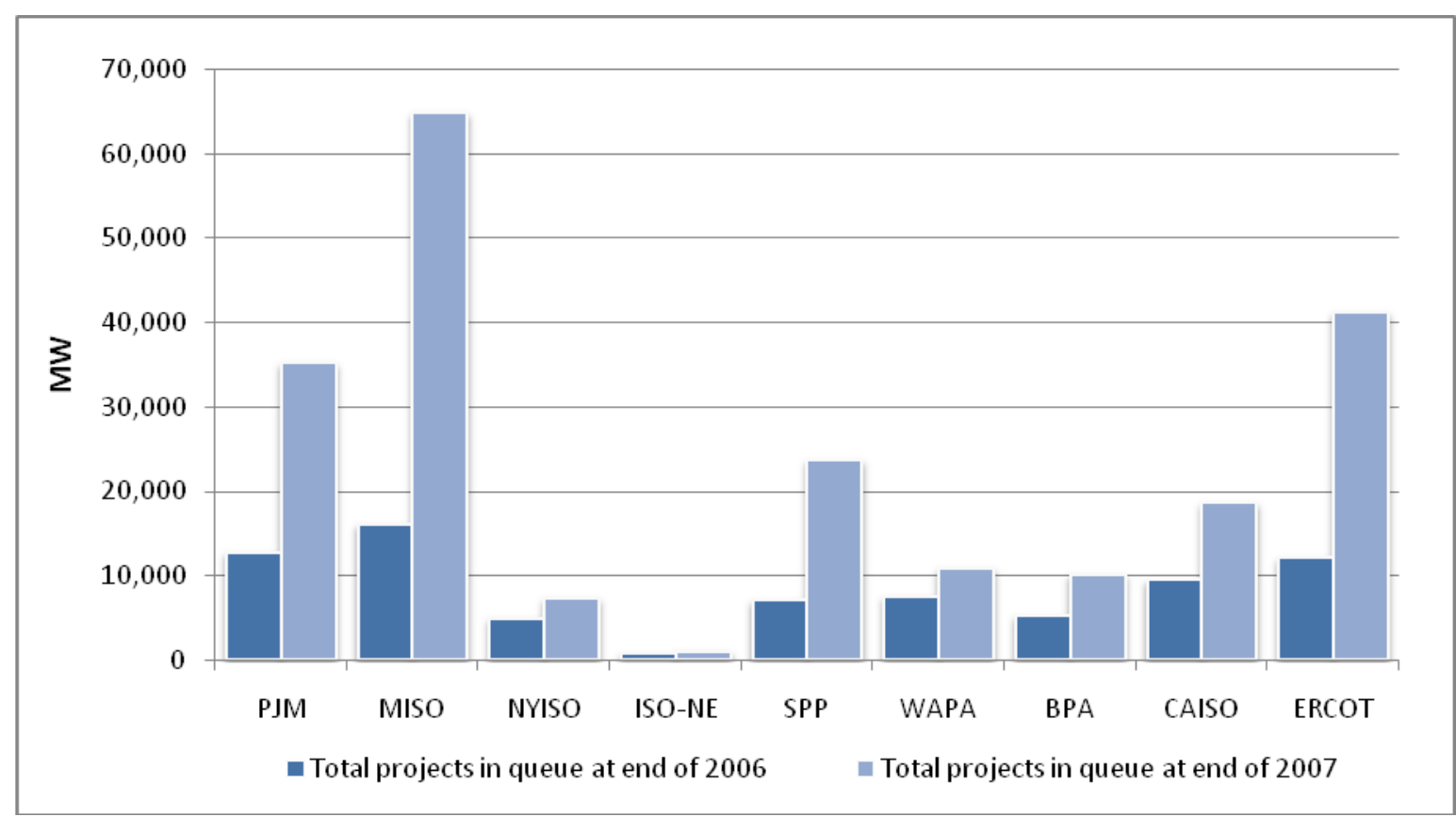

Source: Exeter Associates, Inc., based on data from BPA, WAPA, and the RTOs and ISOs.

Note: ERCOT does not maintain a 'queue,' therefore, project-specific cumulative data is not available; the 2006 ERCOT figure is an estimate only.

The rapid pace for generator interconnection requests has continued for the first 10 months of 2008. As indicated in Figure 8, the nation's RTOs, ISOs, BPA, and WAPA have received 742 interconnection requests in 2008 through October 20, 2008. During that period, the Midwest ISO has received the most interconnection requests, followed by PJM, CAISO, and then SPP and BPA. Of the Midwest ISO's 169 interconnection requests for the first threequarters of 2008, all but 18 are from for wind. Wind accounts for the majority of the interconnection requests made in the first three-quarters of 2008, with 458, or 62 percent of all requests across all of the RTOs and ISOs (see Figure 9). This compares to 450 interconnection requests filed by wind generators for all of 2007. 
Number of Interconnection Requests for 2008 through October 20, 2008

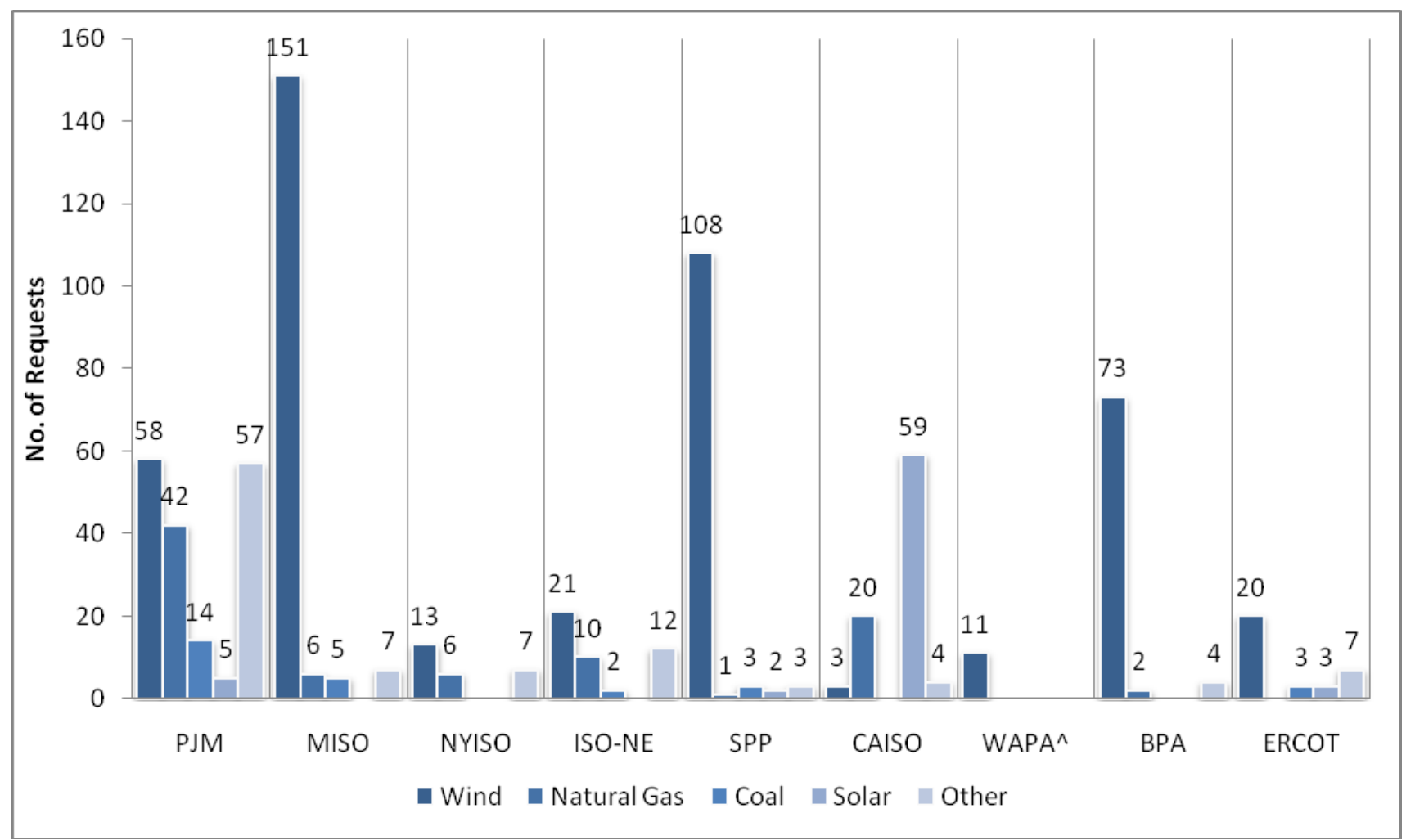

Source: Exeter Associates, Inc., based on data from BPA, WAPA, and the RTOs and ISOs.

Note: ERCOT 2008 specific project data not available; estimates only.

$\wedge$ WAPA through to July 15, 2008.

Figure 9

Number of Interconnection Requests by Fuel Type for 2008 through October 20, 2008

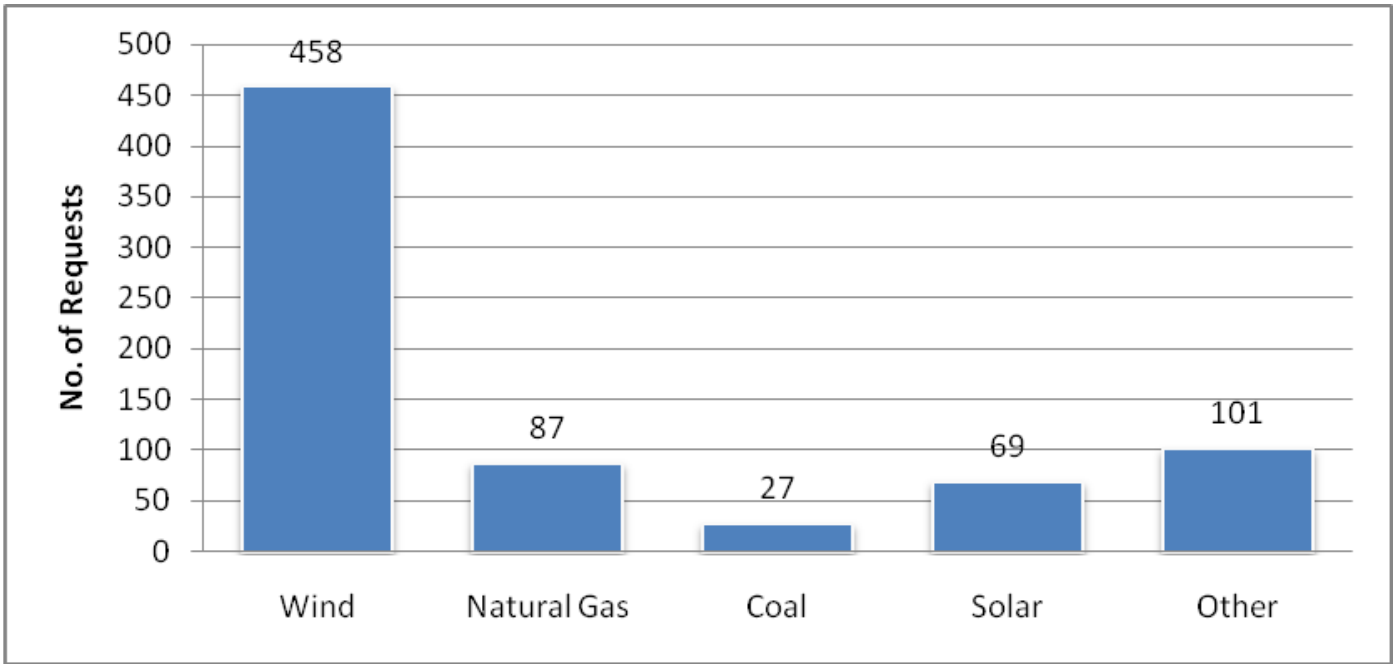

Source: Exeter Associates, Inc., based on data from BPA, WAPA, and the RTOs and ISOs.

Note: ERCOT 2008 specific project breakdown not available; includes estimates only. 
The 742 interconnection requests amount to almost $160 \mathrm{GW}$, with wind accounting for 56 percent of the total capacity. As indicated in Figure 10, PJM has received interconnection requests for the most total capacity, followed by SPP, the Midwest ISO, and CAISO. For wind, SPP has the most capacity of wind interconnection requests, followed by the Midwest ISO, ERCOT, and PJM. Note that the CAISO has received a significant amount of solar capacity requesting interconnection. By fuel type, wind has more than twice the capacity in interconnection requests as natural gas, as indicated in Figure 11.

Figure 10

Capacity of Interconnection Requests for 2008 through October 20, 2008

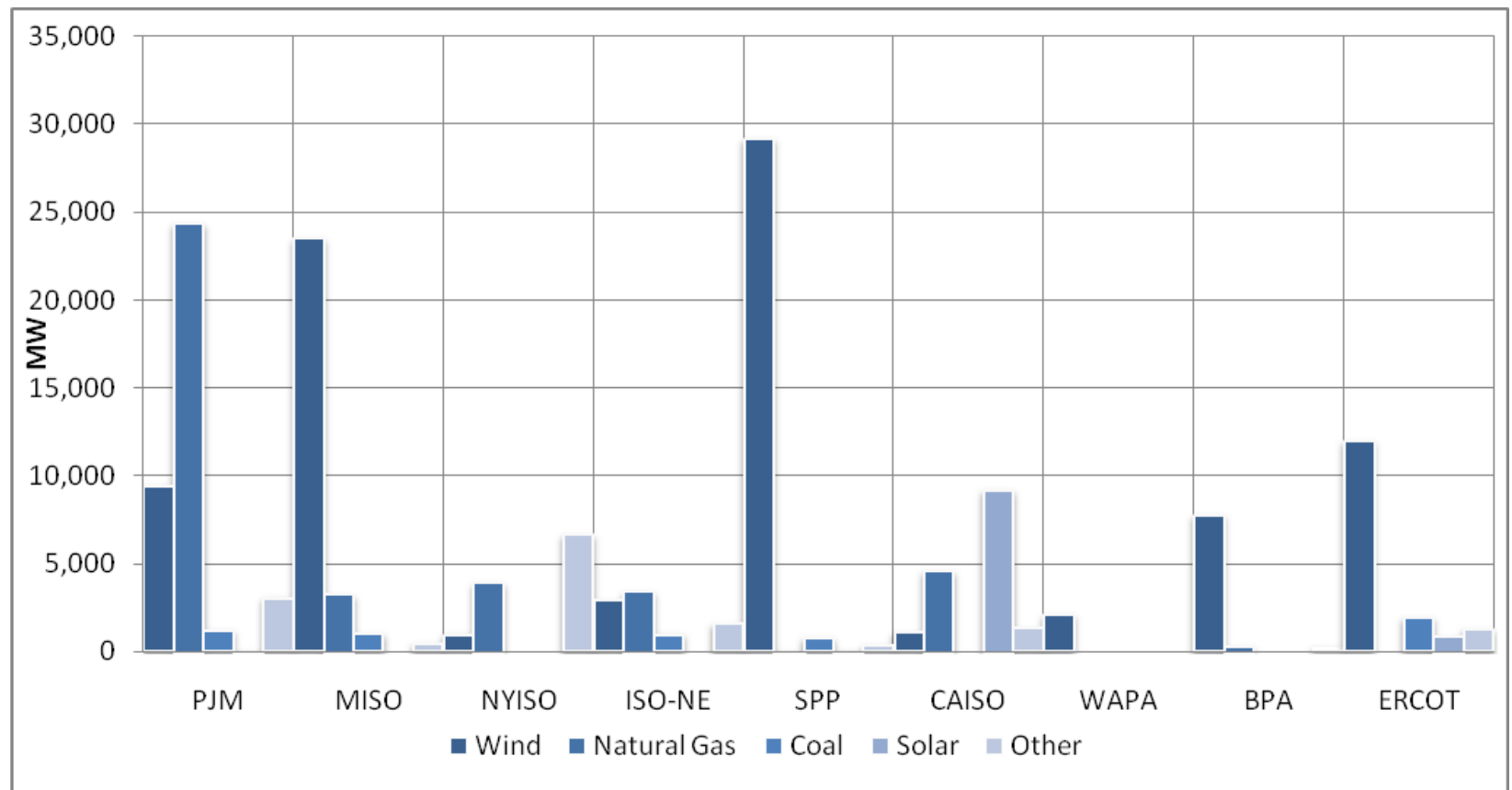

Source: Exeter Associates, Inc., based on data from BPA, WAPA, and the RTOs and ISOs.

Note: ERCOT estimate only.

Figure 11

\section{Capacity of Interconnection Requests by Fuel Source for 2008 through October 20, 2008}

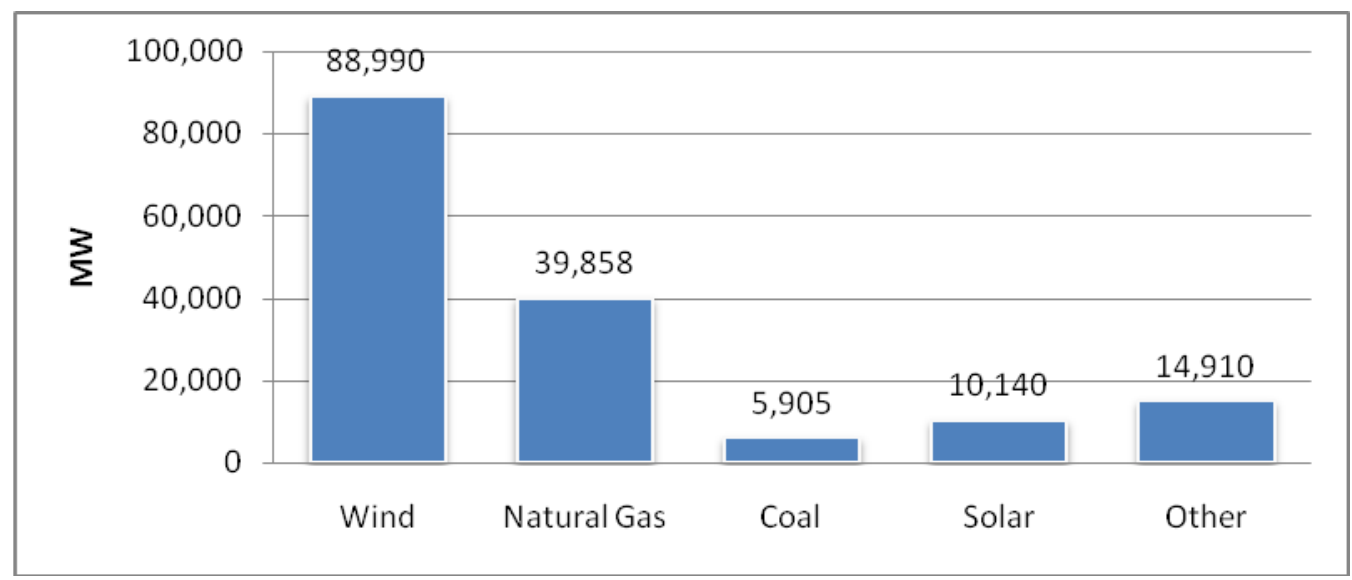

Source: Exeter Associates, Inc., based on data from BPA, WAPA, and the RTOs and ISOs. Note: ERCOT estimate only. 
Table 2 and 3 indicate the percentage of requests that are still in progress, have been withdrawn, or were in service from 2000 through 2007, measured by percentage of the number of generation interconnection requests and by percentage of the capacity of generator interconnection requests. Although a number of generator interconnection requests are still in progress, only a small percentage of total requests have been placed in-service.

\section{Table 2}

\section{Status of Queues as of July 2008, 2000 - 2007 by Number of Requests}

\begin{tabular}{|c|c|c|c|c|c|c|c|c|c|}
\hline \multirow[b]{2}{*}{ ISO/RTO } & \multicolumn{3}{|c|}{$\begin{array}{l}\text { Total Requests from } \\
2000 \text { to } 2004\end{array}$} & \multicolumn{3}{|c|}{$\begin{array}{l}\text { Total Requests from } \\
2005 \text { to } 2007\end{array}$} & \multicolumn{3}{|c|}{$\begin{array}{l}\text { All requests from } \\
2000 \text { to } 2007\end{array}$} \\
\hline & $\begin{array}{l}\text { Still in } \\
\text { Progress }\end{array}$ & $\begin{array}{l}\text { Have Been } \\
\text { Withdrawn }\end{array}$ & $\begin{array}{l}\text { Gone } \\
\text { Into } \\
\text { Service }\end{array}$ & $\begin{array}{l}\text { Still in } \\
\text { Progress }\end{array}$ & $\begin{array}{l}\text { Have Been } \\
\text { Withdrawn }\end{array}$ & $\begin{array}{l}\text { Gone } \\
\text { Into } \\
\text { Service }\end{array}$ & $\begin{array}{l}\text { Still in } \\
\text { Progress }\end{array}$ & $\begin{array}{l}\text { Have Been } \\
\text { Withdrawn }\end{array}$ & $\begin{array}{l}\text { Gone } \\
\text { Into } \\
\text { Service }\end{array}$ \\
\hline PJM & $6 \%$ & $65 \%$ & $29 \%$ & $51 \%$ & $31 \%$ & $18 \%$ & $34 \%$ & $44 \%$ & $22 \%$ \\
\hline $\begin{array}{l}\text { Midwest } \\
\text { ISO }\end{array}$ & $27 \%$ & $59 \%$ & $14 \%$ & $69 \%$ & $30 \%$ & $1 \%$ & $50 \%$ & $43 \%$ & $7 \%$ \\
\hline SPP & $10 \%$ & $74 \%$ & $16 \%$ & $58 \%$ & $38 \%$ & $4 \%$ & $38 \%$ & $53 \%$ & $9 \%$ \\
\hline CAISO & $49 \%$ & $37 \%$ & $14 \%$ & $67 \%$ & $31 \%$ & $2 \%$ & $66 \%$ & $30 \%$ & $4 \%$ \\
\hline ISO-NE & $14 \%$ & $65 \%$ & $21 \%$ & $57 \%$ & $29 \%$ & $14 \%$ & $41 \%$ & $43 \%$ & $16 \%$ \\
\hline NYISO & $40 \%$ & $56 \%$ & $4 \%$ & $68 \%$ & $31 \%$ & $1 \%$ & $55 \%$ & $43 \%$ & $2 \%$ \\
\hline Average & $25 \%$ & $59 \%$ & $16 \%$ & $62 \%$ & $32 \%$ & $7 \%$ & $47 \%$ & $43 \%$ & $10 \%$ \\
\hline
\end{tabular}

Source: Examination of generator interconnection queue information on RTO and ISO web sites.

Table 3

Status of Queues as of July 2008, 2000 - 2007 by MW of Capacity

\begin{tabular}{|c|c|c|c|c|c|c|c|c|c|}
\hline \multirow[b]{2}{*}{ ISO/RTO } & \multicolumn{3}{|c|}{$\begin{array}{l}\text { Total Requests from } \\
2000 \text { to } 2004\end{array}$} & \multicolumn{3}{|c|}{$\begin{array}{l}\text { Total Requests from } \\
2005 \text { to } 2007\end{array}$} & \multicolumn{3}{|c|}{$\begin{array}{l}\text { All requests from } \\
2000 \text { to } 2007\end{array}$} \\
\hline & $\begin{array}{l}\text { Still in } \\
\text { Progress }\end{array}$ & $\begin{array}{l}\text { Have Been } \\
\text { Withdrawn }\end{array}$ & $\begin{array}{l}\text { Gone } \\
\text { Into } \\
\text { Service }\end{array}$ & $\begin{array}{l}\text { Still in } \\
\text { Progress }\end{array}$ & $\begin{array}{l}\text { Have Been } \\
\text { Withdrawn }\end{array}$ & $\begin{array}{l}\text { Gone } \\
\text { Into } \\
\text { Service }\end{array}$ & $\begin{array}{l}\text { Still in } \\
\text { Progress }\end{array}$ & $\begin{array}{l}\text { Have Been } \\
\text { Withdrawn }\end{array}$ & $\begin{array}{l}\text { Gone } \\
\text { Into } \\
\text { Service }\end{array}$ \\
\hline PJM & $3 \%$ & $90 \%$ & $7 \%$ & $60 \%$ & $39 \%$ & $1 \%$ & $38 \%$ & $58 \%$ & $4 \%$ \\
\hline $\begin{array}{l}\text { Midwest } \\
\text { ISO }\end{array}$ & $18 \%$ & $76 \%$ & $6 \%$ & $74 \%$ & $25 \%$ & $<1 \%$ & $45 \%$ & $52 \%$ & $3 \%$ \\
\hline SPP & $11 \%$ & $82 \%$ & $7 \%$ & $64 \%$ & $35 \%$ & $1 \%$ & $35 \%$ & $61 \%$ & $4 \%$ \\
\hline CAISO & $52 \%$ & $42 \%$ & $6 \%$ & $75 \%$ & $24 \%$ & $<1 \%$ & $72 \%$ & $27 \%$ & $1 \%$ \\
\hline ISO-NE & $7 \%$ & $91 \%$ & $2 \%$ & $82 \%$ & $16 \%$ & $2 \%$ & $38 \%$ & $60 \%$ & $2 \%$ \\
\hline NYISO & $14 \%$ & $84 \%$ & $2 \%$ & $52 \%$ & $47 \%$ & $<1 \%$ & $29 \%$ & $70 \%$ & $1 \%$ \\
\hline Average & $18 \%$ & $77 \%$ & $5 \%$ & $68 \%$ & $31 \%$ & $1 \%$ & $42 \%$ & $55 \%$ & $3 \%$ \\
\hline
\end{tabular}

Source: Examination of generator interconnection queue information on RTO and ISO web sites. 


\section{Factors Contributing to the Surge in Interconnection Requests}

A number of factors have led to the backlog in generation interconnection queues across the country. Chief among them are the relatively low requirements for filing an interconnection application, but other significant factors are policy initiatives such as the federal PTC and state renewable portfolio standards, transmission cost allocation policies, and unclear milestones in Order 2003. These issues are discussed in more detail below.

Easy Entry and Exit Requirements: Order 2003 contains relatively low entry and exit requirements for filing a generator interconnection request. Entering the queue requires a $\$ 10,000$ deposit, with an additional $\$ 10,000$ required if site control cannot be demonstrated. A generator can also request that the processing of its interconnection application be suspended at any time, and for multiple times, for a total of up to three years without penalty, or any form of financial deposit other than paying for the interconnection study costs incurred to date.

These minimum requirements, combined with the general market knowledge that there is insufficient transmission, and the uncertainties in estimating the costs of transmission network upgrades and what a generator's cost allocation for upgrades may be, provides an incentive for generators to file interconnection requests early and often. As the queue becomes more congested, more generation interconnection requests may be filed as generators move to secure a position in the queue before it gets even longer.

For these reasons, increasing the requirements (both financial and informational) for entering the interconnection queue and for suspending an interconnection request have been early targets of proposals to reform generator interconnection procedures.

On-Again, Off-Again Availability of the Federal PTC: The production tax credit (PTC) was first introduced in the Energy Policy Act of 1992 and currently provides a tax credit of $2.1 \notin / \mathrm{kWh}$ over the first 10 years of operation for eligible technologies including wind. The PTC has been renewed five times in the last 16 years, but typically only for 1 to 2 years at a time. Indeed, the PTC completely lapsed prior to being renewed on three occasions. More recently, the PTC was renewed in 2006 and applies to all projects that are placed in service by the end of 2008. In October 2008, Congress extended the deadline to the end of 2009. Table 4 below shows the history and duration of the PTC.

The on-again, off-again availability of the PTC may affect the number of interconnection requests for wind projects that are suspended by creating economic uncertainty for developers trying to finance their projects. For example, the Midwest ISO said that of the 4,446 MW of wind interconnection requests processed since December of 2001, nearly 2,200 MW have been suspended. ${ }^{16}$ The PTC lapsed twice during this period, in 2002 and 2004.

\footnotetext{
${ }^{16}$ Clair J. Moeller, Midwest ISO, prepared remarks before the Federal Energy Regulatory Commission's Technical Conference on Interconnection Queuing Practices, December 11, 2007.
} 


\section{Table 4}

\section{Legislative History of the Production Tax Credit}

\begin{tabular}{|l|l|l|l|l|}
\hline Legislation & $\begin{array}{l}\text { Date } \\
\text { Enacted }\end{array}$ & $\begin{array}{l}\text { PTC Eligibility } \\
\text { Window (for wind) }\end{array}$ & $\begin{array}{l}\text { PTC } \\
\text { Lapse } \\
\text { Duration }\end{array}$ & $\begin{array}{l}\text { Effective Duration of } \\
\text { PTC Window } \\
\text { (considering lapses) }\end{array}$ \\
\hline $\begin{array}{l}\text { Section 1914, Energy Policy Act of 1992 } \\
\text { (P.L. 102-486) }\end{array}$ & $1 / 24 / 92$ & $1994-J u n e 1999$ & $\mathrm{n} / \mathrm{a}$ & 80 months \\
\hline $\begin{array}{l}\text { Section 507, Ticket to Work and Work } \\
\text { Incentive Improvement Act of 1999 (P.L. 106- } \\
\text { 170) }\end{array}$ & $12 / 19 / 99$ & July 1999-2001 & 6 months & 24 months \\
\hline $\begin{array}{l}\text { Section 603, Job Creation and Worker } \\
\text { Assistance Act (P.L. 107-147) }\end{array}$ & $03 / 09 / 02$ & $2002-2003$ & 2 months & 22 months \\
\hline $\begin{array}{l}\text { Section 313, The Working Families Tax Relief } \\
\text { Act, (P.L. 108-311) }\end{array}$ & $10 / 04 / 04$ & $2004-2005$ & 9 months & 15 months \\
\hline $\begin{array}{l}\text { Section 1301, Energy Policy Act of 2005 } \\
\text { (P.L. 109-58) }\end{array}$ & $08 / 08 / 05$ & $2006-2007$ & None & 24 months \\
\hline $\begin{array}{l}\text { Section 201, Tax Relief and Health Care Act of } \\
\text { 2006 (P.L. 109-432) }\end{array}$ & $12 / 20 / 06$ & 2008 & None & 12 months \\
\hline $\begin{array}{l}\text { Section 101, Emergency Economic } \\
\text { Stabilization Act of 2008 (H.R. 1424) }\end{array}$ & $10 / 3 / 08$ & 2009 & None & 12 months \\
\hline
\end{tabular}

Source for Original Table: R. Wiser, M. Bolinger, G. Barbose, Using the Federal Production Tax Credit to Build a Durable Market for Wind Power in the United States, Ernest Orlando Lawrence Berkeley National Laboratory, November 2007. http://eetd.lbl.gov/EA/EMP/reports/63583.pdf. (Accessed June 10, 2008).

H.R. 1424, http://www.house.gov/apps/list/press/financialsvcs_dem/essabill.pdf. (Accessed October 27, 2008)

Wind project development shows a distinct pattern of on-again, off-again activity concurrent with the availability of the PTC. Figure 12 below illustrates this pattern.

Figure 12

PTC and Wind Development

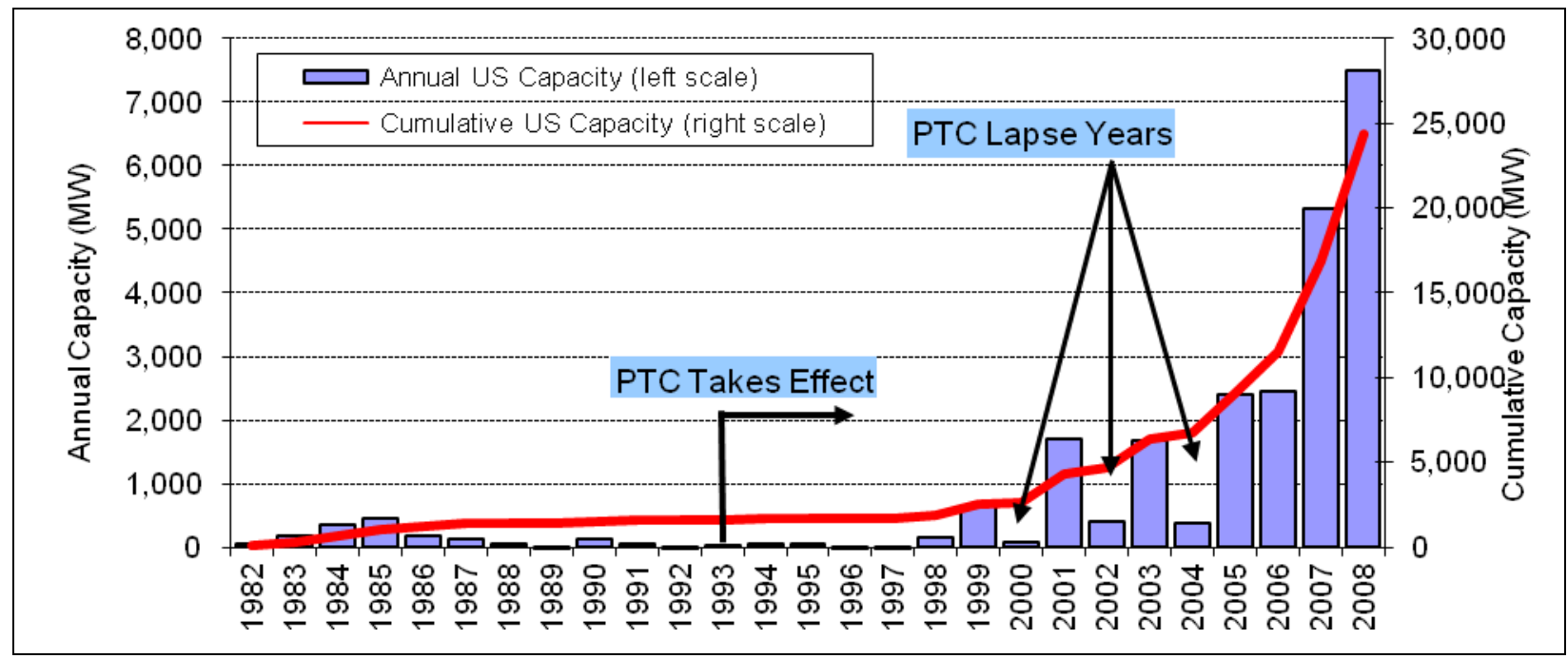

2008 Projected Data: American Wind Energy Association Press Release:

http://www.awea.org/newsroom/releases/Wind Installations Surpass 20K MW 03Sept08.html

2007 data: R. Wiser \& M. Bolinger, "Annual Report on U.S. Wind Power Installation, Costs, and Performance Trends: 2007,"

U.S. Department of Energy, LBNL-275E, May 2008. http://eetd.lbl.gov/EA/EMP/reports/lbnl-275e.pdf

Source for original graph: R. Wiser, M. Bolinger, G. Barbose, "Using the Federal Production Tax Credit to Build a Durable

Market for Wind Power in the United States," Ernest Orlando Lawrence Berkeley National Laboratory, November 2007. 
The number of interconnection requests received by the various RTOs and ISOs also echoes this pattern, with lulls in activity in 2002 and 2004 when the PTC lapsed temporarily (see Figure 13). The number of interconnection requests for wind surged beginning in 2005 and continued through 2006 and 2007 when the PTC was extended through the end of 2008. Congress recently extended the PTC through 2009.

Figure 13

\section{Wind Project Interconnection Requests}

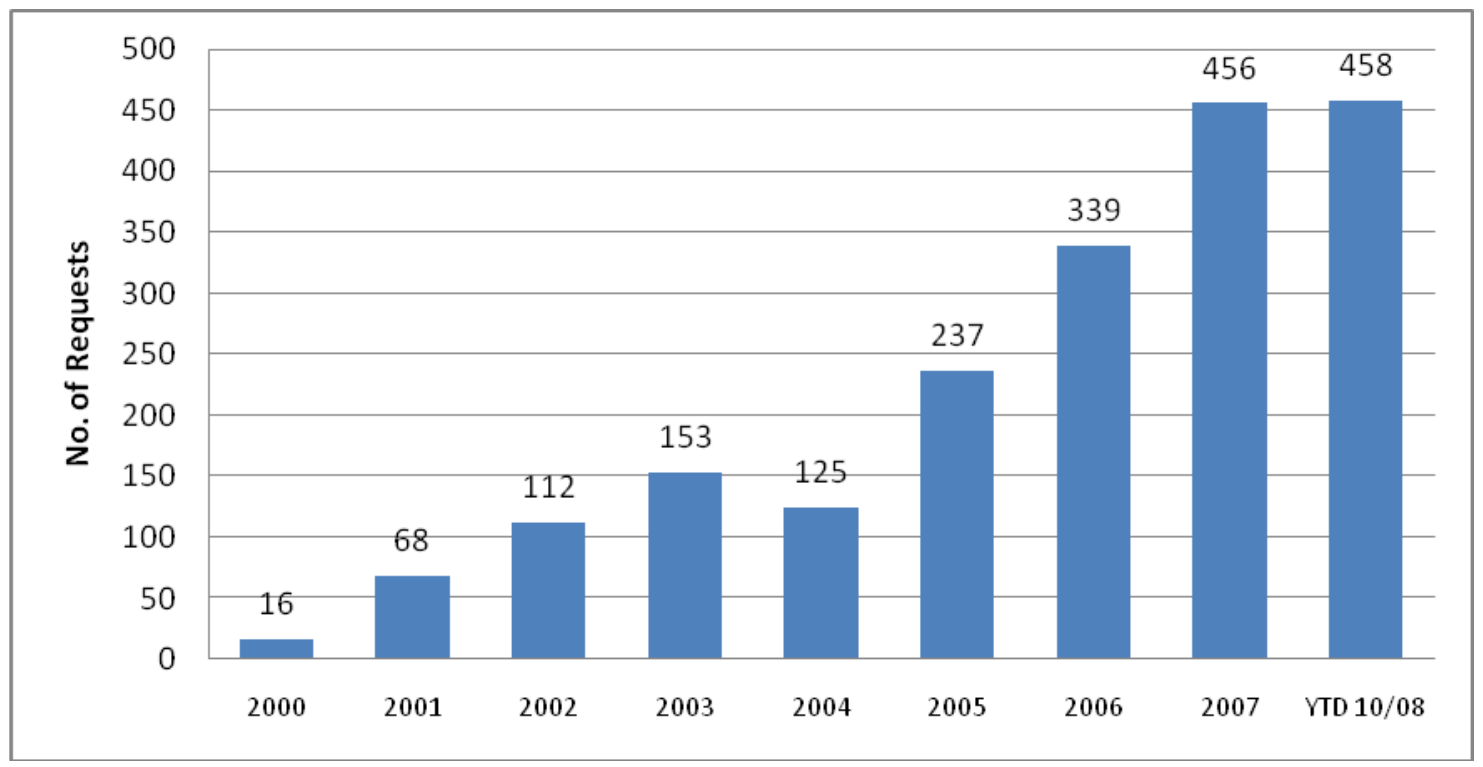

Source: Exeter Associates, Inc., based on data from BPA, ERCOT, WAPA, and the RTOs and ISOs. Note: ERCOT 2008 project-specific data not available; includes estimate of 20 new wind projects.

Transmission Cost Uncertainties: The ease of entry and exit compounds existing uncertainties regarding transmission network upgrade costs that may be necessary for a generator to interconnect. The costs for a generator to interconnect are not specified until an application is submitted and the interconnection studies are performed. Order 2003's pricing policy effectively assigns the costs of a transmission network upgrade, which may be quite significant, to the first generator whose project requires upgrades.

As a result, generators may file multiple interconnection requests for a single project to determine the lowest cost for interconnection, sometimes termed "upgrade shopping." Should the feasibility study or system impact study come back unfavorably, a generator may drop out of the queue. That forces restudies for all the projects lower in the queue, adding to time and costs. The suspension of a project in the interconnection queue also leads to increased uncertainty for projects lower in the queue and increased processing time and costs for the transmission provider. Lower queued projects may have to pay the transmission network upgrade costs if the suspended project does not proceed.

Policy and Regulatory Initiatives: Different policy initiatives and market forces are affecting the type of generating project that is entering the interconnection queue. Of the 28 states and the District of Columbia that have implemented renewable portfolio standards, more 
than half of them (15) have been enacted since FERC adopted Order 2003. In addition, sixteen states with existing RPS policies have amended those policies since the issuance of Order 2003, with most of these states increasing the level of the RPS requirements. All told, $61 \mathrm{GW}$ of renewable energy may be needed to meet state RPS requirements by $2025 .{ }^{17}$ Increasing concern by regulators and policymakers over climate change is also changing the composition of generators entering the interconnection queue. Twenty-eight states have enacted or have joined regional initiatives to combat climate change. ${ }^{18}$

Interaction between Interconnection Queues and Transmission Planning: Underinvestment in new backbone transmission facilities and the surge of applications by generators wishing to interconnect has complicated the processing of interconnection applications. What may originally be thought of as a straightforward generator interconnection request may turn out to be not so simple if large-scale network upgrades need to be made to reliably interconnect the new generation facility. This is particularly true in transmission-constrained areas. Furthermore, these studies can take time to prepare and evaluate and will, by necessity, impact the generator interconnection applications in the queue that follow the one being studied. Market knowledge of these issues is a contributing factor to multiple interconnection requests for the same project, i.e., "upgrade shopping," in an attempt to minimize the possibility of incurring and having to pay for large transmission network upgrades that may doom a project's economics.

Unclear Milestones in Order 2003: Stakeholders have contended that Order 2003 is not clear on some aspects, such as what evidence is required of project developers to demonstrate site control, or what is considered a material modification to an interconnection application that justifies the loss of the position in the queue. One example is whether a change in wind turbines is a material modification that results in the loss of a queue position. SPP, for example, does not consider a change in wind turbines as material but does require a restudy. Substituting different wind turbines has apparently been relatively common, as wind developers enter the queue planning to purchase one type of turbine, and then determine that the turbine is unavailable or that the turbine will require substantial reactive compensation to meet FERC Order 661-A requirements. ${ }^{19}$

\section{Interconnection Queue Reform Initiatives}

All of the nation's RTOs and ISOs have submitted, or are in the process of developing, queue reform proposals in response to FERC's March 20, 2008, order. ${ }^{20}$ FERC conditionally granted the Midwest ISO's queue reform proposal in August 2008. In addition, BPA developed and received FERC approval for an open season whereby generators and load-serving entities signed agreements and placed deposits for BPA to offer existing transmission capacity (if available), or to develop new transmission if BPA can do so under its embedded costs and be in compliance with the National Environmental Policy Act. ${ }^{21}$ In addition, CAISO filed a queue reform proposal before FERC in July 2008 that was approved in September 2008. ISO New England filed its queue reform proposal with FERC in October $2008,{ }^{22}$ and the Southwest Power

\footnotetext{
${ }^{17}$ Ryan Wiser and Galen Barbose, Renewable Portfolio Standards in the United States: A Status Report with Data Through 2007, Lawrence Berkeley National Laboratory, April 2008.

${ }^{18}$ U.S. Department of Energy Annual Energy Outlook 2008, June 2008, http://www.eia.doe.gov/oiaf/aeo/

${ }^{19}$ ISO/RTO Council, ISO/RTO Council White Paper on Interconnection Queue Management Process, January 2008 .
} 
Pool expects to file its queue reform proposal by the end of 2008. NYISO is just beginning its stakeholder process considering queue reforms.

These proposals are summarized below as of October 2008, but note that some of these proposals are still in the drafting phase and may evolve over time. A more complete summary of these initiatives is provided in the Appendices.

Bonneville Power Administration: BPA's queue logjam involved interconnection requests for transmission service rather than for generation interconnection. As noted earlier, BPA relied on an open season as a means of sorting through its queue, and will offer open seasons on an annual basis. BPA's open season requires all those with transmission interconnection requests to participate in the open season or lose their position in the transmission queue. Those who wish to stay in the transmission queue have to sign a precedent service agreement with BPA and to make a deposit equal to one year's worth of transmission service. After the open season closes, BPA then determines what it can satisfy with existing transmission service. For the remaining requests, BPA performs a cluster study and determines what new transmission facilities may be needed to accommodate the requests, and at what cost. If BPA cannot build the transmission at its embedded cost, then it will need to use incremental rates, which requires a federal rate case and public hearings.

BPA held its first open season in May 2008, and initially offered 316 agreements for $14,464 \mathrm{MW}$ of transmission service. The open season closed on June $16^{\text {th }}$, and security deposits were required on June $27^{\text {th }}$. At that time, BPA received 153 signed agreements from 28 participants representing 6,410 MW. Of this, 4,176 MW was from wind. The signed agreements for transmission service differed by duration, with the average being about 13 years. BPA also received about $\$ 83$ million in deposits. ${ }^{23}$

California ISO: CAISO is transitioning its interconnection process from a serial study (first-come, first-served) approach to a cluster approach. CAISO submitted its reform proposal filing to FERC on July 28, 2008, ${ }^{24}$ and received approval on September 26, 2008. ${ }^{25}$ CAISO proposed three study groups as a transition strategy: the Serial Study Group, the Transition Cluster, and the Initial Generation Interconnection Process Reform (GIPR) Cluster. The Serial

${ }^{20}$ Federal Energy Regulatory Commission, Interconnection Queuing Practices, Order on Technical Conference, 122 FERC $\mid 61,252$ (2008).

${ }^{21}$ Embedded costs refers to the total costs of assets and ongoing charges to providing and maintaining a supply of energy or the transmission system. In BPA's case, embedded costs would reference their current transmission rates and therefore does not require a rate increase to pay for transmission upgrades needed to accommodate the new project.

${ }^{22}$ ISO New England, Joint Filing of Proposed Revisions to the Generator Interconnection Process and Forward Capacity Market Participation Provisions Set Forth in the ISO New England Inc. Transmission, Markets and Services Tariff, October 31, 2008, http://www.iso-ne.com/regulatory/ferc/filings/2008/oct/er09-_ -000_10-831 fcm queue.pdf. (Accessed November 4, 2008).

${ }^{23}$ Bonneville Power Administration, 2008 Network Open Season Results. July 7, 2008. http:/www.transmission.bpa.gov/business/IssuesPolicySteeringCmttee/documents/2008 NOS Final PTSA Result s $07 \quad 07 \quad 2008 . p d f$.

${ }^{24}$ California ISO, "California Independent System Operator Corporation Generation Interconnection Process Reform Tariff Amendment," July 28, 2008.

${ }^{25}$ Federal Energy Regulatory Commission, Order Conditionally Approving Tariff Amendment. 124 FERC $\mid 61,292$, September 26, 2008. http://www.caiso.com/2051/20517cf513430.pdf (accessed October 29, 2008). 
Study group will use the existing CAISO serial study processes for generating projects that are further along in the interconnection queue. Specifically, this means generating projects that meet one or more of the following conditions: they have executed a system impact study agreement with an estimated completion of before May 31, 2008; they have an approved or pending power purchase agreement; or they are seeking interconnection to a transmission project that has received state or federal approval.

Those that do not meet these requirements will be placed in the Transition Cluster and will have to submit a deposit of $\$ 250,000$. The deposit will be refundable, minus study and administrative costs, should the proposed generator enter into an interconnection agreement with CAISO. In addition, interconnection customers will have to submit proof of site control; a newly signed interconnection process agreement; any missing technical data; and whether the project is a capacity or energy-only project. Interconnection customers that do not meet those requirements will be withdrawn from the CAISO queue. CAISO plans to suspend the study activities for those projects in the Transition Cluster until all studies in the Serial Study Group are completed, expected to be about July 2009.

All interconnection requests that are received by CAISO after June 2, 2008, will be placed in the Initial GIPR Cluster study group and subject to a temporary suspension. CAISO's LGIP tariff limits the cluster window to 180 days; however, CAISO requested and received a waiver from FERC to extend the window for the Initial GIPR Cluster from June 2, 2008 to July 31,2009 , to coincide with the conclusion of the expected study period of the Transition Cluster.

Once fully in place, CAISO will open two four-month clusters each year. During these windows, interconnection customers will submit an interconnection request with an application and \$250,000 deposit, site control documents, expected in-service date, technical data, and deliverability status (energy only, or capacity and energy). Another $\$ 250,000$ is required if site control cannot be demonstrated. The deposits become non-refundable 19 months after the interconnection application is filed, as the deposits are used to pay for the studies. Before the project is assigned cost responsibility for any necessary transmission network upgrades, the interconnection customer must post an additional deposit of 20 percent of the estimated cost responsibility or $\$ 500,000$, whichever is greater. Once the cluster studies are completed, the interconnection customer must post financial security for 100 percent of the total cost responsibility of the project, or $\$ 500,000$, whichever is greater. Partial refund of these last two sets of deposits are allowed if the interconnection customer could not secure a power purchase agreement or regulatory permits, or if the upgrade costs are at least 30 percent higher than first estimated, or if costs increased because CAISO changed the interconnection point.

Midwest ISO: In September 2007, the Midwest ISO formed the Interconnection Process Task Force, comprised of stakeholders, to identify solutions for reducing the waiting time for projects in the generator interconnection queue, and to increase the certainty and validity of the proposed projects. The reforms create a generation interconnection process that is based on milestones, with four key phases: Pre-Queue, Application Review, System Planning and Analysis, and Definitive Planning.

The Pre-Queue phase is an opportunity for the Midwest ISO and the interconnection customer to interact and discuss the generation interconnection process, timeline, and expectations. The phase consists of meetings and public information sessions, as well as 
collecting application data prior to formally submitting an application. At the end of the phase, interconnection customers are required to submit a non-refundable $\$ 5,000$ application fee, and proof of site control, or a $\$ 100,000$ deposit in lieu of site control to achieve the milestone and move forward through the process. There is also an optional study that interconnection customers may request to see their cost obligation.

The Application Review phase includes technical and non-technical aspects. Generator and project models and one-line diagrams are developed and a study deposit and documentation are submitted. The additional deposit is based on the size of the project and ranges from $\$ 10,000$ to $\$ 120,000$. If a project withdraws before the next phase, any unused portion of the study deposit would be refunded. During this phase, Midwest ISO conducts a feasibility study to determine if the transmission network is "ready," meaning it is able to accommodate the interconnection request without significant transmission network upgrades. A project that cannot be accommodated within the existing transmission system capacity margin may choose to continue with an optional study to estimate its direct facility interconnection and network upgrade costs in a non-binding process.

If the transmission network can accommodate it, the project bypasses the system planning and analysis study and moves directly to the Definitive Planning phase. A project that does this is usually located in a relatively unconstrained area and needs minimal transmission network upgrades. Otherwise, the project moves on to the Planning and Analysis phase where a system impact study determines the upgrades necessary for interconnection. Midwest ISO will study the interconnection requests as groups, organized by region and electrically related projects.

Next, a project proceeds to the Definitive Planning phase where the interconnection customer executes an interconnection agreement, and pays additional study deposits based on capacity size ranging from $\$ 40,000$ to $\$ 520,000$. Additionally, this phase includes a detailed stability model, a final point of interconnection, and recertification of site control. During the second part of the phase, the interconnection customer must provide security for the cost of the transmission network upgrades, an execution of a contract for the sale of energy or capacity, and proof that generating equipment has been ordered. Processing these requests may allow a project to move forward. Once in the second phase of the Definitive Planning phase, suspension of a project is only allowed in cases of force majeure, and even then the interconnection customer must put forward a deposit equal to the higher of the cost of the network upgrades or $\$ 5$ million so that projects placed lower in the queue within the group are not negatively impacted by the suspension.

The Midwest ISO filed their proposed queue reform tariff with FERC on June 26, 2008. On August 25, 2008, FERC issued an order conditionally accepting the reform filing. ${ }^{26}$ FERC largely accepted the proposed filing, requiring only minor modifications on a few issues and rejecting only one change. ${ }^{27}$

\footnotetext{
${ }^{26}$ FERC, “Order Conditionally Accepting Tariff Revisions Addressing Queue Reform,” Docket No. ER08-1169000, August 25, 2008.

${ }^{27}$ FERC ruled that Midwest ISO had not provided sufficient evidence to justify the proposed change to how energyonly resource interconnections will be handled. The Midwest ISO was ordered to revisit this issue along with some other minor modifications and clarifications in a supplemental filing due within 30 days.
} 
Southwest Power Pool: SPP is in the midst of a stakeholder process on interconnection queue reform. Although still under development and subject to change, SPP's proposal would also move to a milestone-based process, with interconnection customers having to meet five milestones before being interconnected. In addition, SPP would also sharply raise deposits.

Specifically, for the preliminary impact study, SPP would require a study deposit of $\$ 40,000$ for proposed projects less than $100 \mathrm{MW}, \$ 60,000$ for proposed projects less than 800 MW, and $\$ 90,000$ for proposed projects exceeding $800 \mathrm{MW}$. The unused portions of the study deposits would be refundable. A demonstration of site control would be required, with no option for paying a deposit in lieu of site control. A generation project's proposed installed capacity must also stay relatively constant with the capacity studied in SPP's preliminary impact study. The proposed project's generating capacity must remain at a level that is no less than 10 percent of the final installed capacity, and no increases in generating capacity will be allowed.

For the next phase, the Definitive Impact Study, interconnection customers would have to provide a $\$ 150,000$ study deposit; a definitive point of interconnection; the final plant capacity rating with no decreases allowed; and detailed study materials for power flow and stability studies. Interconnection customers also would have to provide one of the following: a power purchase agreement; a purchase order for generating equipment specific to the project; an application for an air permit (if applicable); and a security deposit of $\$ 2,000 / \mathrm{MW}$, refundable at time of commercial operation or withdrawal.

For the Facilities Study, SPP would require one of the following: a letter of credit or payment for estimated network upgrades, less the deposit for the Definitive Impact Study; a power purchase agreement; a purchase order for generating equipment specific to the proposed project; an application for an air permit (if applicable); or an executed contract for cooling water supply (if applicable).

After meeting the milestones, SPP and the interconnection customer would negotiate a LGIA, after which the interconnection customer must make a non-refundable payment of estimated network upgrade costs within 30 days. Suspending the LGIA would not stop this payment. Finally, suspending the LGIA requires $\$ 5$ million, less the estimated cost of the network upgrades.

SPP and SPP's Regional State Committee are also working on new ways to allocate transmission costs in particular cases. SPP's new "balanced portfolio" approach will assign the costs of economic upgrades for transmission lines rated $345 \mathrm{kV}$ or higher SPP-wide, as long as the identified balanced portfolio plan has a benefit-to-cost ratio of better than one (for all zones within SPP). SPP's Market and Operations Committee will recommend one balanced portfolio for SPP's Board of Governors to evaluate. If the portfolio receives Board approval, it will be added to SPP's transmission expansion plan. FERC approved SPP's balanced portfolio filing in October 2008. ${ }^{28}$

Separately, SPP's Regional State Committee has proposed a methodology for allocating transmission network upgrade costs for wind projects that are designated to serve network

\footnotetext{
${ }^{28}$ Federal Energy Regulatory Commission, Order Accepting Tariff Revisions as Modified. 125 FERC $\uparrow$ 61,054, October 16, 2008.
} 
transmission customers in SPP. ${ }^{29}$ If approved, this new cost recovery approach would apply for wind capacity up to 20 percent of a load-serving entity's summer peak demand. For the loadserving entity's zone, transmission cost allocation is $1 / 3$ postage stamp, $2 / 3 \mathrm{MW}$-mile. For the other zones, transmission cost allocation is $2 / 3$ postage stamp, $1 / 3$ direct assignment. Transmission additions or upgrades directly related to interconnecting a wind project selected as a designated network resource are limited by a safe harbor limit of $\$ 180,000$ per MW of nameplate generating capacity that is applicable to all sources of generation, again assuming the load-serving entity is below the 20 percent peak demand limitation on wind energy purchases. If the load-serving entity is already at or above the 20 percent limitation, only a percentage of transmission costs equal to the wind project's capacity accreditation factor (about 10 percent) would be eligible for SPP base funding, with the remainder being directly assigned, or participant funded.

ISO New England: ISO-NE's filed its queue reform initiative with FERC on October 31, $2008 .^{30}$ ISO-NE recently launched a Forward Capacity Market (FCM) for soliciting capacity up to three years in advance of need, with the first auction held in February 2008 for delivery in 2010/11. The initial auction highlighted the issues with backlogs in generator interconnection applications, as some generators noted they were unsure they could commit to a 2010/11 timeframe because of where they were in the ISO-NE interconnection queue.

In addition to raising deposits for filing an interconnection request and for the feasibility study, the system impact study, and the facilities study, ISO-NE is proposing to create two new categories for the FCM. One, for conditional qualified capacity resources, would allow a lower queued project that has overlapping system impacts with a higher queued project to qualify for a forward capacity auction along with the higher queued project. Should the higher queued project clear in the forward capacity auction, the lower queued project cannot proceed. If, however, the higher queued project withdraws or fails to meet various milestones, then the lower queued project would proceed instead in the forward capacity auction.

ISO-NE is also proposing a new process for long-lead resources that have longer development cycles than the two-to-three years between the auction and required power delivery time. Essentially, it would allow a long-lead resource to qualify in a forward capacity auction as long as it follows a development schedule and meets certain financial milestones.

Table 5 provides a summary of the different RTO and ISO queue reform initiatives. Some RTOs and ISOs are still deliberating over their interconnection queue reform initiatives; therefore, some of the information in Table 5 is subject to change.

\footnotetext{
29 “SPP Expected to Vote on Postage-Stamp Rate Design for Economic Upgrades, Says CEO," Inside FERC, July 7, 2008, p. 3.

${ }^{30}$ ISO New England, Joint Filing of Proposed Revisions to the Generator Interconnection Process and Forward Capacity Market Participation Provisions Set Forth in the ISO New England Inc. Transmission, Markets and Services Tariff, October 31, 2008. http://www.iso-ne.com/regulatory/ferc/filings/2008/oct/er09-_ _ _000 10-831 fcm_queue.pdf (accessed November 4, 2008).
} 
Table 5

RTO and ISO Generation Queue Reform Proposals (as of December 2008)

\begin{tabular}{|c|c|c|c|c|c|c|}
\hline & PJM $^{1}$ & Midwest ISO & ISO-NE & NYISO $^{3}$ & SPP $^{4}$ & CAISO $^{5}$ \\
\hline Status & $\begin{array}{c}\text { Under Discussion, } \\
\text { Some Approved by } \\
\text { FERC }\end{array}$ & Approved by FERC & $\begin{array}{l}\text { Filed at FERC in } \\
\text { October } 2008\end{array}$ & Under Discussion & Under Discussion & $\begin{array}{l}\text { Approved by } \\
\text { FERC }\end{array}$ \\
\hline $\begin{array}{l}\quad \text { New Initial } \\
\text { Interconnection } \\
\text { Request Deposit }\end{array}$ & $\begin{array}{l}1^{\text {st }} \text { month } \$ 10,000 \\
2^{\text {nd }} \text { month } \$ 20,000 \\
3^{\text {rd }} \text { month } \$ 30,000^{6}\end{array}$ & $\begin{array}{c}\$ 5,000^{7} / \\
\$ 10,000-\$ 120,000^{8}\end{array}$ & $\$ 50,000$ & TBD & $\begin{array}{c}\mathrm{FS}^{8} \$ 10,000 \\
\text { PIS: }<100 \mathrm{MW}- \\
\$ 40,000 \\
100-800 \mathrm{MW}- \\
\$ 60,000 \\
\geq 800 \mathrm{MW}- \\
\$ 90,000\end{array}$ & $\$ 250,000$ \\
\hline $\begin{array}{l}\text { New Site Control } \\
\text { and/or Feasibility } \\
\text { Study Deposit } \\
\text { Requirements }\end{array}$ & $\begin{array}{l}1^{\text {st }} \text { month } \$ 100 / \mathrm{MW} \\
2^{\text {nd }} \text { month } \$ 150 / \mathrm{MW} \\
3^{\text {rd }} \text { month } \$ 200 / \mathrm{MW}\end{array}$ & SC or $\$ 100,000$ & $\begin{array}{l}\text { SC required plus } 100 \% \\
\text { of estimated FS costs }\end{array}$ & TBD & $\begin{array}{l}\text { FS: none } \\
\text { PIS: SC }\end{array}$ & SC or $\$ 250,000$ \\
\hline $\begin{array}{c}\text { Data Requirement } \\
\text { Changes }\end{array}$ & No & No & No & TBD & $\begin{array}{l}\text { FS: none } \\
\text { PIS: all data due, } \\
\text { including from } \\
\text { wind developers }\end{array}$ & $\begin{array}{c}\text { Wind developers } \\
\text { no longer have } \\
60 \text { days }\end{array}$ \\
\hline $\begin{array}{l}\text { Feasibility Study } \\
\text { Timeline Change }\end{array}$ & No & 10 days & No & TBD & $\begin{array}{c}\text { FS: no } \\
\text { PIS: } 150 \text { days }\end{array}$ & $\begin{array}{l}\text { Phase I }-270 \\
\text { days }\end{array}$ \\
\hline Cluster Studies & Conducts & Still Optional & Still Optional & TBD & Still Optional & Now Conducts \\
\hline
\end{tabular}


Table 5

RTO and ISO Generation Queue Reform Proposals (as of December 2008, continued)

\begin{tabular}{|c|c|c|c|c|c|c|}
\hline & PJM & Midwest ISO & ISO-NE & NYISO & SPP & CAISO \\
\hline $\begin{array}{l}\text { New System Impact } \\
\text { Study Deposit }\end{array}$ & $\begin{array}{c}\text { Several options still } \\
\text { under discussion. } \\
\text { Option include: } \\
1 . \$ 20,000 \text { plus } \\
\$ 100 / \mathrm{MW}, \text { Max. } \\
\$ 120,000 \\
2 . \$ 30,000 \text { plus } \\
\$ 300 / \mathrm{MW}, \text { Max. } \\
\$ 300,000 .\end{array}$ & $\begin{array}{l}\text { No deposit, all } \\
\text { funds for FS and SIS } \\
\text { collected upfront } \\
\text { during FS stage. }\end{array}$ & $\begin{array}{l}\text { Three options: } \\
\text { 1. } 100 \% \text { est. study cost } \\
\text { or } \$ 250,000 \\
\text { 2. } 100 \% \text { est. study cost } \\
\text { or } \$ 50,000 \text { plus all } \\
\text { permits. } \\
\text { 3. } 100 \% \text { est. study cost } \\
\text { or } \$ 50,000 \text { plus at-risk } \\
\text { expenditures equal to } \\
\text { amount in (1.) }\end{array}$ & TBD & $\begin{array}{c}<75 \mathrm{MW}-75,000 \\
\geq 75 \mathrm{MW}- \\
\$ 150,000 \\
\text { Plus meet } \\
\text { milestones. }\end{array}$ & $\begin{array}{l}\text { No deposit, all } \\
\text { funds for FS and } \\
\text { SIS collected } \\
\text { upfront in Phase } \\
1 .\end{array}$ \\
\hline $\begin{array}{l}\text { System Impact Study } \\
\text { Timeline Changes }\end{array}$ & No & 1 year & No & TBD & 120 days & $\begin{array}{c}\text { Phase II - TBD, } 1 \\
\text { year }\end{array}$ \\
\hline $\begin{array}{l}\text { New Interconnection } \\
\text { Facilities Study } \\
\text { Deposit }\end{array}$ & $\begin{array}{l}\text { Still under discussion, } \\
\text { considering moving } \\
\text { to milestone based. }\end{array}$ & $\$ 40,000-\$ 520,000$ & $\begin{array}{c}\text { Three options: } \\
\text { 1. } 25 \% \text { est. study cost } \\
\text { or } \$ 250,000 \\
\text { 2. } \$ 100,000 \text { or est. } \\
\text { monthly share of costs } \\
\text { plus all permits. } \\
\text { 3. } \$ 100,000 \text { or est. } \\
\text { study cost plus at-risk } \\
\text { expenditures equal to } \\
\text { amount in (1.) }\end{array}$ & TBD & $\begin{array}{l}\text { Letter of credit or } \\
\text { payment of full } \\
\text { estimated cost of } \\
\text { network upgrades. } \\
\text { Plus must meet } \\
\text { milestones. }\end{array}$ & $\begin{array}{c}\text { Within } 180 \text { days } \\
\text { of Phase II } \\
\text { completion } \\
\$ 500,000 \text { or } \\
100 \% \text { of } \\
\text { estimated costs }\end{array}$ \\
\hline $\begin{array}{l}\text { Suspend Projects } \\
\text { Changes }\end{array}$ & $\begin{array}{c}\text { Up to } 3 \text { years, but } \\
\text { only after signing a } \\
\text { Construction Service } \\
\text { Agreement. }\end{array}$ & Only Force Majeure & No & TBD & $\begin{array}{l}\text { Up to } 18 \text { months } \\
\text { only after signing } \\
\text { the LGIA }\end{array}$ & $\begin{array}{l}\text { Up to } 3 \text { years } \\
\text { but only after } \\
\text { signing the LGIA }\end{array}$ \\
\hline
\end{tabular}


Table 5

RTO and ISO Generation Queue Reform Proposals (as of December 2008, continued)

\begin{tabular}{|c|c|c|c|c|c|c|}
\hline & PJM & Midwest ISO & ISO-NE & NYISO & SPP & CAISO \\
\hline $\begin{array}{l}\text { New Large Generator } \\
\text { Interconnection } \\
\text { Agreement Deposit }\end{array}$ & Still under discussion. & $\begin{array}{l}\text { Based on project } \\
\text { size }\end{array}$ & $\begin{array}{l}\text { IFS can be waived and } \\
\text { project fast-tracked. If } \\
\text { waived deposit equal } \\
\text { to estimated cost of } \\
\text { engineering studies } \\
\text { plus all permits plus } \\
\text { commit to } \\
\text { construction } \\
\text { expenditure schedule. } \\
\text { If IFS conducted, } \\
\text { deposit is } 20 \% \text { of } \\
\text { estimated construction } \\
\text { costs, plus commit to } \\
\text { schedule for } \\
\text { expenditures and } \\
\text { permit milestones. }\end{array}$ & TBD & $\begin{array}{l}\text { Letter, credit, or } \\
\text { payment was due } \\
\text { at IFS deposit } \\
\text { stage. This } \\
\text { payment is } \\
\text { refunded if LGIA is } \\
\text { not signed. }\end{array}$ & $\begin{array}{l}100 \% \text { of } \\
\text { estimated costs. }\end{array}$ \\
\hline
\end{tabular}

1 PJM Tariff changes regarding Feasibility and Interconnection Request deposits have been approved. Other changes are still in progress.

2 FERC approved the Midwest ISO's Queue Reform Proposal on August 25, 2008 and the new study process will be implemented sometime around November 2008.

3 The NYISO just began a stakeholder process on generation interconnection queue reform.

4 SPP has proposed moving to a three-queue system based on project readiness milestones. One queue for customers opting to do an optional Feasibility Study, one for customers opting to go directly to a Preliminary Impact Study, and then one queue for customers that are ready and meet the milestones for entering the Definitive Planning phase.

5 CAISO received approval on September 26, 2008. The new study process is organized according to Phase I and Phase II portions.

6 All deposits based on when project entered queue: in first month of 3 -month cluster window, $2^{\text {nd }}$ month, or $3^{\text {rd }}$ month.

7 Pre-Queue Phase.

8 Application review and feasibility study phase. Amount is scaled depending on the size of the proposed facility.

FS = Feasibility Study, PIS = Preliminary Impact Study; SIS = System Impact Study; IFS = Interconnection Facility Study 


\section{Potential Solutions}

A number of potential solutions have been offered in the reform proposals about addressing clogged interconnection queues. Momentum has gathered around four particular options: (1) increasing the financial deposit requirements for receiving and maintaining a queue position; (2) eliminating the initial feasibility study or re-creating it as an optional screening phase; (3) greater limitations on project suspensions; and (4) moving away from a first-come, first-serve approach towards one that is more milestone-based.

FERC itself lent some weight to these potential options in an Order issued on March 20, 2008. ${ }^{31}$ FERC acknowledged that increasing the amount of the deposits required at different stages of generator interconnection would "more accurately reflect the cost of the necessary studies" and could also increase the probability that only commercially viable projects enter the generator interconnection queue. FERC also noted that eliminating the feasibility study could decrease processing time and also reduce the number of generator interconnection requests, as generators not willing to pay the higher costs of the system impact study will not enter the generator interconnection queue in the first place. Finally, FERC said that there may be advantages in transitioning towards a "first-ready, first-served" approach instead of first-come, first-served.

FERC also indicated, though, that increasing the strictness of required deposits and eliminating the feasibility study requires that other sources of information on available transmission capacity be available to narrow generator interconnection requests toward a single point of interconnection. FERC also stated that increasing the strictness of requirements might place a greater burden on smaller customers.

A number of the more common potential generation queue reform proposals are discussed below.

Increasing Deposit Requirements for Entering and Staying in the Queue: A central theme among transmission providers is the relatively low financial requirements for entering and staying in the interconnection queue. Increasing these financial requirements is considered to be one way to prevent multiple requests on individual projects and future logjams. Based on the generation queue reform initiatives either filed to date or under discussion, it appears that a sizable increase in deposits for all elements of the interconnection process - feasibility study, system impact study, facilities study — can be expected.

Furthermore, for the LGIA, some generation queue reform proposals call for a sizable deposit for identified transmission upgrades, or for suspending a project, to cover the costs of any necessary restudies and to discourage developers from keeping questionable projects in the queue. Figure 14 presents potential generation interconnection deposit costs for a hypothetical 100-MW plant for individual RTOs and ISOs, based on the RTO and ISO generation interconnection queue reform proposals. The estimated deposit costs do not include various deposits that may apply to specific projects, such as additional deposits that may be required if a

\footnotetext{
${ }^{31}$ Federal Energy Regulatory Commission, Interconnection Queuing Practices, Order on Technical Conference, 122 FERC \ 61,252 (2008).
} 
project does not have site control. The deposit estimates in Figure 14 also do not include deposits that may be required after signing an LGIA. Nevertheless, the data in Figure 14 is illustrative and indicates some variation among the different RTOs and ISOs. For instance, only two of the five RTOs and ISOs are keeping the feasibility study as a separate definitive study phase. In addition, the CAISO's up-front deposit is larger than the other RTOs and ISOs, but it covers all of the study work up to the facility study phase.

Figure 14

\section{Potential Estimated Deposits for a 100-MW Project by RTO or ISO}

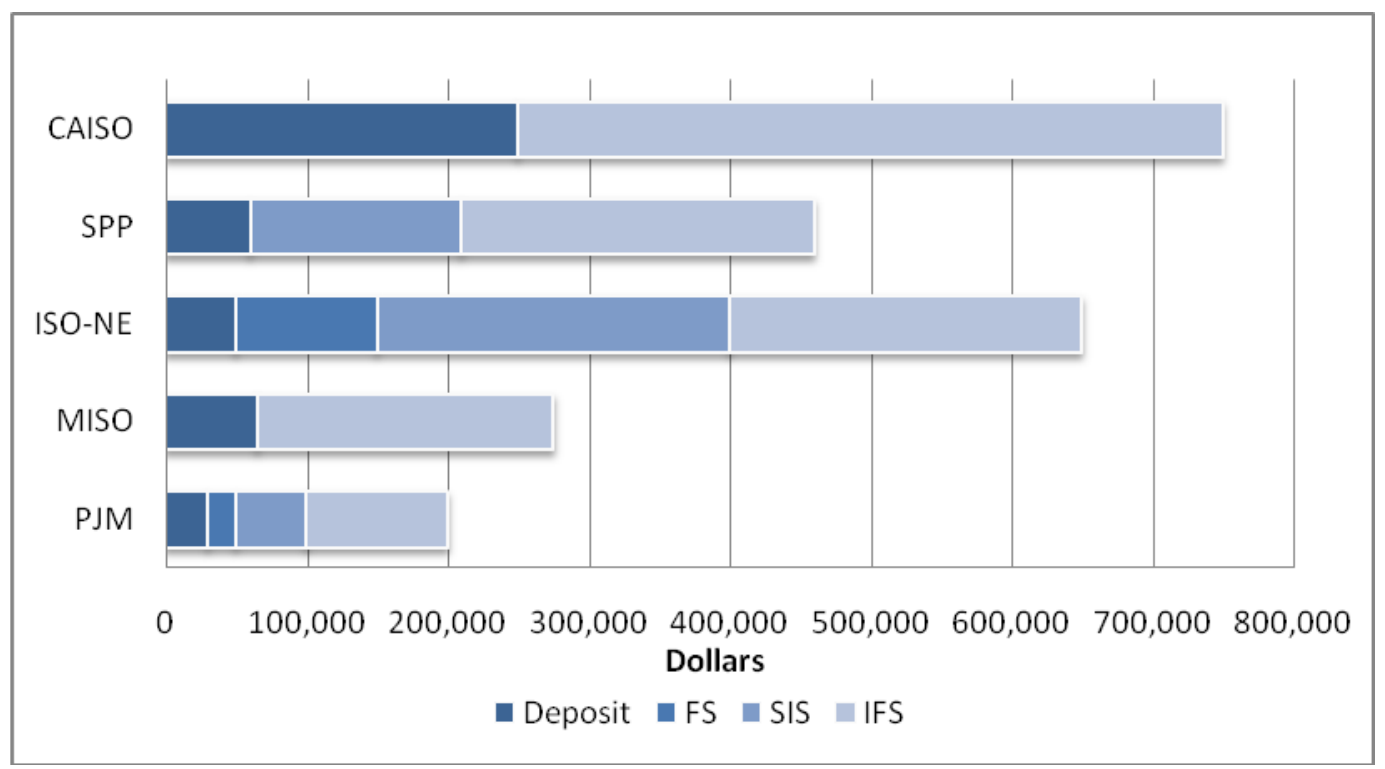

Notes: $\quad F S=$ Feasibility study

SIS $=$ System impact study

IFS = Interconnection facility study

Chart reflects theoretical typical amounts of getting to completion of Facilities Study phase, may be lower if project developer meets certain milestones or fulfills certain conditions, e.g., evidence of at risk expenditures; permits acquired; contracts acquired; and for PJM, earlier applications. With many of the deposits, amounts not used are later refunded.

Total cost can also be higher e.g.,:

CAISO - FS stage, if no site control must pay additional $\$ 250,000$.

ISO-NE - full estimated cost of study due for FS, assumed cost here is $\$ 100,000$.

Midwest ISO - FS stage, if no site control must pay additional $\$ 100,000$.

Project developers will still be required to pay a deposit upon signing an LGIA. The specific amounts are still being discussed by PJM; ISO-NE is $20 \%$ of estimated construction costs; the Midwest ISO is based on project size and estimated costs; and SPP and CAISO is $100 \%$ of estimated construction costs.

Reducing Project Suspension Provisions: Another general area of agreement is that the three-year allowance for interconnection customers to suspend processing on their interconnection applications for a project is too easy to obtain. The Midwest ISO's queue reform initiative bars the use of project suspension except for circumstances of force majeure. SPP is 
tentatively proposing to retain the three-year suspension period, but requiring a deposit of $\$ 500,000$ to pay for the costs of any necessary restudies. Still another possibility is to reduce the period of suspension from three years to one or two years, although that has not been included in any generation queue reform proposal as of yet. These proposals are likely an improvement over the current process of allowing generating projects relatively low-cost suspension while forcing other generating projects lower in the queue to pay for restudy costs.

\section{Making Progress through the Interconnection Queue Based on Milestones Instead of}

First-In, First-Out: Setting defined milestones can allow projects to leap frog over others in the queue that have not yet achieved the milestones. The Midwest ISO's new generation interconnection procedures include use of such milestones and other RTOs and ISOs are considering use of them as well. Potential milestones include proof of site control, completion of data requirements, equipment ordering or purchasing, or a power purchase agreement. The specifics matter greatly, and complexities arise because of the different types of business models companies pursue (i.e., merchant plants that don't rely on a power purchase agreement as compared to an independent power producer or a utility-owned plant) and different technologies. Therefore, some either/or alternatives will likely have to be provided with each milestone. ${ }^{32}$ Furthermore, generators may enter the interconnection queue in order to receive the necessary data from the interconnection studies (i.e., transmission network upgrade costs) as an input for bidding solicitations. The Midwest ISO's optional study process is an example of a process designed to avoid this dilemma.

Depending on the specifics, wind companies may face some difficulties if items such as data requirements are tightened. Under Order 661, the companion to Order 2003, wind companies have six months to provide detailed electrical design specifications after filing an interconnection application. As noted earlier, CAISO has eliminated this six-month window, and reducing or eliminating this window is apparently under discussion at some of the other RTOs and ISOs. Transmission providers have argued that the lack of detailed information makes it difficult to more precisely study proposed wind projects, but the changes in wind technology and wind turbine models can make it difficult for wind developers to pick a turbine and stay with it through the interconnection study process. Wind companies also state they need base case data from the RTO or ISO to determine what specific wind turbine they will need to meet the needs of the grid. In addition, potential provisions such as requiring early-stage documentation of equipment orders before proceeding through the interconnection queue may also prove difficult for wind companies. Given the near-term lack of wind turbines, unless wind companies have locked in a supply of wind turbines in advance, as some have done, it is difficult to guarantee the availability of a turbine too far in advance of construction.

Improving or Eliminating the Initial Feasibility Study: Some have suggested that dropping the initial feasibility study could save time, as the power flow modeling and short circuit analysis is duplicated in greater detail in the system impact study. In some cases, transmission providers allow developers to roll the feasibility study into the system impact study at their option, sometimes requiring a commitment from the developer to follow a pre-defined timeline for bringing projects into operation. The Midwest ISO opted to improve their feasibility

\footnotetext{
${ }^{32}$ ISO/RTO Council, ISO/RTO Council White Paper on Interconnection Queue Management Process, January 2008.
} 
study process through providing greater levels of information up-front in their queue reform initiative.

Open Season: Under this concept, a transmission provider holds an open season for new transmission capacity, whereby transmission customers and generators interested in purchasing new transmission capacity put in financial bids. Should enough bids be submitted and enough transmission capacity subscribed, new transmission can be constructed. The open season is modeled after the natural gas industry, which uses it to fund natural gas pipelines.

Both BPA and the Wyoming Infrastructure Authority (WIA) have implemented different versions of open seasons. BPA used an open season to whittle down a backlog in requests for BPA transmission service and to determine who would be interested in financing new transmission capacity. Along with WAPA and Trans-Elect, WIA is sponsoring the WyomingColorado Intertie $345-\mathrm{kV}$ transmission project that could transfer $850 \mathrm{MW}$ from Wyoming to Colorado. WIA held an open season earlier in 2008 to subscribe capacity to the line, and two wind companies committed to $585 \mathrm{MW}$. WIA is offering the remaining $265 \mathrm{MW}$ through an open access transmission tariff and will hold a subsequent auction if demand exceeds the 265 MW of available capacity. Besides BPA and WIA, the Midwest ISO is also considering holding an open season and may file a proposal with FERC in early $2009 .{ }^{33}$

As indicated, there has been some apparent success with using open seasons to whittle down the backlog in the queue and to locate subscribers for new transmission capacity. That said, it is not clear whether there will be sufficient interest for open seasons to always work, as transmission customers may not want to commit financing for transmission that may not be available for several years, particularly if there is a possibility that transmission may be financed through other cost recovery mechanisms. Indeed, an earlier BPA open season to support the McNary-John Day 500-kV transmission line was unsuccessful when several participants withdrew their applications. ${ }^{34}$

Improving Clustering Processes: Order 2003 allows transmission providers to study interconnection requests as a cluster, rather than each individual project serially. Several ISOs and RTOs use clustering - PJM groups projects through windows that close every four months (recently decreased from six months). NYISO groups projects by year, provided that the generation developer provides a reliability impact study that has been approved by NYISO's Operating Committee and has met at least one regulatory milestone towards obtaining environmental permits or approvals.

The use of clustering for interconnection studies has had mixed results to date. Clustering can reduce study timelines and increase efficiency by studying projects as a group and sizing transmission projects to meet the aggregate need. However, clustering can increase study timelines and costs if projects drop out, forcing the transmission provider to conduct what can be multiple restudies. In some cases, the cluster may span a large geographic region, adding to the complexity of the generator interconnection studies. One example is the Midwest ISO's Group 5

\footnotetext{
${ }^{33}$ Federal Energy Regulatory Commission, Order Conditionally Accepting Tariff Revisions Addressing Queue Reform. 124 FERC $₫ 61,183$ (August 25, 2008).

${ }^{34}$ Bonneville Power Administration, "McNary - John Day Open Season Information." http://www.transmission.bpa.gov/PlanProj/Transmission_Projects/mcnary/mjdosi.cfm. (Accessed September 5, 2008).
} 
cluster that included 36 wind projects and one coal plant and covered an area of 200 miles by 300 miles in Iowa and Minnesota. The group study began in May 2006, and the feasibility study was completed in September 2006. The initial system impact study was not completed until October 2007. The stability results were challenged and subsequently re-analyzed in early 2008 . The Group 5 study was also hampered by about 40 higher-queued projects that collectively required about 80 transmission network upgrades prior to operation of the Group 5 projects.

Some of the negative aspects of clustering can be mitigated by organizing project clusters around similar electrical characteristics, rather than by the time the applications were filed, and through requiring generators to post deposits equal to the upgrade costs once those costs are determined. NYISO requires generators to post security equal to the upgrade costs to obtain an interconnection agreement; alternatively, the generator can decline the cost allocation assignment and enter the next cluster. ${ }^{35}$ CAISO's new generation queue process will also require generation developers to post security equal to the upgrade costs or $\$ 500,000$, whichever is greater.

Transmission providers have also received FERC approval for one-time waivers of timetables, thereby allowing the use of clusters to help clear out their interconnection queues or to conduct more specialized studies. CAISO received a waiver from FERC to do a 33-month cluster study on over 4,000 MW of proposed wind projects in the Tehachapi region of California. CAISO received FERC approval for a waiver for interconnection requests received before June 2,2008 , in order for CAISO to finish work on projects in more advanced stages of the interconnection studies. ${ }^{36}$

Providing Priority to Certain Generating Projects in Interconnection Queue: Generators that successfully participate either in forward-capacity market auctions or in competitive resource solicitations may be impeded by other generating projects that have a higher position in the generator interconnection queue. Moreover, the capacity auctions or bidding solicitations may result in several projects entering the interconnection queue, only to withdraw or suspend their project if they are unsuccessful. Nevertheless, the transmission provider must at least begin processing each interconnection queue application without prejudice or pre-judging the feasibility of a request. Some have suggested allowing projects in state integrated resource plans or winning projects in bidding solicitations to "jump the queue." 37 Moving generating projects forward in the queue because of winning a competitive bid or qualifying for a capacity market auction might be incorporated in a milestone-based interconnection queue process.

Transmission Cost Allocation: Who should pay for transmission network upgrades made necessary from interconnecting a generator or generators is a protracted and long-running debate. Although an oversimplification, the debate has generally occurred along the lines of those who believe that generators should pay all of the costs for upgrading the transmission network through interconnection ("participant funding"), and those that assert that upgrades benefit and improve the reliability of the network as a whole and, therefore, should be paid for by all

\footnotetext{
${ }^{35}$ New York ISO, Status Report of the New York Independent System Operator, Inc., on Interconnection Queuing Issues, Docket AD08-02, April 21, 2008.

${ }^{36}$ Federal Energy Regulatory Commission, California Independent System Operator, 118 FERC 9 61,226, order granting clarification, 120 FERC 91,180 (2007).

${ }^{37}$ Remarks of The Honorable Ron Binz, Colorado Public Utilities Commission, FERC Technical Conference on Interconnection Queues, December 11, 2007.
} 
transmission customers. Another approach is to assign costs to beneficiaries of the transmission upgrades, although these can be difficult to determine as the beneficiaries may change over time.

FERC tried to take the middle ground in Order 2003 by requiring generators to pay the upfront costs of transmission network upgrades, but then requiring transmission providers to reimburse generators over time with either transmission credits or financial transmission rights. As noted earlier, FERC allowed RTOs and ISOs to have "independent entity" variations from Order 2003. The Midwest ISO adopted a 50-50 policy of requiring generators to pay 50 percent of the costs of generator-related transmission network upgrades, while SPP adopted a policy of allowing two-thirds of the costs of transmission network upgrades to be allocated to the zones directly benefitting from the upgrade (as determined through modeling) and one-third spread to all transmission customers in SPP.

FERC, the Midwest ISO, and SPP adopted these cost allocation mechanisms in order to ensure that generators consider grid location in filing interconnection applications, i.e., to incent generators to locate along less constrained transmission lines, as well as to provide a preference for more viable projects to move forward. Arguably, what may have happened is that generators, in an attempt to avoid or minimize incurring significant transmission network upgrade costs, choose to file multiple interconnection applications, which prompts restudies once those applications are suspended or withdrawn.

A revisiting of region-specific transmission cost allocation methods may be forthcoming. The Midwest ISO is considering reopening a stakeholder process on its 50-50 methodology. Earlier, the International Transmission Company (ITC)/Michigan Electric Transmission Company and the American Transmission Company, both of whom operate inside the Midwest ISO, successfully petitioned FERC to revert to FERC Order 2003 generator reimbursement policy for generator interconnections located within their service territory that are designated as either a network resource or have a power purchase agreement of one year or longer. ${ }^{38}$ Since receiving FERC approval, ITC has received 13 new interconnection requests representing 4,500 MW of capacity. ${ }^{39}$ ITC has since received approval from FERC to extend the Order 2003 reimbursement policy to its ITC Midwestern transmission service area that encompasses parts of Iowa, Illinois, Minnesota, and Missouri. ${ }^{40}$

Other regions are pursuing more defined carve-outs from their cost allocation policies. As discussed previously, SPP's 'balanced portfolio' approach has been approved by FERC and will act to spread transmission costs to all customers in SPP for a limited set of transmission portfolios that provide positive cost benefits to all customer zones in SPP. ${ }^{41}$ Separately, SPP's Regional State Committee is devising a cost allocation proposal for network transmission for designated wind resources. Finally, CAISO is implementing its location-constrained resource

\footnotetext{
${ }^{38}$ Federal Energy Regulatory Commission, Int'l Transmission Co., 120 FERC 9 61,220 (2007), reh'g denied, 123 FERC $\$ 61,065$ (2008) and Am. Transmission Co., 120 FERC $\uparrow$ 61,221 (2007), reh'g denied, 123 FERC $\uparrow$ 61,065 (2008) (American Transmission).

${ }^{39}$ National Wind Coordinating Collaborative, Transmission Update, June 2008. http://www.nationalwind.org/pdf/NWCCTransmissionUpdateJune2008FINAL.pdf (accessed November 5, 2008).

${ }^{40}$ Federal Energy Regulatory Commission, Order Accepting Tariff Sheets and Requiring Compliance. 124 FERC 9 61,150 (August 7, 2008).

${ }^{41}$ Federal Energy Regulatory Commission. Order Accepting Tariff Revisions, as Modified. 125 FERC $₫ 61,054$ (October 16, 2008).
} 
interconnection policy that, for regions with high quality location-constrained resources, will spread the initial costs of large-scale transmission facilities to serve those resource areas across all load in CAISO (subject to a cap of 15 percent on the total net high-voltage transmission plant investment in CAISO and other conditions), then have generation projects pay a proportional share as they come on-line.

\section{Summary}

Applications for generator interconnection to the grid have surged in recent years across the country. Wind projects have filed the most applications, spurred in large part by state renewable portfolio standards and the increasing competitiveness of wind power. The large increase in generator interconnection applications has been somewhat unexpected and has strained resources of transmission providers. As a result, processing time for generator interconnection applications has generally increased.

FERC held a technical conference on generator interconnection queues in December 2007, and in March 2008 directed the nation's RTOs and ISOs to file periodic status reports of their generator interconnection queues. FERC's reasoning is that the issue with generator interconnection queues appears most pronounced at RTOs and ISOs. To date, FERC has approved the Midwest ISO's and CAISO's queue reform filings. Other RTOs and ISOs are preparing queue reform initiatives for filing later in 2008 or 2009. Common themes include a significant increase in required deposits for all or nearly all aspects of a generator interconnection (i.e., feasibility study, system impact study, facilities study, and the large generator interconnection agreement), transitioning from first-in, first-out to a milestone-based form of processing interconnection applications, reducing or eliminating the three-year period allowed for suspending projects, and requiring more information from generators.

There is broad support generally across all sectors of the electric power industry for reforming generator interconnection queues, but given the multiple number of business models for developing power projects, exactly how the reforms should be designed and implemented is complex. If converting to a milestone-based process, one strategy for addressing disparate business models is to provide multiple options for meeting a particular milestone. Separately, there also is relatively broad support for increasing deposits, although if not done carefully, it may inadvertently act as a deterrent to small projects or small companies. The Midwest ISO's approach of prorating deposits to the size of the project may help in this regard.

Above all, it is important to link queue reform initiatives with more proactive transmission expansion planning and addition of new transmission. Although the increase in generator interconnection applications has contributed to clogged interconnection queues, lack of transmission capacity also cannot be overlooked. Without new transmission, the queue reform initiatives may simply lead to a faster rejection of the generator interconnection application. Therefore, coupling queue reform initiatives with a re-examination of transmission cost allocation policies, as the Midwest ISO is doing, or combining queue reform initiatives with new transmission initiatives such as network transmission pricing for wind and balanced portfolio transmission expansion, as with SPP, is likely necessary to succeed in alleviating clogged generator interconnection queues. 
APPENDICES 



\section{A. BONNEVILLE POWER ADMINISTRATION}

Similar to other regions, the Bonneville Power Administration (BPA) also has experienced a sharp rise in interconnect requests, the majority of which are from wind. In 2005, BPA received 11 generator interconnection requests worth about 2,300 MW, eight of which were for wind projects representing $900 \mathrm{MW}$. In 2006, BPA received 26 requests worth 4,700 MW and 25 of those were for wind projects representing 4,600 MW. In 2007, BPA received a total of 31 generation interconnection requests, 29 of which were for wind power projects. At the end of 2007, BPA had 52 active requests in its queue for a total of 12,580 MW, with 47 of those requests being for wind power and representing 10,420 $\mathrm{MW}{ }^{1}$

\section{Queue Process}

BPA maintains two separate queues, one for generator interconnection and one for transmission service.

\section{Generator Interconnection ${ }^{2}$}

BPA is a federal entity and therefore, does not fall under FERC jurisdiction. However, for FERC rules and regulations to apply at BPA connections to other transmission systems, BPA submits and receives approval of its OATT. BPA's FERC-approved generator interconnection process very closely follows FERC Order 2003:

1. Interconnection Request - $\$ 10,000$ deposit plus evidence of site control or an additional $\$ 10,000$. The interconnection customer (IC) must identify if they are opting for network resource or energy only interconnection. Additionally, since BPA is a federal entity and therefore, subject to the National Environmental Policy Act (NEPA), an IC must execute an environmental study agreement so that BPA can perform the required NEPA environmental reviews.

2. Feasibility Study - $\$ 10,000$ deposit, BPA will endeavor to complete within 45 days.

3. System Impact Study - $\$ 50,000$ deposit plus evidence of site control, completion in 90 days.

4. Interconnection Facilities Study - deposit of $\$ 100,000$ or the estimated monthly cost, whichever is greater. BPA will endeavor to complete within 90 days at 20 percent accuracy or within 180 days if 10 percent accuracy as requested.

5. LGIA - $\$ 250,000$ deposit plus continued evidence of site control plus one or more of the following (as applicable):

(1) Execution of a contract for the supply or transportation of fuel.

\footnotetext{
${ }^{1}$ All data taken from BPA's published queue.

2 BPA, Attachment L: Standard Large Generator Interconnection Procedures from BPA Open Access Transmission Tariff, issued on October 3, 2008.
} 
(2) Execution of a contract for the supply of cooling water.

(3) Execution of a contract for the engineering for, procurement of major equipment for, or construction of, the facility.

(4) Execution of a contract for the sale of electric energy of capacity from the facility.

(5) Application for an air, water, or land use permit.

\section{Transmission Interconnection Network Open Season ${ }^{3}$}

In an effort to expedite its queue process for transmission requests, BPA introduced its new cluster-based network open season procedure. BPA filed its tariff to implement the network open season process with FERC in March 2008, followed by some amendments in May 2008. FERC issued a declaratory order on June 13, 2008, accepting tariff revisions to implement the network open season procedures. ${ }^{4}$

BPA will conduct network open seasons at least annually for all long-term firm transmission service requests on its transmission network. Each customer must sign a Precedent Transmission Service Agreement (PTSA) to remain in the queue. The PTSA is modeled after similar precedent agreements use in the natural gas industry, where pipeline developers must subscribe sufficient demand in order for construction to go forward. Under BPA's open season, customers subscribe in advance for transmission capacity (i.e., through a PTSA), allowing BPA to determine if there is sufficient demand for transmission in an area for them to proceed with construction. Customers must provide a security deposit along with the PTSA, equivalent to oneyear's worth of the requested service. While point-to-point customers will generally submit a security deposit, network integration customers have the option to designate a new network resource through an attestation and exempt themselves from the security requirement.

The PTSA obligates customers to take the transmission service if BPA fulfills the following conditions: (a) determines that it can provide the requested service at its embedded point-to-point and network integration rates, and (b) completes its required NEPA obligations and determine that the results are acceptable for building the required facilities. BPA is a federal agency and is required to conduct environmental reviews of all projects.

Following the open season, BPA will study all valid transmission requests as a cluster to determine aggregate system impacts, facility requirements, and estimated construction costs. The open season cluster study approach is all-inclusive and replaces the previous individual feasibility, system impact, and facility studies. All study costs will be borne by BPA, which has set the following timeline: within eight months, BPA must decide if it can provide the requested service at embedded cost rates; and within 36 months of making the above determination, BPA must have completed the NEPA studies. If BPA determines it will miss these deadlines but that it

\footnotetext{
${ }^{3}$ BPA, “2008 Network Open Season, Version 2,” April 17, 2008 and FERC Filing Docket No. NJ08-7: http://www.transmission.bpa.gov/business/IssuesPolicySteeringCmttee/default.cfm?page=ipqm

${ }^{4}$ FERC Docket No. NJ08-7-000, Declaratory Order, June 13, 2008: http://www.transmission.bpa.gov/business/IssuesPolicySteeringCmttee/documents/FERC_Order_Granting_NOS_T ariff_Changes.pdf
} 
can eventually complete the request, it will notify customers of the delay, and each customer will be given the option of terminating their PTSA. Once the studies are complete, BPA will arrange financing for planning, designing, and constructing the required transmission facilities. To recover costs, BPA will determine the benefits that will accrue to the integrated network from the new facilities and allocate that portion of costs to the network. The remaining costs will be recovered from the subscriptions made by the PTSA customers.

After the network open season, BPA will restack the queue in queue order for transmission requests for which a PTSA was finalized, with all other requests being considered as withdrawn. Cluster studies will then be based on this restacked queue. However, after the network open season window closes, BPA will again accept transmission requests on an individual basis and continue processing requests in queue order, if transmission capacity becomes available. BPA will also continue to process transmission requests that have no or de minimus impacts on available transmission capacity as individual requests. Transmission requests still in the queue that have not been processed by the time of the next network open season window will be included in that network open season. BPA also has a provision for accepting clustered requests outside the network open season process. A group of customers can make a cluster study request at any time, but all study costs must be borne by the customers. Additionally, any customers that withdraw from the process will still be liable for their portion of study costs. Since the cluster study is all-inclusive and represents all previous studies from feasibility to facility, cluster study costs can be substantial.

BPA's first network open season ran from April 15 to May 15, 2008. All customers that previously requested transmission services or submitted a transmission request by May 15 received a PTSA. Customers then had until June 16 to sign and return the PTSA and until June 27 to provide a security deposit in the form of a letter of credit, a deposit into an escrow account, or a cash deposit to BPA. Customers that chose not to execute the PTSA were removed from the BPA queue but may reapply at any time and will be eligible to participate in any subsequent network open season. The first network open season results were released on July 7 , 2008. A total of 153 completed PTSAs were executed for a total of 6,410 MW from 28 participating customers who had posted a total of $\$ 83,238,144$ worth of deposits. ${ }^{5}$ BPA notes in the results that 4,716 MW (74 percent) are associated with wind development with an average weighted transmission service request duration of 13.65 years. Independent power producers accounted for 100 requests worth 4,327 MW and utilities for 53 requests worth 2,083 MW. BPA also noted they had declined 153 requests totaling 7,299 MW because they did not meet the 2008 NOS obligations.

\footnotetext{
${ }^{5}$ Bonneville Power Authority, “2008 Network Open Season Results,” July 7, 2008.
} 


\section{B. CALIFORNIA INDEPENDENT SYSTEM OPERATOR ${ }^{1}$}

\section{Compliance with FERC Order 2003}

The California Independent System Operator's (CAISO) Large Generator Interconnection Procedures (LGIP), established in compliance with FERC Order No. 2003, has a centralized interconnection study procedure through which each project is reviewed and analyzed serially for its impact on the regional transmission system. However, it took several years for CAISO's tariff to come into compliance with Order 2003; FERC accepted the LGIP and LGIA in May 2006.

One issue that initially complicated the process was the definition of a Regional Transmission Organization (RTO) and whether or not CAISO was to be considered as an RTO. Under Order 2003, non-independent transmission providers were limited to the use of the pro forma LGIP and LGIA as provided in the Order. However, FERC allows RTOs flexibility in structuring interconnection agreements and study practices, and in transmission cost allocation. Ultimately, CAISO and FERC resolved that CAISO was to be considered as an independent entity treated in the same manner as an RTO. ${ }^{2}$

Once CAISO was recognized as an independent entity, CAISO revised its process to better meet FERC's direction in Orders 2003, 2003-A, 2003-B, and 2003-C. On January 5, 2005, CAISO filed its LGIP in compliance with Orders 2003 and 2003-A. At the same time, CAISO also filed a LGIA in conjunction with the California Participating Transmission Owners (PTOs), San Diego Gas and Electric, Southern California Edison, and Pacific Gas and Electric. One month later, on February 5, CAISO issued an additional filing to FERC further modifying its LGIP to comply with Order 2003-B. Because of these filings, CAISO established a single interconnection queue and a single pro forma interconnection agreement and centralized study process for the entire CAISO service territory.

Under the LGIP and LGIA tariffs, effective May 24, 2006, analytic activities are shared by CAISO and California's PTOs. The centralized, serial study system analyzed the higher queued projects first, requiring that the analysis be largely completed prior to initiating the study of an "electrically related" project placed lower in the queue. This was true for each of the three studies: feasibility study, system impact study, and facilities study. The number of studies that could be underway at any particular time depended on the ability of analysts to be able to complete the studies in a reasonable time, based on the point of interconnection, the number of electrically-related projects with pending interconnection requests, the availability of transmission capacity, and the amount of restudy that was required if higher-queued projects withdrew. However, section 13.4 of CAISO Tariff Appendix U, Standard Large Generator Interconnection Procedures, does allow third party consultants to assist in performing studies.

\footnotetext{
${ }^{1}$ The California ISO did not respond to requests to review this appendix. The information in this appendix is based on the authors' understanding of the California ISO's generator interconnection procedures.

${ }^{2}$ In a 2002 Order, Order Concerning Governance of the California Independent System Operator, 100 FERC ๆ61,059 at p 1-2 (2002), FERC determined that CAISO had failed to meet the "independence" status deemed necessary to be formally classified as an RTO.
} 
The interconnection customer (IC) can request that CAISO utilize a third party consultant to perform the interconnection study under the direction of CAISO if the study could not be completed within 120 days of signing the interconnection study agreement. The use of a third party consultant is limited to situations where CAISO finds that it will help accelerate the study process.

CAISO is currently overwhelmed with interconnection requests and there is a long backlog of projects. Recognizing the need to revise the interconnection request procedures, FERC suggested that CAISO engage stakeholders in a process to reform to the LGIP and prepare a subsequent filing to revise the relevant sections of CAISO tariff.

\section{Status of the Queue}

As of April 18, 2008, there were 265 active interconnection requests representing approximately 77,614 MW in the CAISO queue (Table B-1). By comparison, there were 173 projects in the queue as of December 31, 2007 for approximately 57,686 MW. Thus, in the first four months of 2008, there was a 53 percent increase in the number of projects requesting interconnection studies.

Table B-1

Current Size of the Interconnection Queue

\begin{tabular}{|l|c|c|}
\hline & \# of projects & \# of projects \\
\hline Active projects in the queue & 265 & 77,614 \\
\hline Active renewable projects in the queue & 183 & 48,114 \\
\hline Active projects in feasibility study stage & 102 & 33,379 \\
\hline Active projects in system impact study stage & 55 & 18,418 \\
\hline Active projects in facilities study stage & 37 & 9,209 \\
\hline Active projects in LGIA negotiation stage & 36 & 12,560 \\
\hline $\begin{array}{l}\text { Projects not yet data adequate but have submitted } \\
\text { interconnection request }\end{array}$ & 35 & 4,048 \\
\hline $\begin{array}{l}\text { Renewable projects not yet data adequate but that have } \\
\text { submitted interconnection request }\end{array}$ & 31 & 2,150 \\
\hline $\begin{array}{l}\text { Source: Grant Rosenblaum, Senior Counsel of CAISO, Interconnection Status Report of the California Independent System } \\
\text { Operator, submitted to FERC in Docket AD08-2-000, April 21, 2008, p. 2. }\end{array}$ \\
\hline
\end{tabular}

Nearly 60 percent of all active projects are located in Southern California Edison's (SCE) service territory. The large number of requests within the SCE territory has become the limiting factor for processing studies serially and moving projects along in the interconnection queue. Under a serial study approach, CAISO could process approximately 20 studies at any one time, taking approximately 6 months to completely study a project all the way through the facilities study analysis. This estimate is because there are five distinct electrically related geographic areas in the SCE territory and that four studies might be performed simultaneously for each area. Assuming that each study takes 6 months to complete, it would take approximately 3.3 years to complete all of the studies currently listed as active in the CAISO queue. 
Nearly 70 percent of the projects in the queue are renewable energy projects. Complicating matters further is that a great number of the proposed renewable energy project interconnection requests are located within the same geographic location, typically areas with significant wind resources. Three transmission corridors-Tehachapi, East of Lugo, and Devers Valley_account for nearly 40,000 MW of the proposed projects, more than 80 percent of the renewable projects in the queue, and more than half of all projects proposed. This large number of proposed renewable energy projects can be attributed in large part to the California renewable portfolio standard (RPS) that requires California's investor-owned utilities, community choice aggregators, and electric service providers to have 20 percent renewable energy in their portfolio by 2010 .

\section{Move to Clear the Serial Queue and Transition to Cluster Studies}

This Generator Interconnection Process Reform (GIPR) process began in January 2008 when CAISO published an issues paper and held the first of many stakeholder meetings. This process continued throughout the first half of 2008 and resulted in CAISO filing its final proposal with FERC on July 28, 2008. ${ }^{3}$ FERC approved this filing via letter order on September $26,2008 .^{4}$

The GIPR changes the interconnection study process from a serial study to a cluster study. Clustering allows CAISO to study all interconnection requests received during a "Queue Cluster Window" as a group, rather than serially, for conducting the system impact study. Section 4.2 of the CAISO's LGIP (Appendix U to the CAISO Tariff), effective May 25, 2006, grants CAISO authority to use "clustering" to process interconnection requests. CAISO has only exercised this authority once, with special permission from FERC, for the limited purpose of studying the Tehachapi Wind Resource Area (TWRA).

The Tehachapi Transmission Project that was examined as part of the CAISO South Regional Transmission Plan (CSRTP) as the least-cost solution for developing transmission infrastructure that would interconnect planned generation projects in the TWRA to the CAISO grid. Rather than extend the grid to Tehachapi in a piece-meal, costly manner, CAISO sought to identify and group a number of proposed projects so that the expansion of Southern California Edison's (SCE) transmission system would be appropriately sized to handle the large number of projects contemplated for the region.

The TWRA is California's largest wind resource area and is expected to generate at least 4,500 MW from wind power facilities. To study the interconnection of TWRA to the CAISO grid, CAISO requested to modify the LGIP accepted by FERC in July 2005. Section 4.2 of the LGIP provides for the study of interconnection requests serially or in clusters for all interconnection requests received within a period not to exceed the queue cluster window of 180 calendar days. Furthermore, Section 4.2 provides that CAISO may agree to separately study an interconnection request based upon the electrical remoteness of the proposed generating facility. Unlike a typical interconnection study, the Tehachapi interconnection study focused exclusively

\footnotetext{
${ }^{3}$ CAISO, "California Independent System Operator Corporation Generator Interconnection Process Reform Tariff Amendment," filed with FERC, July 28, 2008.

${ }^{4}$ FERC, “Order Conditionally Approving Tariff Amendment," Docket No. ER08-1317-000, September 26, 2008.
} 
on identifying network upgrades necessary to interconnect the project to the CAISO grid in an integrated manner. The study did not include the cost of any direct connection facilities, i.e., radial wind collector systems that interconnect the individual generation projects to the grid, and that these facility interconnection costs would be the responsibility of generation developers following a separate, more traditional serial interconnection study process. The full cost and ownership of the transmission network facilities associated with the Tehachapi Transmission Project are to be assigned to SCE and recovered through the CAISO Transmission Access Charge.

CAISO proposed to deviate in several respects from a typical clustered interconnection study. Specifically, CAISO requested and was granted a waiver to establish an extended thirtythree month window for the cluster study as necessary to obviate the need for duplicative and redundant incremental studies and to allow for greater efficiency in the design of necessary network upgrades. This allowed sufficient time for potential developers to submit documentation for planned wind projects that were uneconomic and not possible, barring transmission network expansion to the region.

The estimated cost of this 5-year project is $\$ 1.8$ billion. The cost includes the addition and upgrades of several transmission lines, but excludes the cost of Interconnection Facilities. The CSRTP identified five alternative plans of service, but each of them cost more than the proposed plan, with no additional benefits. Beginning in early 2008, the first segment of the project is planned to be in-service by December 2008, with the other ten segments being completed and in-service by November of 2013.

On April 8, 2008, CAISO issued a Market Notice indicating the process through which CAISO plans to transition from a serial interconnection review to the cluster approach. CAISO is creating three study groups to proceed through a transition to the cluster study: the Serial Study Group, the Transition Cluster, and the Initial GIPR Cluster. CAISO was issued a waiver on July 14,2008 , that allows an expedited process for interconnection projects that have signed system impact study agreements as well as those with pending or approved power purchase agreements. ${ }^{5}$

Those interconnection requests that are currently included in the serial study queue will be processed as part of the "Serial Study Group." Selection for the Serial Study Group is based on interconnection status and not queue position. Projects have to meet one or more of the following criteria:

- Projects characterized as late-stage interconnection requests, defined as those that have executed an Interconnection System Impact Study (ISIS) agreement with a results due date prior to May 31, 2008,

- Existing power purchase agreements that are approved or pending approval from the state regulatory authority, and

- Interconnection requests that have received land use approvals from local, state, or federal agencies, as applicable.

\footnotetext{
${ }^{5}$ FERC, Order on Petition for Tariff Waiver, re: California Independent System Operator, ER08-960, July 14, 2008.
} 
Based on these criteria, the Serial Study Group is projected to include 85 of the projects in the queue, 60 of which are in the serial study phase or later. The Serial Study Group should include approximately 25 percent of the proposed renewable energy projects, slightly more than $12,000 \mathrm{MW}$. Some renewable energy projects expected to move forward with the Serial Study Group include 17 projects representing 4,413 MW seeking interconnection to the Tehachapi Renewable Transmission Project and 5 projects seeking interconnection to the Sunrise Power Link for a total of 1,760 MW. ${ }^{6}$

The Transition Cluster will include the remaining early stage interconnection requests, and those that do not meet the criteria to be placed in the Serial Study Group, but that have validated interconnection requests received prior to June 2, 2008. CAISO plans to suspend the study activities for those projects in the transition cluster until all studies in the Serial Study Group are completed. Based on the estimated timing to complete the Serial Study Group requests, CAISO expects to begin work on the Transition Cluster requests by November 2008, with all studies completed by July 2009. Projects placed in the Transition Cluster will be required to provide the following:

- A new, signed, interconnection process agreement,

- Any missing technical data not previously provided, for example, preferred point of interconnection, voltage delivery, electrical design specifications, and equipment specifications,

- Specified deliverability status of either full capacity or energy only,

- Proof of site control for each interconnection request in the form of ownership of leasehold documents, development rights, or other legal documentation providing rights and access to the property, and

- ', subject to refund net of any study and administrative costs with a completed interconnection agreement.

Project developers currently in the queue who do not provide the information and funds listed above will be withdrawn from the queue.

All interconnection requests that are received by CAISO after June 2, 2008, will be placed in the Initial GIPR Cluster study group and subject to a temporary suspension. CAISO's LGIP tariff limits the cluster window to 180 days, however, CAISO requested a waiver from FERC to extend the window for the Initial GIPR Cluster from June 2, 2008, to July 31, 2009, to coincide with the conclusion of the expected study period of the Transition Cluster. CAISO does not anticipate or intend on processing interconnection requests received during the initial queue cluster window until the interconnection requests submitted prior to June 2008 are fully studied as part of either the Serial Study Group or the Transition Cluster Study Group.

\footnotetext{
${ }^{6}$ Stephen Rutty, Manager Grid Assets, CAISO, Declaration of Stephen Rutty in Support of Petition for Waiver of Tariff Provisions to Accommodate Transition to Reformed Large Generator Interconnection Procedures, submitted to FERC, May 15, 2008.
} 


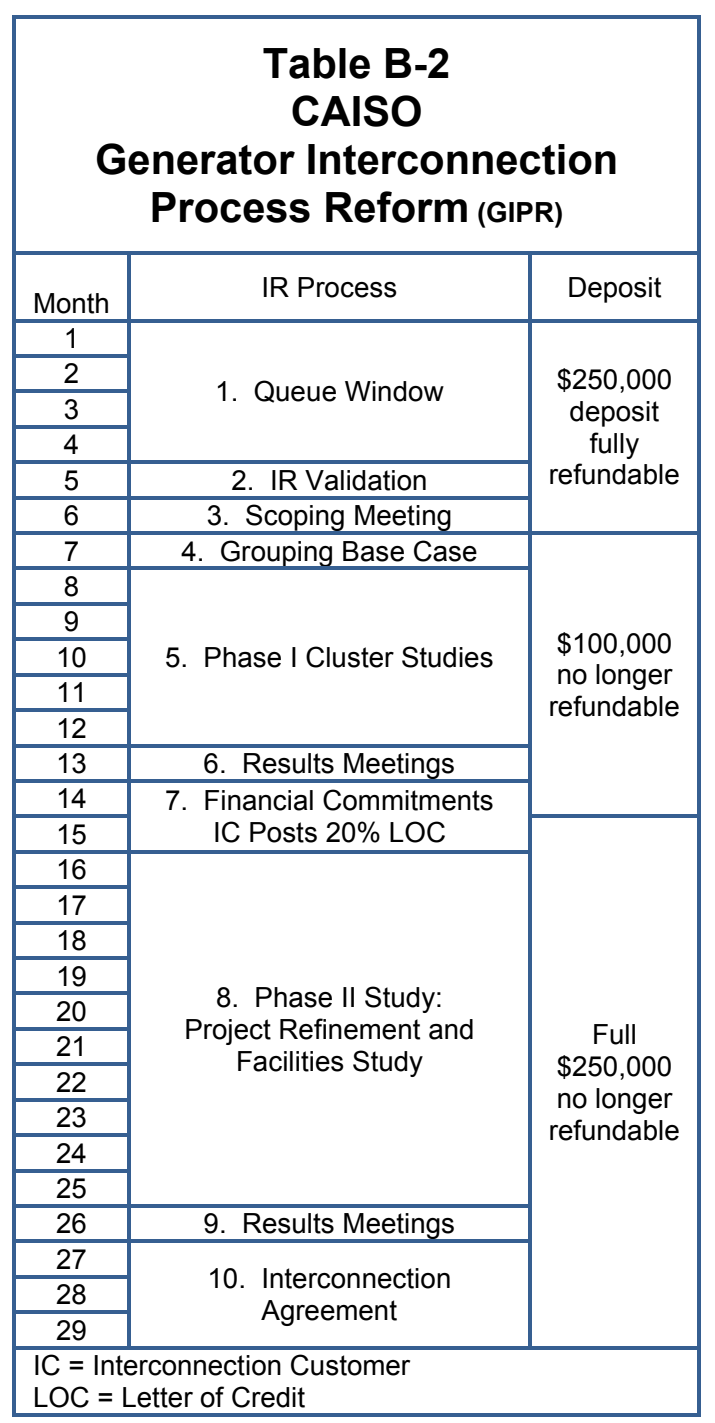

from the queue, forfeiting their position.

\section{Interconnection Process $^{7}$}

The new interconnection request system establishes a ten-step process through which interconnection requests will be studied. The ten steps are listed in Table B-2 along with the approximate timelines for each step. According to CAISO, an interconnection agreement will be executed approximately 2 years after the close of the queue window.

Just two four-month cluster windows will be opened each year. The first opens April 1st and closes July 31 st, and the second opens October 31 st and closes January 31 st of the following year. During these windows, ICs will submit an interconnection request with an application and $\$ 250,000$ deposit, site control documents, expected in-service date, technical data, and deliverability status (energy only or capacity and energy). In a significant change, ICs are limited in when and how they may modify the in-service date. There are three opportunities to modify the in-service date: within 5 days of the scoping meeting; prior to the initiation of Phase II studies; and, at the meeting to discuss the Phase II results. Extensions of the commercial operation date are limited to a maximum of 3 years, however, the IC must still meet all financial commitments, and CAISO notes that suspension does not materially alter the IC's financial exposure. ICs that do not follow these guidelines may be withdrawn

After closing the queue window, validating applications, and conducting all scoping meetings, CAISO will group projects in the cluster based on interconnection points and shared transmission needs based on engineering judgment (Step 4). Different base cases will be developed to focus on a stressed dispatch level for each group while evaluating balance loads and resources. Results and variables of the base case scenarios will be provided on a passwordprotected CAISO webpage.

Under the GIPR, interconnection studies will consist of a Phase I Interconnection Study and a Phase II Interconnection Study. The feasibility study, performed under the prior interconnection study process, and the optional study will no longer be required and have been removed from the tariff. The GIPR has arranged Phase II studies to closely coordinate them with

\footnotetext{
${ }^{7}$ The information in this section is from the proposed LGIP Tariff: CAISO, "California Independent System Operator Corporation Generator Interconnection Process Reform Tariff Amendment," filed with FERC July 28, 2008.
} 
CAISO's annual Transmission Planning Process and to facilitate this, will aim to have Phase II scheduled so that it is completed within 330 days from January 1 st of each year.

The new procedures also have a provision for certain projects to move forward in an expedited manner. This is aimed at giving generation projects located in an area that is independent of other projects (i.e., not needing to be clustered) a way to move ahead to construction more quickly. A project developer can request to enter the Accelerated Project Refinement and Facility Study Process after the completion of their particular Phase I study if they meet the following criteria:

- The interconnection request was not grouped with any others during the Phase I study process or was identified as having an interconnection point that accesses currently available transmission capacity.

- The IC can show that the established study timelines will not allow the project to meet its in-service date.

\section{Interconnection Study Fees and Financial Security for Network Upgrades}

In an effort to limit interconnection requests to only those projects that are economically and technically viable, CAISO has made significant increases to interconnection fees. Prior to the GIPR, ICs were required to provide a $\$ 10,000$ deposit along with their application. ${ }^{8}$ All or part of the deposit was refunded if the project was withdrawn and study costs were less than the deposit. Under the new system, ICs will have to provide a $\$ 250,000$ refundable deposit at the time that they submit their interconnection request, and an additional $\$ 250,000$ deposit if they are unable to provide documentation of 'site exclusivity,' a modified definition of site control. During the stakeholder process, the Federal Bureau of Land Management (BLM) expressed concerns with the definition of site control. Due to this feedback, CAISO has created a new category termed site exclusivity that includes separate criteria for private and public lands. Documentation requirements are as follows:

(1) For private land: either ownership of, a leasehold interest in, or a right to develop the land on which the facility will be located consisting of a minimum of 50 percent of the required acreage; or, an option to purchase or acquire a leasehold interest in the above.

(2) For public land: includes any lands controlled or managed by any federal, state, or local agency. The IC must have a final, non-appealable permit, license, or other right to use the property for generating electricity in the acreage reasonably expected to accommodate the facility, and additionally, an exclusive right to use public land under management of the BLM must be in a form specified by the BLM.

After about 19 months from when the interconnection application is filed, the IC is no longer able to request a refund because the fee is used to cover the cost of the studies.

\footnotetext{
${ }^{8}$ An additional $\$ 10,000$ refundable deposit was required if demonstration of site control (e.g., lease or ownership documents) is not provided with the application.
} 
Those projects that are placed in the Transitional Cluster or the Initial GIPR Cluster will also be subject to the higher fees. Those projects in the late stages of interconnection study to be included in the Serial Study Cluster will not have to pay the higher fee.

The estimated costs of a project's network upgrades are estimated as part of the Phase I Interconnection Study, according to per unit cost assessments provided by the applicable transmission owner prior to the April 1 queue cluster window opening. Within 90 days of an IC entering the Phase II Study period, and prior to definitively assigning responsibility for financing network upgrades, the IC must post financial security for 20 percent of the estimated total cost responsibility assigned to the IC in the Phase I study, or $\$ 500,000$, whichever is greater. Within 180 days of publication of the Phase I Study report, the IC must post financial security for 100 percent of the total cost responsibility of the project, as estimated in the Phase I study, or $\$ 500,000$, whichever is greater.

According to Section 9.4 of the revised LGIP tariff, in the event that a project is withdrawn after posting its financial security, the IC is still required to satisfy the cost responsibility for the network upgrades assigned to the customer in Phase I of the interconnection study. There are conditions under which a partial recovery of financial security is allowed, including:

- Failure to secure a power purchase agreement,

- Failure to secure a permit,

- Increase in costs to network upgrades as a result of the Phase II study that are greater than 30 percent of the estimated Phase I cost responsibility, and

- Increased costs due to a CAISO-required change in interconnection point. 


\section{ELECTRIC RELIABILITY COUNCIL OF TEXAS}

The Electric Reliability Council of Texas (ERCOT) coordinates all transmission planning and development on a regional basis in most of Texas. In 2005, ERCOT received a total of 44 interconnection requests worth approximately $12,000 \mathrm{MW}$, and 31 of those requests were from wind projects representing 5,000 MW. ${ }^{1}$ In 2006, ERCOT received a total of 94 requests worth $55,000 \mathrm{MW}$ with 54 of those for wind projects representing 12,000 MW. ${ }^{2}$ During 2007, ERCOT received 129 interconnection requests representing approximately 62,000 MW of capacity. Seventy projects went through the full interconnection study phase and nine interconnection agreements representing 3,900 MW were signed. As of December 10, 2007, ERCOT was tracking a total of $91,551 \mathrm{MW}$ worth of interconnection requests in various stages of the process. $^{3}$ Installed capacity at the end of 2007 was approximately $81,000 \mathrm{MW}$. With load growth projected at 2.1 percent annually to 2013 , this is far more generation capacity than will be required to be built in the ERCOT region. ${ }^{4}$

\section{Generation Interconnection Process ${ }^{5}$}

ERCOT coordinates the generation interconnection process and oversees the study requirements on behalf of the transmission providers in its jurisdiction. The actual interconnection agreement, however, is ultimately the responsibility of the transmission providers and the interconnection customer (IC). The affected transmission providers and the IC negotiate and sign the interconnection agreement at the end of the study phase. The Public Utility Commission of Texas (PUCT) has designed the transmission development cost allocation system and they must approve transmission projects. The PUCT has designated transmission development as a social good and costs - both upgrades and generation interconnections - are delegated to load. Transmission providers are required to build facilities to interconnect generators (with PUCT approval) and costs are ultimately rolled into rates through ERCOT-wide postage-stamp transmission rates. ERCOT coordinates and provides independent review for Regional Planning Groups (RPG) made up of stakeholders, market participants, or other interested parties in an open process. Projects are presented to the affected planning groups for review and feedback. ERCOT assesses all generation and transmission additions through its Power System Planning Charter and Process, including all input from the planning groups.

\section{Stage 1: Screening Study}

The first stage of the interconnection process under ERCOT is the screening study phase. An IC begins the interconnection process by submitting an interconnection request, preliminary data, and a non-refundable security screening study fee. The fees are based on the size of the generation project as follows:

\footnotetext{
${ }^{1}$ Communications with ERCOT, December 2007.

${ }^{2}$ Ibid.

${ }^{3}$ ERCOT Report on Existing and Potential Electric System Constraints and Need, December 2007.

${ }^{4}$ Ibid.

${ }^{5}$ Information in this section from: System Planning, Transmission Services, "Generation Interconnection or Change Request Procedure," ERCOT, August 2004.
} 
- 10 to $74 \mathrm{MW}-\$ 1,000$

- 75 to $149 \mathrm{MW}-\$ 2,000$

- 150 to $249 \mathrm{MW}-\$ 3,000$

- 250 to $499 \mathrm{MW}-\$ 4,000$

- $500 \mathrm{MW}$ and greater - $\$ 5,000$

A separate request is required for each individual interconnection location, in-service date, and total plant capacity at that location. The screening study is a steady-state screening study, including power flow and transfer studies applied to the proposed in-service year to determine the feasibility of the site, the amount of known generation in that area, and the level of expected generation that may be utilized from the project. The results of the screening study will tell the project developer if that particular site is able to accommodate the proposed project, or will provide an estimate of the magnitude of transmission network upgrades and additions necessary for the project to achieve full potential. The timeframe for completion of the screening study phase is from three to 90 days of receipt of all necessary request items. ERCOT provides the information to the IC, which then has 180 days to notify ERCOT if it wishes to move ahead to the next study stage. If notice is not received within that time frame, ERCOT will consider the request cancelled and no longer valid.

\section{Stage 2: Full Interconnection Study}

Once notice of intent to proceed is received, ERCOT schedules a meeting with the IC and the primary transmission provider. Other interested transmission providers are invited to participate, if desired. Together, these entities decide on a path forward with respect to study requirements, timelines, deposit requirements, and cost estimates. The primary transmission provider maintains a lead role and other transmission providers or ERCOT provide any additional analysis that may be required. Prior to the start of the interconnection study, the IC must submit a model fee of $\$ 15$ per MW and proof of site control. The model fee is used to develop stability models for generators and to update ERCOT's current set of models to reflect equipment additions. The IC is responsible for paying the cost of the full interconnection study, and the primary transmission provider bills the IC directly.

Site control is demonstrated through showing that the company, an affiliate, or a trustee has one or more of the following:

- Is fee-simple owner of the real property to be used for the site;

- Holds a valid written leasehold interest in the site;

- Holds a valid written option to purchase or obtain a leasehold for the site;

- Holds a duly executed written contract to purchase or obtain a leasehold interest for the site.

The IC must maintain site control throughout the duration of the study up to the signing of the interconnection agreement. If the IC loses site control, it has 30 days to regain it or ERCOT will consider the request withdrawn.

Following the establishment of eligibility, the IC and affected transmission providers have 60 days to complete the study scoping process and sign a study agreement outlining 
assumptions, timetables, cost estimates, and requirements for interconnection. Once the agreement is signed, the full interconnection study stage begins and includes the following steps:

(1) Steady State \& Transfer Analysis Study - within 10 to 90 days

(2) System Protection Analysis - within 10 to 30 days after study (1)

(3) Dynamic Analysis - within 10 to 90 days after study (2)

(4) Facilities Study - within 10 to 90 days

Once all the above studies are completed, the parties will meet to examine the results. The IC and transmission providers then have 180 days to negotiate and complete an interconnection agreement at which time the project will be considered 'confirmed'. A generation project in the ERCOT region is not considered public and details are not posted on the ERCOT site until that project achieves confirmed status.

\section{FERC Order 2003 Compliance}

ERCOT does not have to comply with Order 2003 since ERCOT is not regulated by FERC other than on issues arising under the Energy Policy Act of 2005. That said, the ERCOT interconnection process follows a similar format. The screening study is almost the same as the feasibility study set out in Order 2003, but ERCOT requires smaller deposit amounts and sets the study time limit at 90 days as opposed to 45 days. The other studies required under Order 2003 have been combined in the full interconnection study as a package and ERCOT can take up to 210 days to complete all the study parts. ERCOT requires a deposit partially based on generator size, which can result in total amounts smaller or larger than those set out in Order 2003. ERCOT does not allow project suspensions and does not maintain a public queue, considering projects confidential until an interconnection agreement is executed or a public letter is issued by the owner. Additionally, costs are allocated to ERCOT load rather than to ICs, and as a result, projects and transmission upgrades meeting voltage level or cost criteria are assessed by ERCOT through its RPG process. Transmission construction, both for generator interconnections and network upgrades below the criteria, does not need to undergo the RPG process, but still must be approved by the PUCT.

\section{Clustering - Texas Competitive Renewable Energy Zones}

Texas has perhaps the most successful renewables portfolio standard in the nation, in terms of new renewable energy capacity. As of January 2008, ERCOT is tracking over 41,000 MW of wind generation interconnection requests in various stages of the process. ${ }^{6}$ In January 2007, the Texas RPS was revised to include a type of clustering for wind energy development called Competitive Renewable Energy Zones (CREZ). ${ }^{7}$ CREZs consist of designated areas with large wind generation potential that lack adequate transmission. Transmission will then be developed for the zone to connect multiple wind generators, as opposed to being built for one particular project. An ERCOT study identified 25 potential zones, and in October 2007, the

\footnotetext{
${ }^{6}$ System Planning Division, "Monthly Status Report to Reliability and Operations Subcommittee for December 2007," ERCOT, December 2007.

${ }^{7}$ Public Utility Commission of Texas, Public Utility Regulatory Act, Section 25.174. http://www.puc.state.tx.us/rules/subrules/electric/25.174/25.174.pdf
} 
PUCT issued an interim order granting CREZ designation to six of those zones. ${ }^{8}$ The PUCT announced that these six zones, located around Amarillo, Abilene, and McCamey, met the criteria established by the Public Utility Regulatory Act 2007 - sufficient renewable energy resources, suitable land areas, and a significant level of financial commitment displayed by generation developers. The PUCT directed ERCOT to conduct a CREZ Transmission Optimization Study on four different wind scenarios involving potential wind generation levels in the CREZs, to determine what transmission needs to be/should be built to access the zones. The optimization study released in April 2008 outlined cost estimates for the transmission requirements. The scenarios ranged from $5,150 \mathrm{MW}$ of wind spread across the six zones to $17,956 \mathrm{MW}$, with costs estimated at $\$ 2.95$ billion to $\$ 6.22$ billion. In August 2008, the PUCT issued an order approving a transmission development plan that could result in 18,456 MW of transfer capacity from the CREZs at a projected cost of $\$ 4.93$ billion. $^{9}$

\footnotetext{
${ }^{8}$ Public Utility Commission of Texas, PUC Docket No. 33672, Interim Order, October 2007.

${ }^{9}$ Public Utility Commission of Texas, Order, PUC Docket No. 33672, "Commission Staff's Petition for Designation of Competitive Renewable Energy Zones,” August 2008.
} 


\section{ISO NEW ENGLAND}

ISO-New England's interconnection queue has experienced growth rates similar to other regions, though unlike most areas, wind power accounts for only a small portion of the interconnection requests. Natural gas is the major driver in New England generation development, followed by a mix of other renewables that include biomass, hydropower, and landfill gas (LFG). In 2005, ISO-NE received 16 interconnection requests for a total of 1,550 MW. In 2006, that number had risen to 56 requests for a total of 8,640 MW, with 28 of them for natural gas generation. That number held steady for 2007, with a total of 57 requests for 10,710 MW, 32 of which were for natural gas projects and 19 for a variety of other renewables (LFG, hydro, wood); only 5 requests were for wind power projects. At the end of 2007, ISO-NE had approximately 19,100 MW of active projects in its queue, more than half of the ISO's total installed capacity, which is approximately 37,500 MW.

\section{Generator Interconnection Queue Process ${ }^{1}$}

The ISO-NE generator interconnection process is initiated by an interconnection customer (IC) submitting an interconnection request and providing a $\$ 10,000$ deposit that will be applied towards subsequent study costs. An IC may submit multiple requests for each site but must provide a separate interconnection request and deposit for each one. The interconnection request must provide an expected initial synchronization date for the generation facility that is within seven years of the request; however, if the project needs additional time, the IC can submit evidence to that affect and negotiate a longer time period. Within five business days, ISO-NE will acknowledge the request by providing a feasibility study agreement, and within ten days scheduling the initial scoping meeting to be held within 30 days. At the scoping meeting, the parties will exchange pertinent data, determine potential points of interconnection, and estimate timelines for conducting the necessary studies. The IC then has five days to notify ISONE that it will proceed with the project and provide the completed study agreement noting the definitive point(s) of interconnection to be studied. Along with the completed study agreement, the IC must demonstrate it has site control or provide an additional $\$ 10,000$ deposit that will also be applied towards study costs.

\section{Feasibility Study}

ISO-NE assigns a queue position when it receives an interconnection request based on the time and date it first received the initial interconnection request. The IC can withdraw from the queue at any time but will be liable for any study costs incurred to date. ICs also have the option of waiving the feasibility study after the initial scoping meeting with ISO-NE and proceeding straight to the system impact study.

ISO-NE will use all reasonable efforts to complete the feasibility study within 45 days and will notify the IC if unable to do so. After completing the feasibility study, ISO-NE will provide a draft copy to the IC and schedule a meeting to discuss the results, to be held within ten

\footnotetext{
${ }^{1}$ Procedures in this section from: ISO New England Inc., "Schedule 22 - Standard Large Generator Interconnection Procedures (LGIP)," issued January 8, 2005.
} 
business days. The feasibility study will include an initial good-faith cost estimate. If a re-study is required due to a higher queued project withdrawing from the queue, ISO-NE will notify the IC and conduct the re-study within 60 days. Re-study costs throughout the interconnection process are the responsibility of the IC.

\section{System Impact Study}

Following the finalization of the feasibility study, ISO-NE will furnish the IC with a system impact study agreement. The IC then has 30 days to return the executed agreement along with all required technical data, a demonstration of site control, and a deposit. The deposit will be the lesser of $\$ 50,000$ or the estimated cost. ISO-NE will make reasonable efforts to complete the impact study within 90 days and following completion will provide a draft of the system impact study and schedule a meeting to discuss the results, to be held within the next 10 business days. Within five days following meeting, the IC must notify ISO-NE as to whether or not it intends to continue with the project. The IC has the option of requesting an interconnection facilities study or waiving the interconnection facilities study and moving to expedited interconnection. If the IC chooses expedited interconnection, the project will move directly to the LGIA and must commit to meeting the following milestones, within an agreed timeframe:

1. Obtain siting approval.

2. Conduct engineering of interconnection facilities as approved by the interconnection transmission owner.

3. Order long lead-time materials.

4. Set an initial synchronization date.

5. Set a commercial operation date.

The IC has the option of signing an Engineering and Procurement Agreement (discussed later in this section) in order to meet some of the above requirements.

\section{Optional Interconnection Study}

Following completion of the system impact study, an IC has the option of requesting an additional interconnection study that is designed to provide additional data respecting expected costs for interconnecting the project to the grid. The cost for this study will be borne by the IC

and requires an additional $\$ 10,000$ deposit. The timeframe for completing an optional study will be mutually agreed to between ISO-NE and the IC.

\section{Interconnection Facilities Study}

Within three business days following the system impact study meeting, ISO-NE will furnish the IC with an interconnection facilities study agreement and a good faith cost estimate. If the IC has chosen to proceed with the facilities study (as opposed to withdrawing, requesting an optional study, or choosing expedited interconnection), it has 30 days to return the fully executed agreement along with all required technical data and a deposit. If the estimated cost is less than $\$ 100,000$, the deposit will be in the amount of the estimate. If the estimate cost is greater than $\$ 100,000$, the deposit will be $\$ 100,000$ or the IC's portion of the estimated monthly 
cost of the facilities study. ISO-NE will make reasonable efforts to complete the facilities study within 90 days and then deliver a draft to the IC and schedule a meeting to discuss results, to be held within the next 10 business days.

\section{Engineering and Procurement Agreement}

The Engineering and Procurement (E\&P) Agreement is an optional agreement between the transmission owner and the IC (ISO-NE is not involved) that can be entered into in advance of executing the LGIA in order to get a project moving forward. An E\&P agreement authorizes the relevant transmission owner to begin engineering work and long lead-time materials procurement for construction of the required interconnection facilities.

\section{Large Generator Interconnection Agreement}

Following either the system impact study meeting or the facilities study meeting, depending on which path the IC has chosen, the IC has 30 days in which to comment on the reports results. Fifteen days following the comment period ISO-NE (together with the transmission owner) will, unless otherwise agreed upon in an E\&P agreement, deliver a draft LGIA to the IC. The IC then indicates an interest in executing the LGIA and after that, ISO-NE issues a final LGIA, all within the next 30 days. Alternatively, the IC can request a negotiation proceeding if it disagrees with the results. Following the execution of the LGIA, the IC must, within 15 days, provide evidence of site control and post a non-refundable $\$ 250,000$ deposit that will be applied towards the future construction costs. The IC must also show that one or more of the milestones within the LGIA has been achieved. These milestones include:

1. Execution of a contract for the supply or transportation of fuel.

2. Execution of a contract for supply of cooling water.

3. Execution of a contract for engineering, procurement of major equipment, or for construction (can be accomplished through signing an E\&P Agreement).

4. Execution of a contract for the sale of energy or capacity from the facility.

5. Application for an air, water, or land-use permit.

\section{Cost Allocation}

In ISO-NE, all study and re-study costs due to higher queued project withdrawals, and both interconnection facility costs and network upgrade costs, are the responsibility of the IC. If the network upgrades result in increased transmission capability, the IC will receive firm transmission rights for that net increase in transmission capability.

\section{Clustering}

The ISO-NE Schedule 22 - LGIP did not originally contain provisions for clustering studies as it was thought unnecessary. ${ }^{2}$ FERC issued Order 890 Final Rule in February 2007 requiring all ISO and RTO's to add tariff language for clustering for transmission interconnection requests-ISO-NE still conducts studies for generator interconnections on a

\footnotetext{
${ }^{2}$ ISO New England Inc., "FERC Order 890 Compliance Filing,” April 15, 2008.
} 
serial basis. As a result, on April 15, 2008, the ISO-NE filed amendments to Schedule 22 LGIP, including provisions allowing the ISO to open a cluster window for transmission interconnection requests by announcing the start and end dates, if it chooses to do so. ${ }^{3}$ The ISONE clustering provision applies only to system impact studies, thereby allowing the ISO to conduct impact studies as a group if necessary. To date, however, ISO-NE does not seem to have utilized this provision and re-iterated in a 2008 FERC filing that cluster studies were not a good solution in the region. ${ }^{4}$

\section{FERC Order 2003 Compliance}

ISO-NE Schedule 22 - LGIP follows Order 2003 procedures, study cost, and study time guidelines almost exactly, with the addition of some unique features such as the expedited interconnection process. However, ISO-NE does not allow projects to enter suspended status per Order 2003 during the study phase. Once an LGIA is in effect, the IC can, upon giving notice to the ISO, enter suspended status for up to three years but is liable for any construction/preconstruction costs incurred to date. If the IC does not recommence work within the three-year period, ISO-NE will consider the LGIA terminated. ${ }^{5}$

\section{Proposed Reforms}

ISO-NE filed its generator interconnection tariff reform proposal with FERC on October 31,2008 . $^{6}$ The filing proposes to change both the generator interconnection process and certain aspects of Forward Capacity Market (FCM) participation. ISO-NE recently introduced an FCM and the first auction was held in February 2008 for delivery of capacity into 2010/11. This first auction highlighted the issue of queue backlog as projects participating in the FCM were faced with uncertainty as to whether they can meet the 2010/11 target due to being held up in the ISONE queue. In addition, the FCM relied on interconnection queue position to determine the priority between generating projects that shared the same transmission capacity. This was not viewed as ideal, and as a result, ISO-NE formed the Forward Capacity Market/Generator Interconnection Process Stakeholder Group in mid-2007 to examine and propose reforms to the generator interconnection process that would allow for better coordination with the FCM. The Stakeholder Group held a series of meetings from September 2007 through April 2008, and on June 11, 2008, issued a set of proposed queue reforms that were subsequently incorporated into the tariff filing. The proposed reforms include creating categories for Conditional Qualified Capacity Resources and Long-Lead Resources (discussed below) and the following changes to the interconnection queue:

1. Interconnection Request: Proposing to increase the deposit from $\$ 10,000$ to $\$ 50,000$ and require a demonstration of site control. Any unused portions of the

\footnotetext{
3 Ibid.

${ }^{4}$ ISO New England Inc., “ISO New England Inc.'s Interconnection Queuing Practices Status Report,” FERC Docket No. AD08-2-000," April 21, 2008.

5 ISO New England Inc., "Schedule 22 - Standard Large Generator Interconnection Procedures (LGIP)," Issued January 8, 2005.

${ }^{6}$ ISO New England, "Joint Filing of Proposed Revisions to the Generator Interconnection Process and Forward Capacity Market Participation Provisions Set Forth in the ISO New England Inc. Transmission Markets and Sevices Tariff," filed with FERC October 31, 2008. http://www.iso-ne.com/regulatory/ferc/filings/2008/oct/er09_____000_10-8-31_fcm_queue.pdf
} 
deposit will be refundable if the project withdraws within ten days of the scoping meeting.

2. Feasibility Study: Proposing to make the deposit equal to 100 percent of the estimated study costs. Upon completion of the feasibility study, any funds remaining will be applied to the system impact study or refunded if the project withdraws.

3. System Impact Study: ICs could choose between three options for the required deposit. These options are:

a) The greater of 100 percent of the estimated study costs or $\$ 250,000$.

b) The lower of the estimated study costs or $\$ 50,000$, plus copies of all relevant major permit applications.

c) The lower of the estimated study costs or $\$ 50,000$, plus demonstration of 'at risk" ${ }^{7}$ project expenditures in at least an amount equal to the amount in (a) above.

4. Interconnection Facilities Study: ICs could choose one of the following three options:

a) The greater of 25 percent of the estimated study costs or $\$ 250,000$.

b) The lower of $\$ 100,000$ or the estimated monthly share of the study costs, plus copies of all relevant major permit applications.

c) The greater of $\$ 100,000$ or the estimated study costs, plus demonstration of 'at risk' project expenditures in at least an amount equal to the amount in (a) above.

5. Large Generator Interconnection Agreement: ICs would have two options depending on whether or not the facilities study was waived. These options are:

a) If the facilities study was waived, then the IC must provide a deposit equal to estimated cost of the engineering studies that would have been a part of the facilities study, commit to an agreed-upon upgrade expenditure schedule, and provide copies of all relevant major permit approvals.

b) If the facilities study was conducted, then the IC can provide a deposit equal to 20 percent of the cost of the estimated construction costs as calculated in the facilities study, commit to the remaining schedule of upgrade expenditures, and include milestones for the completion of major permit approvals.

Additionally, the reform proposal has provisions for allowing a project to choose an energy-only or a capacity resource interconnection. If a project chooses the energy-only option, it cannot participate in the FCM auction. For a project to qualify as a capacity resource in the FCM, it must apply for interconnection as such. If it wishes to, the project can receive energy-

\footnotetext{
7 'At risk" expenditures are those expenditures that could not be recovered if the project is terminated; e.g., lease payments, permit costs, non-refundable equipment deposits.
} 
only interconnection service until any necessary network upgrades are in place. The reform proposal also includes new categories for capacity resources in an attempt to base queue positioning and progress on FCM economics rather than date and time of request. ${ }^{8}$

\section{Conditional Qualified Capacity Resources}

This category is being proposed as an option for allowing lower queued capacity resources to participate in Forward Capacity Auctions (FCA). A capacity resource that has overlapping impacts (competing for the same transmission capacity) with higher queued projects may still 'conditionally qualify' for an FCA along with the higher queued project. The higher queued project would be considered the primary resource and the lower queued, the conditional resource. If the primary resource clears in the FCA, then the conditional resource cannot. If the primary resource withdraws from the FCA or fails to post financial deposits, then the conditional resource would become the primary resource and could clear in the auction. Under this proposal, a higher queued resource cannot block a lower queued resource from participating in an FCA by applying for the auction and then withdrawing prior to clearing.

\section{Long-Lead Resources}

ISO-NE has proposed this option for large projects with longer development cycles than the time between the auction and the delivery year. These projects need a way of securing a transmission interconnection at a certain point in their development for them to be able to proceed. An IC with a proposed generating facility that has a summer net electrical output of 100 MW or greater may request that it be considered a Long-Lead Resource (LLR) when filing its interconnection request. ISO-NE will examine the details surrounding the request and make a determination to grant or deny the LLR designation. ICs with a proposed generating facility under $100 \mathrm{MW}$ can also petition ISO-NE for LLR designation. An LLR resource will then be eligible to participate in an FCA and secure an interconnection at a certain stage of project development. This will include an LLR being required to submit and follow a schedule of development and continue providing specific amounts of financial assurance, until it clears in an FCA.

\footnotetext{
${ }^{8}$ ISO New England Inc., "Summary of the Forward Capacity Market (FCM) / Generator Interconnection Process Stakeholder Group," presentation to the Joint MC/RC/TC, June 11, 2008.
} 


\section{E. THE MIDWEST INDEPENDENT SYSTEM OPERATOR}

\section{Compliance with FERC Order 2003}

FERC Order 2003 allowed independent transmission providers, e.g., recognized RTOs, the flexibility to deviate from the pro forma LGIP and the LGIA as needed to meet their regional needs. On June 20, 2004, the Midwest Independent System Operator (Midwest ISO) proposed several variations to the LGIP and LGIA that were filed with, and ultimately accepted by FERC on July 8, 2004. The majority of the variations from the pro forma tariffs under Order 2003 customize the agreements to include the transmission owner as a signatory to the agreements. The Midwest ISO's more substantive modifications to FERC's LGIA and LGIP pro forma tariffs include the deferral of transmission credits for network upgrades in certain situations, payment for reactive power, compensation for rescheduling maintenance at the request of the Midwest ISO, and modifications to various definitions.

Within their June 20, 2004, filing to FERC, the Midwest ISO requested the right to perform studies out-of-queue order based upon: the electrical remoteness of the proposed facility; or at the mutual request and agreement of the interconnection customer (IC) and the Midwest ISO. The Midwest ISO also proposed a group study format instead of the cluster study approach set forth in Order 2003. The Midwest ISO based its request on the expansive geographic scope of the RTO's footprint, adding that it is inefficient to process interconnection requests together as a group (or cluster) according to time of receipt and with no regard to geographic location. The Midwest ISO believed that an interconnection request in an area with a short, light queue should not be held up waiting for a formal system-wide queue window to close. The Midwest ISO describes its group study as a single study that is more complex and allows the RTO to consider a more efficient set of expansions that would accommodate the group in a more cost-effective manner than considering individual upgrades. The Midwest ISO proposed conducting group studies under the following conditions:

- When a backlog of interconnections develops with electrically connected projects;

- Upon the request of a group of ICs;

- In connection with a state-sanctioned resource solicitation process; and

- To coordinate studies of interconnection requests on non-Midwest ISO system operator systems that might also impact operations on the Midwest ISO system.

FERC rejected The Midwest ISO's proposal to perform out-of-order and group studies as well as the request to extend the study period to 180 days from 90 days as established in the pro forma tariff. FERC stated that "queue windows with regular, fixed, opening and closing dates 
are essential to an orderly process."1 The Midwest ISO requested rehearing of FERC's rejection of the proposed group study process, and out-of-queue-order studies. In its rehearing request, the Midwest ISO clarified that it does not intend to have "mini-queues" in its region and that it has sufficient resources to begin group studies soon after the receipt of several interconnection requests that are within a short time frame and in close proximity. The Midwest ISO proposed that the group studies would be performed based on queue position, in close proximity in time and in space, without regard to the nature of the underlying interconnection service arguing that they provide efficient, effective and flexible processing of projects to the benefit of all ICs. In its filing to FERC, the Midwest ISO suggested that using the queue cluster window suggested by FERC's pro forma tariff would add up to 180 days to the time to process an interconnection request. Additionally, the Midwest ISO transmission owners argued that FERC's rejection of the proposed variations relating to group studies and out-of-queue-order studies could preclude certain transmission owners from complying with state resource solicitation processes, and thus, improperly imposes FERC's authority over these state-regulated programs.

In its Order on Rehearing, Clarification, and Compliance Filing issued October 28, 2004, FERC reversed its prior decision, conceding to allow the group studies. However, the Midwest ISO was required to keep to the timelines established in FERC Order 2003. Furthermore, FERC required the Midwest ISO to honor requests by ICs that wish to move ahead with the study process as a stand-alone project. Under the revised LGIP, an IC may retain both an individual queue position and a group-study position. The result of the debate over group studies was to allow, and in some instances require, both a group study and a stand-alone project study and analysis. It seems that the negotiation to allow both group studies and individual studies may have created an environment encouraging duplicate interconnection requests and interconnection requests for multiple projects responding to an RFP process where only the winning project will be economically feasible. The high number of duplicate entries provided a high number of suspensions and withdrawals from the queue.

Under the FERC-approved LGIP, the IC initiated the study process by submitting a valid application. A complete application included a \$10,000 deposit; application form "Appendix 1" of the LGIP tariff; and either demonstration of site control or a posting of an additional deposit of $\$ 10,000$. After a valid application is completed, the Midwest ISO held a scoping meeting to discuss the project with the IC and the affected transmission owners. Following the scoping meeting, there were five steps to the interconnection process for the Midwest ISO:

1. Feasibility study, consisting of a power flow analysis and potentially a short circuit and stability analysis as needed or requested by the IC or transmission provider;

2. System impact study, including more detailed short circuit analysis, stability analysis, and a power flow analysis; ${ }^{2}$

\footnotetext{
${ }^{1}$ Order Accepting in Part and Rejecting in Part Compliance Filings to Oder Nos. 2003 and 2003-A., Issued July 8, 2004 in Docket Nos. ER04-458-000 and ER04-458-001, p. 46.

${ }^{2} 1$. Any stability analysis performed in a system impact study may include transient stability, large and small signal, sub-synchronous stability, dynamic voltage stability, mid-term and long-term stability, voltage flicker analyses, and excessive neutral current.
} 
3. Facility study, specifying and estimating the cost of the required equipment, engineering, procurement and construction work, including the electrical switching configuration needed to physically and electrically connect the interconnection facilities to the transmission or distribution system;

4. Optional study as requested by the IC to evaluate varying MW injection levels; and

5. An executed interconnection agreement, including either evidence of continued site control, or posting of $\$ 250,000$ non-refundable additional security, as well as evidence of other project milestones, including fuel or water supply contracts, engineering and construction contracts, and copies of air, water, or land use permits.

\section{The Midwest ISO Group Studies}

\section{Overview}

The Midwest ISO adopted procedures for group interconnection studies in 2002. These studies were intended to group into a single interconnection study requests that are close in geographic location and time proximity. Four group studies were completed, Group Study 5 (described below), and Group Study 6 (1500 MW in 21 requests; 20 wind and 1 biomass) were underway when the Midwest ISO made its reform filing. Additionally, prior to undertaking the queue reform process early in 2008, the balance of the interconnection queue was given preliminary assignment to Group Studies 7 through 22 with approximate start of study dates ranging out to 2022 .

\section{Group 5}

The Midwest ISO performed a group study of interconnection of 2,860 MW of new generation, the Group 5 projects, to the Midwest ISO transmission system. The projects, 36 wind plants and one $750-\mathrm{MW}$ coal plant, are distributed through an area approximately 200 miles by 300 miles in Iowa and Minnesota. Queue dates for projects in this group range from July 2004 to May 2006. The Group 5 study began in May 2006, and the feasibility study was completed in September 2006. The initial system impact study was not completed until October 2007. Stability results were challenged and subsequently re-analyzed in early 2008.

The large number of unresolved higher queued interconnection requests has been a major challenge to implementing Group 5 projects. There are nearly 40 higher queued requests that are in various stages short of operation (facility study, interconnection agreement

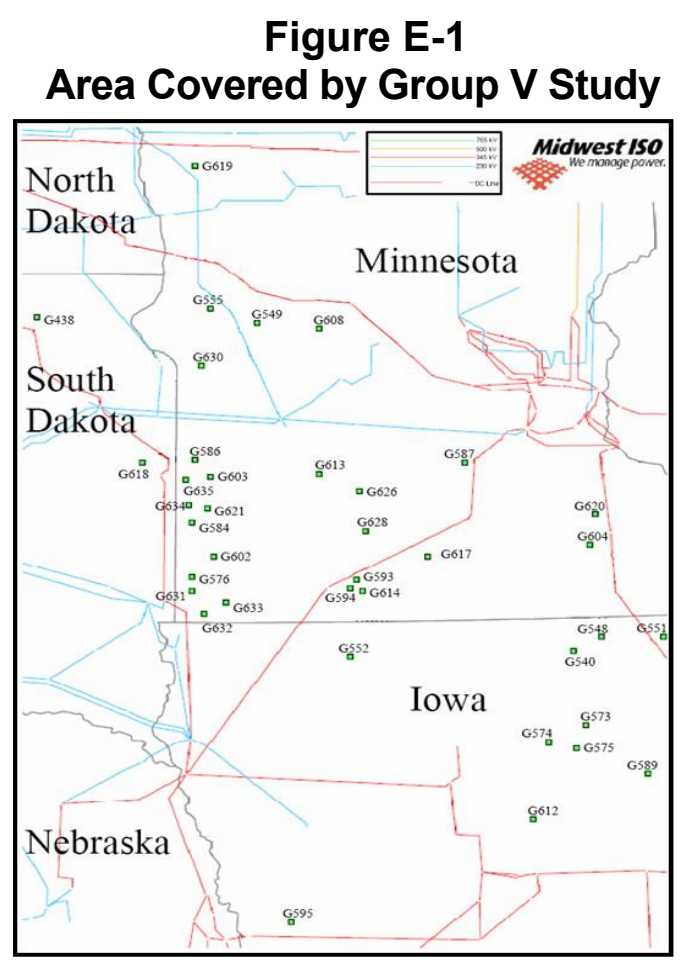


completed, suspended, etc.). ${ }^{3}$ These higher queued projects have nearly 80 associated separate transmission upgrades that may need to be constructed prior to construction and operation of Group 5 projects.

\section{Status of the Queue}

The Midwest ISO has more pending projects and capacity in its interconnection queue than any other RTO or ISO. Currently there are $83 \mathrm{GW}$ of generation in 402 active requests in the Midwest ISO queue. ${ }^{4}$ Using the literal interpretation of the FERC Order 2003 first-in-firstout process and excluding group studies, it would take approximately 425 years to clear the current Midwest ISO interconnection queue. ${ }^{5}$ Even with use of group studies and a 'semiparallel' process, where studies for sequential queue positions are overlapped in time, it is estimated that processing of current requests would not be completed until 2050. Figure E-2 shows the number of new entries by fuel type in 2007, and the cumulative total of projects in the queue as of December 31, 2007. The number of requests for generator interconnection in the Midwest ISO has increased rapidly in recent years, due in large part, to state renewable portfolio standards (RPSs). There were more than 200 generator interconnection requests initiated in 2007 with an additional 135 requests added to the queue in the first half of 2008 . This is a significant increase over the number of requests received in 2006 (more than 60 percent), and more than twice the requests received each year from 2002 to 2005 . $^{6}$

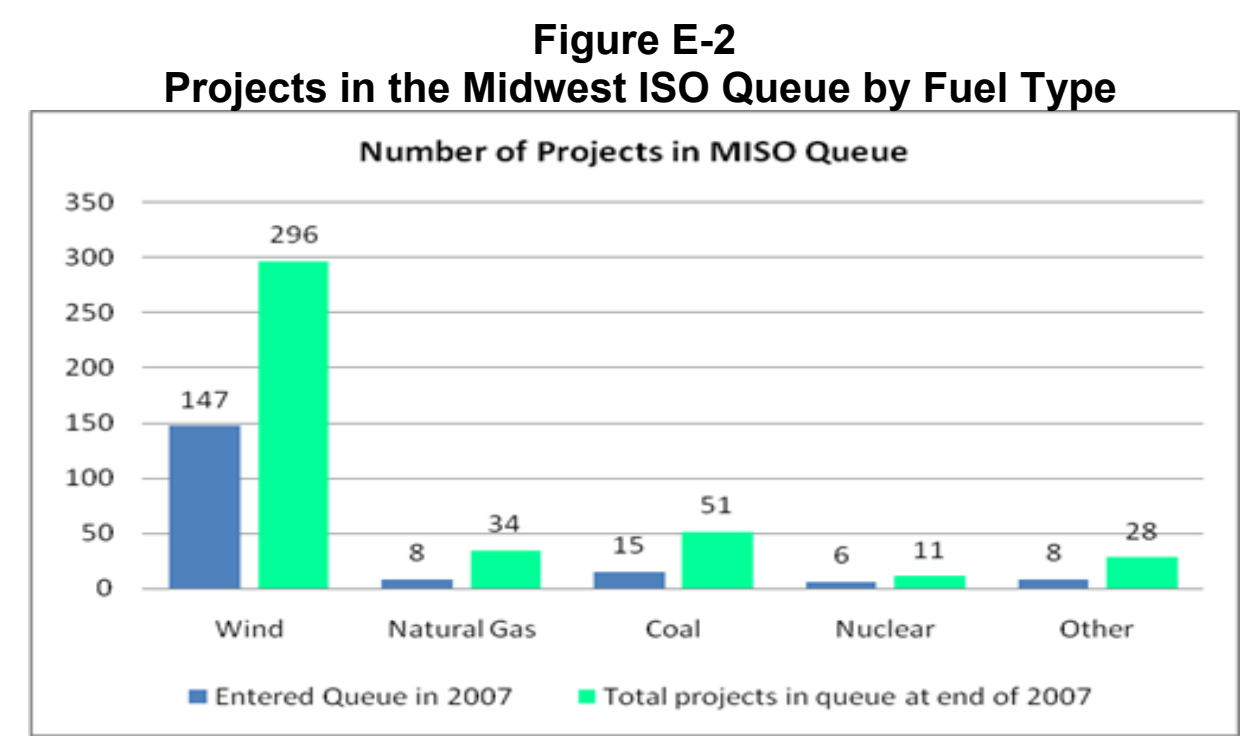

Wind power projects requesting interconnection in the Midwest ISO footprint have grown enormously, with the number of wind projects in the queue doubling from the end of 2006

\footnotetext{
${ }^{3}$ As of March 1, 2008.

${ }^{4}$ Midwest ISO Initiates Queue Reform Proposal, Midwest ISO Press Release, June 26, 2008.

${ }^{5}$ Eric Laverty, Senior Manager, Transmission Access Planning, Midwest ISO, Interconnection Process Task Force Update, presentation provided on March 18, 2008 as part of the AWEA/CanWEA Wind and Transmission Workshop, slide 2.

${ }^{6}$ Proposal to Revise Generator Interconnection Procedures, Midwest ISO While Paper (Draft 1), January $23,2008$.
} 
to the end of 2007. Interconnection requests for wind power generation are nearly $70 \mathrm{GW}$ of the total $83 \mathrm{GW}$ in the queue. Much of the wind generation in the Midwest ISO footprint is located in remote areas, anywhere from 200 to 600 miles away from loads. For example, Buffalo Ridge, a region in the southwestern the Midwest ISO footprint, has over 22,000 MW of wind project interconnection requests, however, the current Midwest ISO transmission plan includes only $1,900 \mathrm{MW}$ of additional planned transmission capacity by $2014 .^{7}$

Primary factors leading to the current queue backlog included the low cost of queue entry, no cost for suspension, and lack of needed transmission expansion to support generator interconnection. With the low cost of entry at the beginning of the process and no cost for suspension at the end, participants were encouraged to enter the queue early and often. The logjam was amplified by the high number of interconnection requests in areas where the grid is weak and transmission upgrades are needed.

\section{The Midwest ISO Queue Reform}

In September 2007, the Midwest ISO created a stakeholder committee called the Interconnection Process Task Force that reports to the Midwest ISO Planning Advisory Committee. Stakeholders, including transmission owners, load serving entities, generation developers, and state regulatory staff worked to identify solutions to reduce time and increase certainty in the generator interconnection process. The Task Force proposed a milestone-based approach that could allow projects to proceed based on readiness rather than solely on queue order. The Midwest ISO formally filed their proposal with FERC on June 26, 2008. On August 25,2008 , FERC issued an order conditionally accepting the reform filing effective immediately. ${ }^{8}$ FERC largely accepted the proposed filing, requiring only minor modifications on a few issues, a list of metrics to evaluate the effectiveness of the queue reforms, and submission of annual reports on the queue changes for the next three years. FERC did rule that the Midwest ISO had not provided sufficient evidence to justify the proposed change to how energy resource interconnections will be handled. The Midwest ISO asserted that energy resource customers had an unfair advantage over network customers because energy resource customers do not have to factor in network upgrade costs in submitting energy bids. The Midwest ISO had proposed energy resource customers either finance network upgrade to resolve transmission constraints and be subject to a cap on output, or enter into an alternative dispatch arrangement with the local control area. FERC ruled that the Midwest ISO did not provide adequate justification for their proposed changes to the energy resource interconnection service and rejected them without prejudice.

The main differences of the new process when compared to the previous process include how projects meet the milestones, the different paths a project can take through the process, the addition of a "fast lane" for interconnection agreements that are relatively simple, increased study deposit fees, and increased suspension penalties. A central theme of the queue reform is to minimize the uncertainty of the process regarding project withdrawals, suspensions, and the need for restudy.

\footnotetext{
${ }^{7}$ Ibid.

${ }^{8}$ FERC, “Order Conditionally Accepting Tariff Revisions Addressing Queue Reform,” Docket No. ER08-1169000, August 25, 2008.
} 
The new generator interconnection process uses milestones as the basis for moving projects through the queue. The milestone process is divided into four phases (see Figure E-3 below): Pre-Queue (yellow), Application Review (green), System Planning and Analysis (light blue), and Definitive Planning (dark blue). There is also an optional study process for projects that are not ready to enter the Definitive Planning phase.

Figure E-3 - The Midwest ISO Generator Interconnection Process
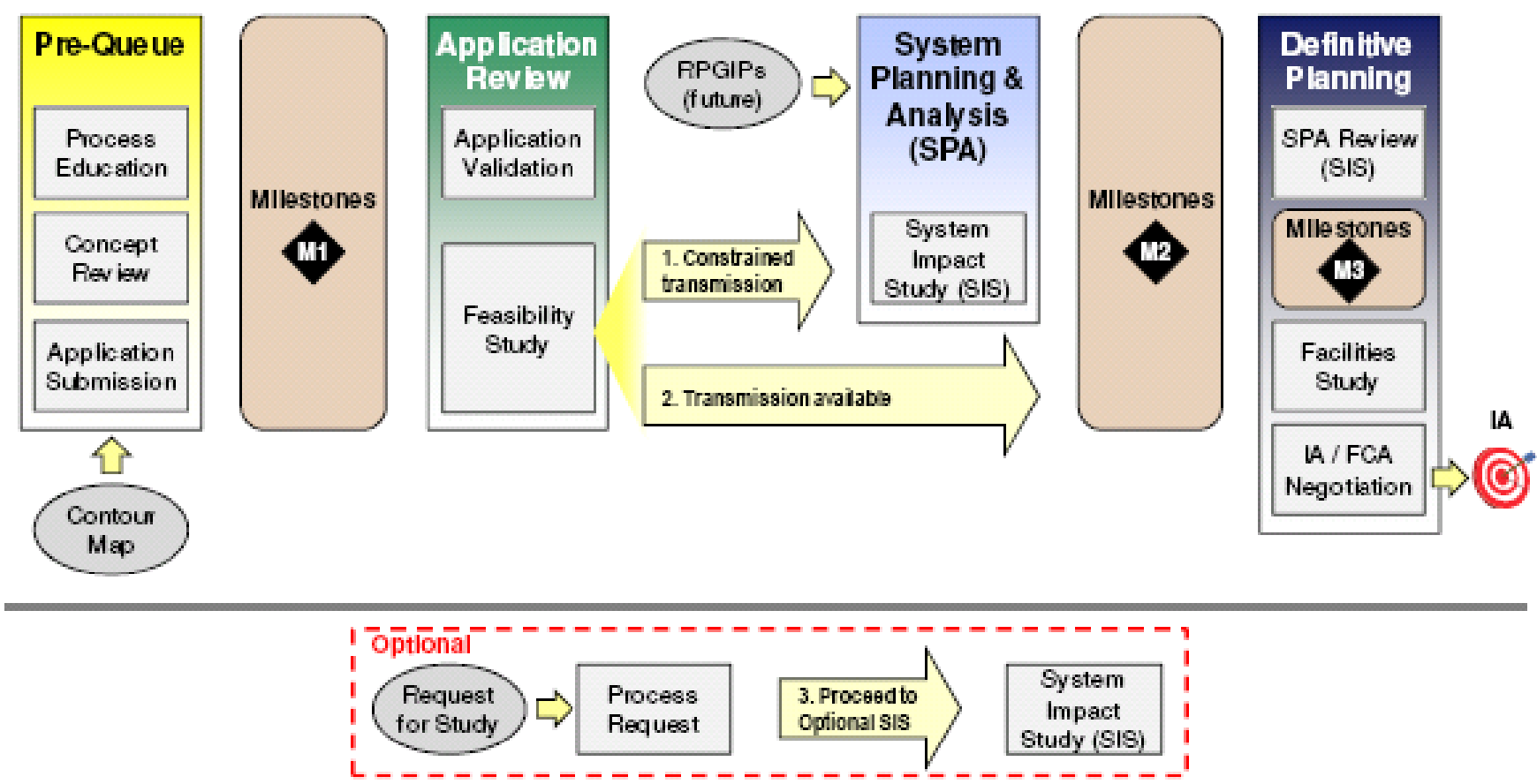

The Pre-Queue phase, which is unlike any phase in the previous process, will provide the customer with an overview to the process, timeline, and expectations. Designed to facilitate a dialogue between the Midwest ISO and the IC, the Pre-Queue phase includes a variety of interconnection education and training materials, contour maps indicating incremental transfer capability on the system, and an estimate of the time it will take to proceed through the interconnection queue at a given location. The Pre-Queue phase includes project-specific meetings and interaction between the Midwest ISO and the IC as well as participation in regularly scheduled Midwest ISO public information sessions. As part of the pre-queue phase, the IC will collect application data prior to formally submitting the application and interconnection request. A non-refundable \$5,000 application fee is required at the end of the pre-queue phase, along with the submission of the application, in order to achieve milestone one (M1) and as a prerequisite to moving to the Application Review phase. Proof of site control, or a $\$ 100,000$ deposit in lieu of site control, is also required at this time. The $\$ 100,000$ deposit is refunded at the time that site control is demonstrated so long as it is prior to the Definitive Planning phase.

The Application Review phase modifies and expands upon the feasibility study required under the previous process. This second phase includes review and clarification of the application and an initial screening to determine the path the project will take in the 
interconnection study process. The Application Review milestones (M2) are technical (generator and project models, one-line diagrams) and non-technical (deposits and documentation). The deposits are scaled based on the size of the project. A Midwest ISO review of prior study costs demonstrates that while there is not a linear correlation between study costs and project size, there is a step function so that larger projects have higher study costs than smaller projects. There is a base level of work for all requests related to running the initial models but as a project increases in size, it becomes likely that more costly solutions requiring more complicated engineering analysis and design will be required. The Midwest ISO now has eight deposit levels (Table E-1) with any unused portions of the study deposit to be refunded should the project withdraw prior to entering the Definitive Planning Phase.

Table E-1

Schedule for Pricing Study Deposits Paid at Application Review

\begin{tabular}{|c|c|c|}
\hline $\begin{array}{c}\text { Project Greater than } \\
\ldots .\end{array}$ & $\begin{array}{c}\text { Project Less than } \\
\text { or Equal to.... } \\
(\mathrm{MW})\end{array}$ & Deposit Amount \\
\hline 0 & 6 & $\$ 10,000$ \\
\hline 6 & 20 & $\$ 20,000$ \\
\hline 20 & 50 & $\$ 30,000$ \\
\hline 50 & 500 & $\$ 60,000$ \\
\hline 500 & 1000 & $\$ 90,000$ \\
\hline 1000 & unlimited & $\$ 120,000$ \\
\hline
\end{tabular}

As part of the Application Review phase, the Midwest ISO will conduct a feasibility study to determine whether the transmission system is "ready," or capable of accommodating the interconnection request. The results of the feasibility study will determine if the addition of the facility would result in transmission constraints that exceed a pre-determined level. The Midwest ISO will evaluate up to three points of interconnection (or voltage levels) as part of the feasibility study. Based on the results of the feasibility study, the IC will indentify a single point of interconnection and the voltage level to be studied through the rest of the process.

If constraints fall within a pre-determined level, the system is found to be ready and the project will bypass the system planning and analysis studies, instead moving directly to the Definitive Planning phase. This typically means that the project is located in a relatively unconstrained area and that any minimal transmission upgrades can be resolved in the first stage of the Definitive Planning phase. Otherwise, the project will continue through the System Planning and Analysis phase where a system impact study will determine the nature of the upgrades required for their interconnection prior to entering the Definitive Planning phase (Figure E-4). Alternatively, if the feasibility study finds that the constraints are within the acceptable limit, i.e., they do not exceed the pre-determined level, and the IC is not ready to proceed to the Definitive Planning phase, the IC can request an optional study to get an indication of their cost obligation. The scope of the optional study is similar to that of the system impact study, but the results are non-binding. Interconnection feasibility studies will be done at regular intervals (approximately every six weeks) and timed to allow entry to the scheduled Definitive Planning phase process. The milestones that must be completed prior to moving beyond the Application Review phase include: 
1. Complete application and associated application fee,

2. Proof of land/site control or additional deposit, and

3. Applicable study deposits received.

\section{Figure E-4 - Review Process for Generator Interconnection Applications}

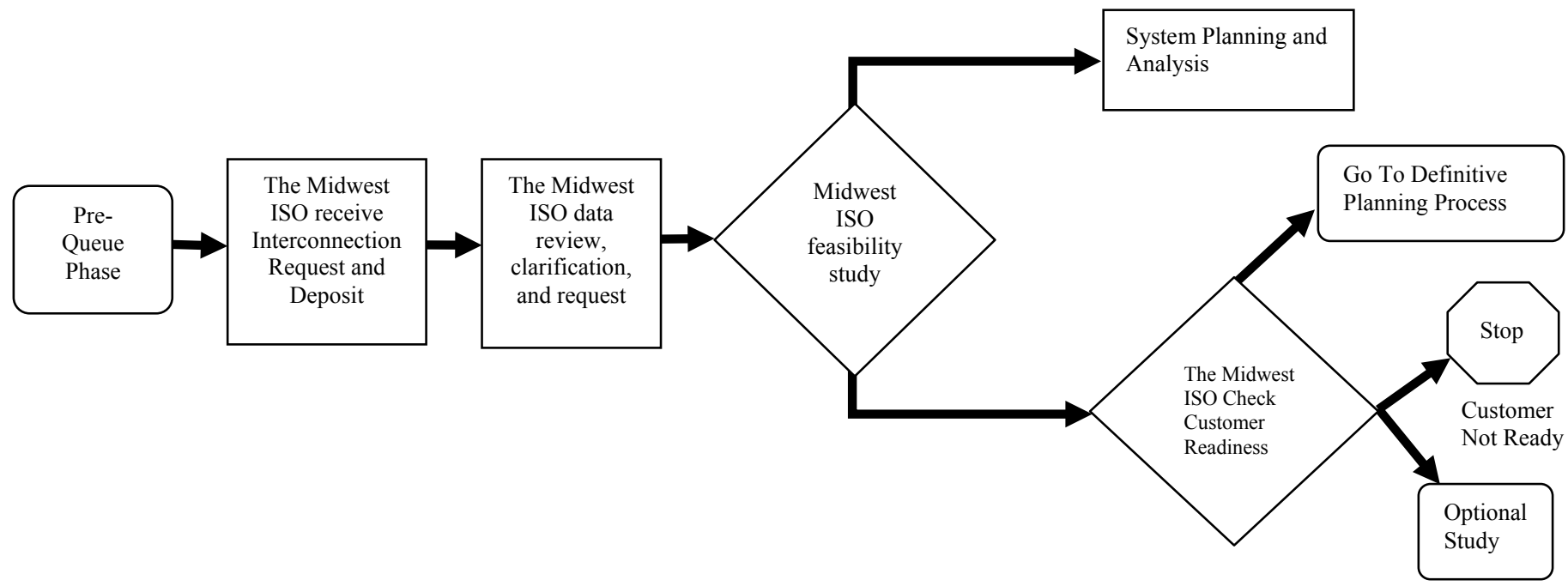

In the System Planning and Analysis phase, a group system impact study (including thermal, short circuit, and stability analyses) will be conducted (see Figure E-5.) The study is conducted by Midwest ISO staff or consultants to the Midwest ISO, or some combination of the two. This phase is similar to the previous system impact studies, except that projects located in constrained areas will no longer hold up projects that are not constrained and could otherwise move forward. Under the new queue process, group studies will be the default (previously group studies were 'permitted'). The Midwest ISO will assemble study groups at periodic intervals based on electrical proximity and common constraint impacts. In the event that a project drops out of the queue after being selected as part of a group study, the Midwest ISO will seek to identify the next eligible, similarly sized project located in the same general area to backfill the group study and avoid restudies. The queue position can change throughout the process until the project goes into the final Definitive Planning phase. Within a study group, the queue positions will be determined based on the order for which the final milestone for each project is met. Network upgrade costs will be allocated based on the MW impact from each project on the constrained facility. 


\section{Figure E-5 - System Planning and Analysis}

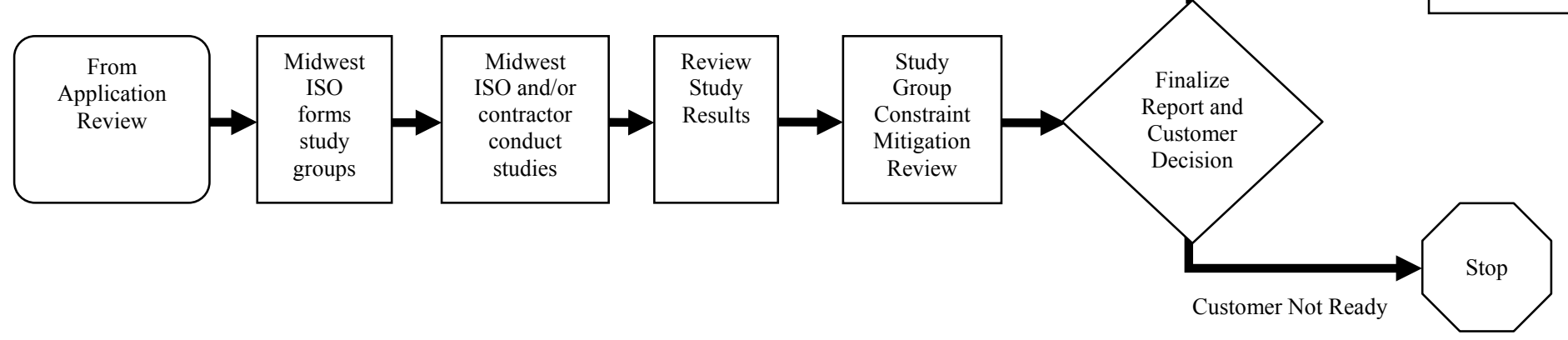

Entry into the Definitive Planning phase requires satisfaction of additional milestones and deposits. All milestones and deposits must be met within 10 days prior to the start of the next Definitive Planning phase. If an IC is not prepared, they may sit out one cycle of the Definitive Planning phase without having to re-submit an application and re-do the feasibility study. The Definitive Planning phase will start on a periodic basis, but specific study window start dates have not been defined. To address the problem of restudy costs, the IC is required to pay a deposit of twice the expected study costs in the Definitive Planning phase (Table E-2). If the project withdraws after entering this phase, the additional study deposit will be used to offset the restudy costs of projects lower in the queue that are electrically connected and impacted by the withdrawal. Unused portions of the additional deposit would be returned to the IC. Furthermore, once an IC has executed an interconnection agreement, it is expected that the project will meet the agreed upon construction schedule and project milestones. Suspension of a project is only allowed in cases of force majeure, and even then, the IC must put forward a deposit equal to the larger of the cost of the network upgrades or $\$ 5$ million, so that projects within the group and placed lower in the queue are not negatively impacted by the suspension. However, the Midwest ISO allows up to six months from the completion of the system planning and analysis review and the start of the facilities study in the Definitive Planning phase, and another three months after the facilities study is completed and before the LGIA is executed, for the IC to address any project-specific issues and to market its capacity. 
Table E-2

Schedule for Pricing Study Deposits Paid at Definitive Planning Phase

\begin{tabular}{|c|c|c|}
\hline $\begin{array}{c}\text { Project Greater } \\
\text { than .... } \\
\text { (MW) }\end{array}$ & $\begin{array}{c}\text { Project Less than } \\
\text { or Equal to.... } \\
\text { (MW) }\end{array}$ & Deposit Amount \\
\hline 0 & 6 & $\$ 40,000$ \\
\hline 6 & 20 & $\$ 100,000$ \\
\hline 20 & 50 & $\$ 150,000$ \\
\hline 50 & 100 & $\$ 210,000$ \\
\hline 100 & 200 & $\$ 260,000$ \\
\hline 200 & 500 & $\$ 360,000$ \\
\hline 500 & 1000 & $\$ 440,000$ \\
\hline 1000 & unlimited & $\$ 520,000$ \\
\hline
\end{tabular}

Other milestones to enter Definitive Planning phase include a detailed stability model; the definitive, final point of interconnection; one-line diagrams showing the facility and associated electrical equipment; the definitive capacity size of the project; and recertification of site control (see Figure E-6). At this point, if the IC cannot establish site control, they may not enter the Definitive Planning phase without losing the $\$ 100,000$ deposit paid at the time when the application was first submitted. After the first stage of the Definitive Planning phase is complete, the transmission provider will request the following items, which the interconnection customer has 30 days to provide: security for the cost of network upgrades estimated in the system planning and analysis review and an execution of a contract for the sale of energy or capacity, or notification from the appropriate state agency that the facility is included in a state resource plan; and demonstration that turbines have been ordered. Processing the data requests quickly and expeditiously meeting the milestones may allow an IC to move up in the queue.

\section{Figure E-6 - Definitive Planning Process}

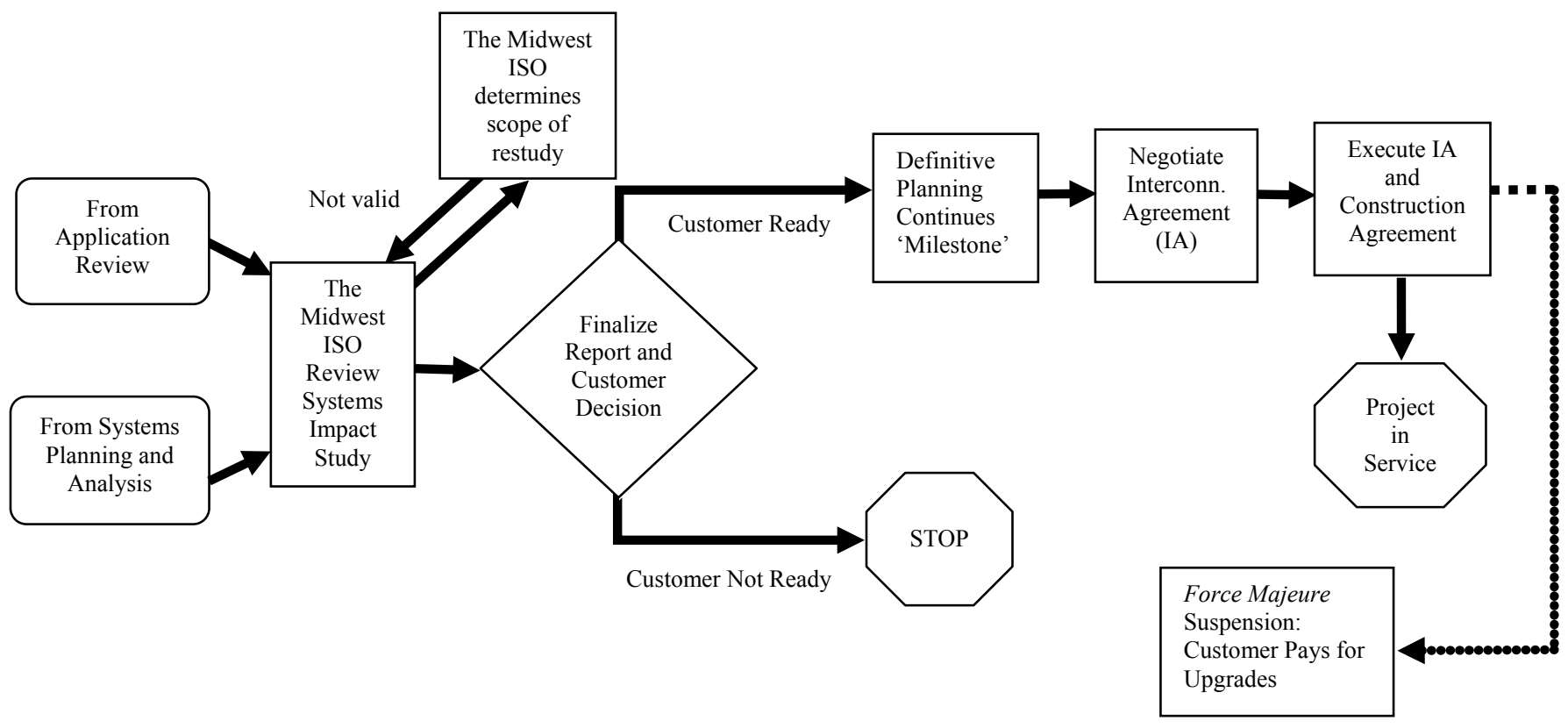




\section{Move to Clear the Queue and Transition to New Study Process}

ICs that have been assigned a queue position prior to the effective date of the revised LGIP (August 25, 2008) will retain their queue position. However, in order to maintain their position and avoid being removed from the queue, ICs must meet certain minimum requirements. Specifically, ICs had 60 days in which to complete their current interconnection process, withdraw from the queue, or decide to continue moving forward under the revised study procedures according to the process and milestones established in the new LGIP. The ICs also had to provide any applicable deposits at the levels required in the revised LGIP within 60 days. Should the IC decide to withdraw from the queue, they could do so within the 60-day period without penalty.

Interconnection requests with an executed system impact study agreement that have unresolved constraints identified through the current stability and analysis study process will have to execute a feasibility study under the revised LGIP, moving back to the Application Review phase. Through this process, the IC will need to update the previously submitted interconnection request and application to conform to new data and deposit requirements.

\section{Next Steps}

\section{The Midwest ISO Transmission Planning}

The recent influx in queue requests is due in part to the development of state RPS policies. In the Midwest ISO footprint, seven states currently have RPS policies and one state has a renewable energy goal. ${ }^{9}$ The current RPS policies will create a demand for approximately $20 \mathrm{GW}$ of new renewable generation in the next 10 to 15 years. Much of this demand will be met by the development of new wind power facilities that are typically located in remote regions where the transmission system may be weak. Attempts to accommodate the need for planning regional transmission expansion through the generation interconnection queue have been problematic and unsuccessful. Without planning backbone transmission for long-term energy delivery needs, the backlogs in the queue will likely continue, even with the queue reform process. The Midwest ISO is working to identify transmission projects through a regional transmission planning process in order to interconnect remotely located generation resources such as wind. The Midwest ISO terms these projects Regionally Planned Generation Interconnection Projects (RPGIP).

The Midwest ISO Board of Directors' planning principles to support the concept of regional planning and are stated as follows:

- Make the benefits of a competitive energy market available to customers by providing access to the lowest possible electric energy costs.

- Provide a transmission infrastructure that safeguards local and regional reliability.

\footnotetext{
${ }^{9}$ FERC Renewable Energy Standards, December 5, 2008. http://www.ferc.gov/market-oversight/mktelectric/overview/elec-ovr-rps.pdf.
} 
- Support state and federal renewable energy objectives by planning for access to all such resources (e.g. wind, biomass, demand-side management).

- Create a mechanism to ensure investment implementation occurs in a timely manner.

- Develop a transmission system scenario model and make it available to state and federal energy policy makers to provide context and inform the choices they face. ${ }^{10}$

The Midwest ISO is currently involved in number of transmission planning activities including: reliability ( 5 to 10 year North American Electric Reliability Corporation (NERC) Reliability Assessment), targeted studies (Narrowly Constrained Areas, Regional Generation Outlet, ITC 765, Southwestern Indiana Economic Transmission); and long-term (the Midwest ISO Transmission Expansion Plan, Joint Coordinate System Plan).

The Midwest ISO's Transmission Expansion Planning (MTEP) is done on overlapping annual and biennial cycles. The fourth regional expansion plan, MTEP-07, was approved by the Midwest ISO Board of Directors in February 2007. ${ }^{11}$ The three primary objectives of the MTEP are:

- Perform reliability assessment of the Midwest ISO integrated transmission system

- Review transmission owning members transmission plans and make sure that appropriate projects are reviewed and recommended to the Midwest ISO Board of Directors for approval

- Develop transmission plans to improve market performance

MTEP-08, which the Midwest ISO Board of Directors approved in December 2008, includes evaluation of four distinct economic futures (reference, environmental, renewable, and limited fuel). The renewable future is based on an assumption that 20 percent of the Midwest ISO region's energy resources will come from wind power.

Furthermore, the Midwest ISO launched the Regional Generation Outlet study in April 2008 to identify near and mid-term regional transmission requirements needed to support renewable energy standards in the Midwest ISO footprint. ${ }^{12}$ A key objective of this study is to identify specific transmission facilities (i.e., regionally planned generation interconnection projects) which can be recommended to the Midwest ISO Board for approval in the MTEP-09. A second phase of this work will focus on current lack of The Midwest ISO-wide consensus on appropriate cost allocation for transmission facilities driven by state renewable energy policies.

\footnotetext{
${ }^{10}$ Planning Objectives Discussion, Midwest ISO Panning Advisory Committee meeting, December 5, 2007. http://www.midwestiso.org/publish/Document/5d42c1_1165e2e15f2 -7ee80a48324a?rev=1.

${ }_{11}$ MISO Transmission Expansion Planning, http://www.midwestiso.org/page/Expansion+Planning.

${ }_{12}$ MISO Regional Generation Outlet study, http://www.midwestiso.org/publish/Folder/6871db_117a25bcaa6 _798d0a48324a.
} 


\section{F. NEW YORK INDEPENDENT SYSTEM OPERATOR ${ }^{1}$}

The New York Independent System Operator (NYISO), a not-for-profit corporation established in 1999, operates New York's bulk electricity grid, administers the state's wholesale electricity markets, and provides reliability planning for the state's bulk electricity system. Like other RTOs and ISOs, the NYISO has seen an increase in the number of interconnection requests submitted since the Standard Large Facility Interconnection Procedures (LFIP) went into effect in August 2004. During 2005, the NYISO received 47 interconnection requests, 30 of which remained in the queue. In 2006, 35 additional requests were received by the NYISO, 25 of which remained in the queue. And in 2007, the NYISO received 38 additional requests, 31 of which remained in the queue. Of the 120 total interconnection requests received by the NYISO from 2005 through 2007, 75 (62.5 percent) were for wind generation projects.

As of April 15, 2008, NYISO's interconnection queue contained 138 separately queued projects, representing more than $26,000 \mathrm{MW}$ of proposed generation and 5,820 MW of proposed transmission.

\section{Generator Interconnection Queue Process ${ }^{2}$}

NYISO receives, processes, and analyzes interconnection requests, assigns queue positions to interconnection customers (IC), and then works with the affected transmission owners to complete the required interconnection studies.

\section{Interconnection Request}

An IC begins by submitting an interconnection request along with a $\$ 10,000$ deposit, demonstration of site control or an additional $\$ 10,000$, and all the required data. A separate interconnection request must be submitted for each site but an IC may submit multiple requests for a single site if, for example, the IC wishes to have the same site evaluated at different voltage levels. NYISO assigns the queue position based on the date and time of receipt of the valid completed interconnection request. A scoping meeting will be held within 30 days at which time the parties will discuss alternative interconnection options and potential feasible points of interconnection.

\section{Interconnection Feasibility Study}

Within five days following the meeting, the IC must specify the desired point of interconnection and any reasonable alternative points. NYISO will then provide the interconnection feasibility study agreement (IFSA) containing a good faith cost estimate for completion. The IC has 30 days to execute the IFSA and provide a $\$ 10,000$ deposit along with all required technical data. NYISO will use all reasonable efforts to complete the study within 45

\footnotetext{
${ }^{1}$ The New York ISO declined to review this appendix. The information presented here is based on the authors' understanding of the New York ISO's generator interconnection procedures.

${ }^{2}$ Information in this section: New York Independent System Operator, Inc., "Standard Large Facility

Interconnection Procedures," FERC Electric Tariff, last updated: July 1, 2008. Accessed August 25, 2008.
} 
days. If a higher queued project drops out of the queue, or if some other modification is made, NYISO may determine that a re-study is necessary. The IC is responsible for all costs associated with a re-study. NYISO, the transmission owner, and the IC may agree to forego the feasibility study, in which case NYISO will initiate an interconnection system reliability impact study to which the $\$ 10,000$ deposit will be applied.

\section{Interconnection System Reliability Impact Study}

Following the feasibility study results meeting (or if the feasibility study has been waived), NYISO shall provide an interconnection system reliability impact study agreement (ISRISA). The IC must execute the agreement within 30 days and provide a $\$ 50,000$ deposit along with demonstration of site control. The impact study consists of a short circuit analysis, a stability analysis, and a power flow analysis and will ultimately provide a list of facilities that are required because of the interconnection request. The NYISO will utilize existing studies to the extent practicable when it performs the study. NYISO reserves the right to study interconnection requests serially, or in clusters, for the system reliability impact study. Clustering will be implemented based on queue position with NYISO including requests that were received within a period not to exceed 180 days. NYISO will make every reasonable effort to deliver the completed impact study within 90 days of receipt of the agreement or within 90 days of the close of the queue cluster window if clustering is used.

\section{Interconnection Facilities Study}

Interconnection facilities studies (IFS) in NYISO are coordinated with the Annual Transmission Reliability Assessment (ATRA). ICs included in each ATRA are referred to as being studied in that "class year" and ICs with IFS agreements made prior to the start of the ATRA are included in the class year studies (discussed in more detail in the next section). Thirty days prior to the start of date of the ATRA, NYISO provides IFS agreements to "eligible developers" who have not already received an agreement for the next class year. An eligible developer refers to an IC that (1) has not been in a prior class year and satisfies the criteria for inclusion in the ATRA, or (2) has been in a prior class year and NYISO assigned the project to the next class year or, the IC had elected to enter the next class year. The IC must execute the agreement by (1) the start date of the ATRA or (2) within 30 days following receipt of the agreement, whichever is the later date. The IC must provide all required technical data and $\$ 100,000$, or the IC's portion of the estimated monthly cost of the study, whichever is greater. As was the case with the system reliability impact study, NYISO will utilize existing studies to the extent practicable when it performs the class year facilities study.

\section{Engineering and Procurement Agreement}

The Engineering and Procurement (E\&P) agreement authorizes the transmission owner to begin engineering and procurement of long lead-time items necessary for the establishment of the interconnection. The E\&P agreement is an optional procedure and will not alter the IC's queue position or in-service date. 


\section{Optional Interconnection Study}

When an IC initiates an interconnection system reliability impact study, they may also request that NYISO perform a reasonable number of concurrent optional studies. Any optional studies performed are solely for informational purposes. NYISO will provide the IC with an optional interconnection study agreement that will:

- Specify the technical data that the IC must provide for each phase of the optional study;

- Specify the IC's assumptions as to which interconnection requests with earlier queue priority dates will be excluded from the optional study case; and

- NYISO's estimate of the cost of the optional study.

\section{Standard Large Generator Interconnection Agreement}

NYISO and the transmission owner(s) will offer the developer a draft standard LGIA. Following execution of the facilities study agreement and at the request of the IC, NYISO and the transmission owner(s) may begin negotiations with the IC on the LGIA and its appendices. Upon completion of the negotiation process, the final LGIA is provided to the IC within 15 business days. Within 15 business days of receiving the final LGIA, the IC must provide NYISO and the transmission owner(s) either reasonable evidence of continued site control, or an additional, non-refundable $\$ 250,000$ deposit which will be applied to future construction costs.

\section{NYISO Initiatives to Address Interconnection Queuing Issues}

NYISO is experiencing some delays in the completion of interconnection studies because of the more involved study process coupled with the substantial growth in the number of projects in the queue. Further complicating the processing of pending interconnection requests are the frequent requests from ICs to modify their project proposals. NYISO has found that the pro forma technical requirements and the detailed base case requirements contained in the tariff do not allow it to customize the interconnection study to a particular project.

Rather than modifying the interconnection queue process itself, NYISO has made changes to how it administers the interconnection queue. When the LFIP went into effect, NYISO restructured its planning department to create a group dedicated to processing interconnection requests. Additional administrative and technical personnel were hired to support the work of this new group. Even with a more robust staff, NYISO has had to expand its use of outside consultants and often requests individual transmission owners to perform portions of the interconnection studies as the sheer volume of work generated by the interconnection requests is more than NYISO can handle in-house.

On top of the staffing increases and use of consultants, NYISO conducted a comprehensive study of the administrative processes required under the LFIP. Specific process improvement measures were identified that have allowed NYISO to expedite the scheduling of scoping meetings for projects entering the interconnection queue. The process improvement measures include: 
1. NYISO will provide the IC with an unexecuted version of the IFSA within five days of receipt of the IC's designation of the point of interconnection,

2. NYISO and the transmission owner(s) will execute the IFSA within 30 days of its receipt by the IC, and

3. NYISO and the transmission owner(s) will execute the ISRISA within 30 days of its receipt by the IC.

Finally, in 2005, NYISO and the New York State Energy Research and Development Authority completed a joint study that evaluated the ability of the New York Control Area's transmission infrastructure to support installed wind generation up to 3,300 MW. The study is currently being updated to evaluate the impact of higher levels of wind generation on the transmission system by load zone. The updated study will focus on four primary issues: (1) performance evaluation of wind generation; (2) a centralized wind forecasting system for greater than 3,300 MW; (3) operating and planning strategies; and (4) reviewing market risk changes to accommodate wind energy. The anticipated completion date for the study update is December $31,2008$.

\section{NYISO Clusters: The Class Year Facilities Study}

NYISO has had a form of clustering in place since FERC approved its open access transmission tariff (OATT) in 2004. Attachment S of the NYISO OATT outlines detailed procedures to allocate the costs of network upgrades amongst a group of proposed projects known as a 'class year'. Under Attachment S, NYISO conducts an annual transmission reliability assessment to identify the network system upgrades required for all generation and merchant transmission projects that are included in a class year cluster. Each project in a class year shares in the then currently available electrical capability of the transmission system and each is allocated a share of the cost of the network system upgrades based on the pro rata impact of its project.

When submitting its compliance filings with Order No. 2003, NYISO expanded the study performed under Attachment $\mathrm{S}$ to a clustered interconnection facilities study. For a project to enter a class year, it must satisfy two milestones by March 1 of that year. ${ }^{3}$

1. The project must have a tariff-compliant interconnection system reliability impact study that has been approved by NYISO's operating committee.

2. The project must satisfy a "regulatory" milestone that indicates progress towards obtaining the necessary environmental permits or approvals. The applicable regulatory milestone depends on the nature of the project; however, satisfying the milestone demonstrates that a significant step in project development has been completed.

\footnotetext{
${ }^{3}$ New York ISO, "Status Report of the New York Independent System Operator, Inc., on Interconnection Queuing Issues," Docket No. AD08-2-000, April 21, 2008.
} 
Eligibility for a class year is not limited to the strict first-come, first-served constraints of an interconnection request's queue position. Once a project receives its assigned cost allocation, it must decide, within a specified period, whether or not to accept it. A project that accepts its cost allocation must post security in the full amount of its allocated share before moving onto an interconnection agreement. Pending certain limitations, a project that does not accept its cost allocation responsibilities may remain in the queue and enter a subsequent class year.

Two components of the class year process have aided in the administration of the interconnection queue. First, requiring that ICs meet two milestones before entering the class year allows them to move through the interconnection process at different speeds, regardless of the relative queue position of its interconnection request or status of projects ahead of it in the queue. Second, requiring that an IC post security at the completion of the class year facilities study provides ICs some level of certainty regarding their system upgrade costs, while minimizing the likelihood that one project's costs could increase as a result of another project dropping out after the study is complete.

\section{FERC Order No. 2003 Compliance}

NYISO's LFIP was approved by FERC and went into effect on August 6, 2004. While the LFIP by and large follows the pro forma procedures under Order No. 2003, they did retain NYISO's cost allocation process that allows NYISO to evaluate network upgrades required by generators on a system-wide basis. The cost allocation process is a type of cost clustering, through which NYISO conducts a facilities study for a group of projects, the class year for each ARTA, identifies the total network system upgrades required to interconnect the new facilities reliably, and then allocates the cost of those upgrades amongst the class year members according to each project's contribution.

\section{Additional Proposed Reforms}

Through an internal process, NYISO identified areas within both the LFIP and Attachment $\mathrm{S}$ that could be improved through tariff amendments. The proposed amendments will be brought through the NYISO stakeholder process. They include, but are not limited to:

1. Clarifying the interconnection request form to streamline the process of obtaining required data from developers;

2. Modifying base case requirements for interconnection feasibility studies and system reliability impact studies to allow for the increased use of "off-the-shelf" base cases;

3. Eliminating unnecessary analysis now called for under Attachment $\mathrm{S}$ by making the IC responsible for the increased costs of network system upgrades caused by a change to the design or operating characteristics of its own project and for costs for items outside the scope of the class year facilities study; and

4. Establishing clear metrics for identifying and removing speculative projects. 
NYISO has begun working with stakeholders to review and identify additional tariff modifications that will improve the interconnection study process. It is anticipated that the discussions will eventually lead to a tariff filing under Section 205 of the Federal Power Act to reform NYISO's interconnection study process. 


\section{G. PJM INTERCONNECTION}

As with other RTO and ISO queues, PJM's generation interconnection requests have grown in the last few years. In 2005, PJM received a total of 116 generator interconnection requests worth approximately 18,000 MW, 66 of which were for wind projects representing 6,300 MW. In 2006, PJM received 146 requests worth 31,000 MW, with 60 of those for wind projects worth $8,000 \mathrm{MW}$. PJM received 170 interconnection requests in 2007 representing almost 38,000 MW of generation; 57 of these were for wind projects worth 22,871 MW. By the end of 2007, PJM had 355 requests in various stages of study and construction in their queue, representing over 74,000 MW of generation, with wind power projects accounting for 162 requests worth over $35,000 \mathrm{MW}$. $^{1}$ PJM's existing capacity at the end of 2007 was approximately $165,000 \mathrm{MW}$.

\section{Queue Process $^{2}$}

Through 2007, the PJM generator interconnection process utilized a form of time-based clustering. PJM previously conducted studies (in groups) twice a year following a six-month application window. In November 2007, PJM submitted a filing to FERC requesting to change the twice-yearly cluster windows to four times per year. ${ }^{3}$ This change was approved by FERC via letter order in January 2008. The windows for receiving applications now run from February $1^{\text {st }}$ to April $30^{\text {th }}$, May $1^{\text {st }}$ to July $31^{\text {st }}$, August $1^{\text {st }}$ to October $31^{\text {st }}$, and finally November $1^{\text {st }}$ to January $31^{\text {st }}$ of the following year. Additionally, the feasibility study phase was extended from 60 days to 90 days in the filing and, thus, begins on the first day of the month following the close of the cluster window. This cluster window system feeds into the PJM Regional Transmission Expansion Planning (RTEP) process. Generator interconnection requests are studied in geographically arranged clusters within each time-based window. PJM allows interconnection customers (IC) to request that their projects be put on suspended status for a maximum cumulative total of three years, but only after the execution of an Interconnection Construction Service Agreement.

\section{Feasibility Study}

The interconnection process begins with the filing of an interconnection request. The IC must provide a fully completed feasibility study agreement along with the required project data. PJM's deposit requirement used to be $\$ 10,000$, but has recently been increased to values that are commensurate with the size of the project and the timing of the application. ICs are required to provide a non-refundable deposit of $\$ 10,000$ for requests made during the first month of the cluster window; $\$ 20,000$ for requests made during the second month; and, $\$ 30,000$ for requests made in the last month. Additionally, ICs are required to provide an initial per MW deposit that will be credited towards feasibility study costs. The study deposit is $\$ 100$ per MW for requests

\footnotetext{
${ }^{1}$ All interconnection data taken from PJM published queue.

${ }^{2}$ Information in this section from: System Planning Division, "PJM Manual 14B: PJM Regional Planning Process," PJM, October 2007 and PJM Open Access Transmission Tariff Effective 10-8-08. Accessed October 29, 2008. http://www.pjm.com/documents/downloads/agreements/tariff.pdf

${ }_{3}^{3}$ PJM Interconnection, “PJM Interconnection, L.L.C., Docket NO. ER08-280-000,” November 30, 2007.
} 
made in the first month; $\$ 150$ per MW for requests made in the second month; and, $\$ 200$ per MW for requests made in the final month. The IC is then assigned a queue position within the current interconnection window. When the window closes, the projects that received queue positions in that time period are studied in clusters. The feasibility studies for that window are to be completed within 90 days of the beginning of the study cycle (May $1^{\text {st }}$ for the window closing April $30^{\text {th }}$ ). The feasibility study consists of a rough approximation of the transmission related costs for each project. Upon completion of the feasibility studies, PJM will conduct scoping meetings with each IC, presenting the results. An IC then has 30 days to decide to move forward with the project by filing a completed system impact study agreement.

In addition to the increased deposit requirements, PJM will conduct initial scoping meetings with all ICs. Scoping meetings will be held within 45 days for requests received within the first month of the cluster window; within 30 days for requests in the second month; and, within 20 days for requests in the last month. At the scoping meeting, an IC can identify two potential points of interconnection for their project, a primary and a secondary. The primary point of interconnection will be used for the feasibility study and the secondary point will be used to conduct a sensitivity analysis. An IC will then have the option to use either the primary or secondary point of interconnection in the system impact study phase. If an IC fails to attend the scoping the meeting and provide the necessary information, or inform PJM of its desire to waive the scoping meeting, PJM will consider the request withdrawn.

\section{System Impact Study}

If an IC wishes to proceed with the project, it must provide the system impact study agreement, all required data, proof of initial applications for any required air permits for the project, and a $\$ 50,000$ deposit. If the IC fails to provide the above within 30 days following the date at which PJM issued the feasibility study results, PJM will consider the request withdrawn. Clustered impact studies are conducted for all projects opting to continue during the next study cycle, beginning 30 days following the end of the feasibility study phase for each cluster. PJM aims to complete the impact studies within 120 days of the start date, but if this is not possible, PJM will contact ICs and inform them of the new anticipated completion date. The system impact study is a comprehensive regional analysis of the impact of adding all the new generation projects within the cluster study window to the PJM system. The study will identify all necessary generator attachment facilities, local upgrades, and general network upgrades, along with estimates of the costs involved and the allocation of those costs.

Once the impact studies are completed, PJM will inform the ICs of the results. ICs then have 30 days to request up to two optional studies if they require more information to make a decision to continue. Within 30 days of receiving the final study results, the ICs must execute a facilities study agreement with PJM, along with a deposit of $\$ 100,000$ or the estimated amount of the IC's costs for the first three months of study work, whichever is greater. PJM will then determine if there is a need to conduct updated impact studies, taking into account any project withdrawals. The final results of the impact study cycle are then rolled into the annual RTEP process for inclusion in the RTEP plan that is submitted to the PJM Board of Managers for approval. 


\section{Interconnection Facilities Study}

The final stage consists of detailed facilities studies for the set of projects within each time-based window that have elected to continue through to the interconnection phase. The facility studies will provide details of the engineering design work required to construct transmission facilities. The study will also outline PJM's good-faith estimate of the cost responsibilities of each participant and the time required to complete each project's required facilities and upgrades. Cost responsibility as allocated through the facilities study and the RTEP process identifies two types of costs:

1. Direct connection attachment facilities - the equipment required for the generator to get to the point of interconnection with the PJM grid. All direct connection facilities costs are borne by the particular generation project.

2. Network reinforcements - these are all the grid upgrades required to accommodate the new generation from all the projects in the plan. Project owners are subsequently reimbursed for these costs through the receipt of firm transmission rights. Cost allocations for network upgrades are based on the cost for resolving reliability issues associated with the generation projects. If the cost of the network upgrades for resolving any single reliability violation is estimated to be less than $\$ 5,000,000$, then all costs are allocated amongst the projects in each geographic study cluster according to the percent impact that each project contributes to network upgrade requirements. If the cost of network upgrades associated with any single reliability violation is estimated to cost greater than $\$ 5,000,000$, then:

i. The transmission providers must identify the first project that triggers the additional cost.

ii. Costs for the relevant network upgrades are then allocated to that first project and all the projects following it in the interconnection queue, according to their pro rata contribution.

\section{Interconnection Service Agreement and Construction Service Agreement}

Following completion of the study stages, an IC has 60 days to execute an interconnection service agreement. This must include a letter of credit or other form of security in an amount equal to the estimated costs allocated to their project and all required technical data. Additionally, ICs must demonstrate that the following have been obtained:

- Fuel and/or water delivery agreement if needed;

- Control of rights-of-way for fuel and/or water connections if needed;

- Any local, county, state site permits required; and

- Signed memoranda of understanding for major equipment.

If an IC disagrees with the terms in their interconnection service agreement, or is unable to negotiate terms in the agreement which are acceptable to all parties, they may request to have an unexecuted service agreement filed with FERC, or may request initiation of a dispute 
resolution process. Coincident with or following the execution of the service agreement, the IC must execute a construction service agreement within 90 days of receiving the agreement for execution, if PJM and the affected transmission owner(s) determine that such an agreement is necessary. Execution of a construction service agreement will allow work to commence on the engineering, design, and construction of the required facilities. PJM allows an IC to design, construct and install some portions of the required transmission facilities if the IC and the transmission owner(s) can reach agreement on the terms of this construction under the 'option to build'.

\section{Wind Interconnection and Capacity Status}

PJM allows ICs to choose whether they wish to be considered an energy-only resource or a capacity resource. Capacity resources are subsequently allowed to participate in PJM's capacity market. Study requirements and the upgrades developed for the two types of resources differ, dependant upon the reliability requirements associated with each type of resource and, hence, costs may be different. PJM allows wind power projects to apply for capacity resource status and then models new wind projects with a class average capacity value, currently set at 13 percent. The class average capacity value for wind is determined annually by the collection capacity factor of wind generation in PJM between the hours of 2 p.m. to 6 p.m., inclusive, between June through August. A wind project may request a different capacity factor be used if adequate supporting data can be provided. ${ }^{4}$

\section{Proposed Reforms ${ }^{5}$}

The PJM Regional Planning Process Working Group (RPPWG) is examining further reforms to the interconnection process. For example, a reform under discussion is an increase to the system impact study deposit that would link it to the size of the project. Options presented have included:

1. A $\$ 20,000$ non-refundable deposit plus $\$ 100$ per $\mathrm{MW}$, maximum $\$ 120,000$.

2. A $\$ 30,000$ non-refundable deposit plus $\$ 300$ per $\mathrm{MW}$, maximum $\$ 300,000$.

Additionally, the RPPWG is examining changes to the facility study aimed at moving projects faster through the planning process, adding milestones to demonstrate financing, including a non-refundable deposit based on project size, and providing a higher level of certainty. The specifics of these changes are still under discussion and are subject to change.

\section{FERC Order 2003 Compliance}

The PJM interconnection process mostly follows Order 2003 standards, adapting them for the particular form of clustering that fits with the PJM regional planning process.

\footnotetext{
${ }^{4}$ System Planning Department, "PJM Manual 21: Rules and Procedures for Determination of Generating Capability,” PJM, April 2008.

${ }^{5}$ PJM Regional Planning Process Working Group materials. Accessed December 3, 2008. http:/www.pjm.com/committees/working-groups/rppwg/rppwg.html
} 


\section{H. SOUTHWEST POWER POOL ${ }^{1}$}

The Southwest Power Pool (SPP) is an RTO designed to ensure reliable supplies of power, adequate transmission infrastructure, and competitive wholesale prices of electricity. SPP has members in nine states-Arkansas, Kansas, Louisiana, Nebraska, Mississippi, Missouri, New Mexico, Oklahoma, and Texas - for which it oversees compliance enforcement and reliability standards development. SPP has experienced significant increases in new interconnection requests in the last two years. At the end of 2007, there were 128 projects representing 30,129 MW in the queue. As of July 22, 2008, there were 205 active generator interconnection requests, which represent a 64 percent increase as compared to 2007. Those 205 generator interconnection requests amount to almost 51,143 MW (see Table H-1).

Nearly 85 percent of the projects in the queue are renewable energy projects. Of these, all but one of the renewable energy projects are wind projects. The projects are fairly evenly distributed among Kansas, Missouri, New Mexico, Oklahoma, and Texas. Just two of the states - New Mexico and Texas - have a renewable portfolio standard, and may not directly account for the drastic increase in projects. The significant increase in wind projects may more directly be attributed to uncertainty in the availability of the federal production tax credit and above-average wind resources within the SPP footprint.

Table H-1 - SPP Interconnection Queue ${ }^{2}$

\begin{tabular}{|c|c|c|}
\hline & $\begin{array}{l}\text { No. of } \\
\text { Projects }\end{array}$ & MW \\
\hline Feasibility Study Requested & 89 & $26,564.1$ \\
\hline Feasibility Study Completed or In-Progress ${ }^{(1)}$ & 25 & $6,835.2$ \\
\hline Active Projects in Impact Study Stage (Completed or In-Progress) & 13 & $2,455.0$ \\
\hline Active Projects in Facility Study Stage (Completed or In-Progress) & 13 & $2,485.2$ \\
\hline Active Projects - Interconnection Agreement (IA) Pending & 10 & $2,367.5$ \\
\hline $\begin{array}{l}\text { Active Projects - IA Fully Executed (Commercial Operation, } \\
\text { On Suspension, On Schedule) }\end{array}$ & 53 & $10,035.9$ \\
\hline Active Wind Projects in the Queue & 174 & $42,941.1$ \\
\hline Active Other Renewable Projects in the Queue & 1 & 16 \\
\hline Active Projects in the Queue - Total & 205 & $51,142.9$ \\
\hline
\end{tabular}

\section{Compliance with FERC Order No. 2003}

SPP was granted preliminary RTO status on February 10, 2004, and final RTO status on October 1, 2004. Their compliance filing (i.e., Order No. 2003) was accepted by the FERC on June 21, 2004. SPP's LGIP, established in compliance with FERC Order 2003, consists of a

\footnotetext{
${ }^{1}$ The Southwest Power Pool was unable to provide review comments. The information presented here is based on the authors' understanding of the Southwest Power Pool's generation interconnection procedures.

${ }^{2}$ As of July 22, 2008.
} 
centralized study process. Each proposed project is reviewed and analyzed, with respect to the other projects earlier in the queue, to assess the impact on the regional transmission system.

\section{Generation Interconnection Queue Process ${ }^{3}$}

SPP coordinates the generation interconnection process and oversees the study requirements on behalf of the transmission providers in its jurisdiction. Under the LGIP and LGIA tariffs, the SPP serves as the primary coordinator of analytic activities; however, the studies themselves may be performed by SPP, transmission owners, or external contractors. While SPP's generation interconnection process is structured such that the projects higher in the queue are analyzed first, if an interconnection customer (IC) fails to meet designated timelines during the process, their queue position will be deemed withdrawn by SPP.

The SPP tariff contains provisions for SPP to perform cluster studies but to date, SPP has opted to use a serial study format. In its current form, SPP's sequential queue process consists of the following:

\section{Interconnection Request}

An IC submits an interconnection request along with a refundable $\$ 10,000$ deposit and demonstration of site control or an additional $\$ 10,000$. The request must specify the type of interconnection desired: energy resource or network service. A scoping meeting will be held at which time a point of interconnection and feasible alternative points will be discussed. SPP will assign the IC a queue position based on the date and time the interconnection request was complete.

\section{Interconnection Feasibility Study}

Following the scoping meeting, SPP will provide a feasibility study agreement with a cost estimate for completion. The IC has 30 days to execute the agreement and provide the required data along with a $\$ 10,000$ deposit. The IC and transmission owner(s) may choose to forego the feasibility study, in which case the $\$ 10,000$ deposit will be applied to the costs of the system impact study. SPP will use reasonable efforts to complete the study within 45 days.

\section{Interconnection System Impact Study}

Within three days following the feasibility study results meeting, SPP will provide a system impact study agreement along with a cost estimate and time frame for completion. The IC has 30 days to execute the agreement along with demonstration of site control and a $\$ 50,000$ deposit. SPP will use reasonable efforts to complete the study within 90 days.

\footnotetext{
${ }^{3}$ Information in this section from: Southwest Power Pool, "Open Access Transmission Tariff for Service Offered by Southwest Power Pool: Attachment V, Standard Large Generator Interconnection Procedures," FERC Electric Tariff with revisions approved through December 1, 2008, accessed December 3, 2008.
} 


\section{Interconnection Facility Study}

Within three days following the impact study results meeting, SPP will provide a facilities study agreement along with a good faith estimate of the cost and timeframe for completion. The IC has 30 days to execute the agreement and provide the required technical data along with a $\$ 100,000$ deposit or the IC's portion of the estimated monthly cost of the study, whichever is higher. SPP will use reasonable efforts to complete the study within (1) 90 days at $+/-20$ percent of cost or (2) 180 days at +/- 10 percent of the cost, as requested by the IC. If a higher queued project drops out of the queue, or if modifications are made to a higher queued project then a re-study is required. SPP will notify the IC in writing of such a requirement and any associated costs shall be borne by the customer.

\section{Engineering \& Procurement Agreement}

This is an optional agreement that allows a transmission owner to begin engineering and procurement of long lead-time items.

\section{Large Generator Interconnection Agreement}

Following the results meeting and any needed negotiations, the IC must execute an LGIA and provide evidence of continued site control or post $\$ 250,000$ non-refundable additional security. The IC must also provide evidence that one or more of the following (as applicable) has been achieved:

- Execution of a contract for supply or transportation of fuel.

- Execution of a contract for cooling water.

- Execution of a contract for engineering for, procurement of major equipment for, or construction of, the facility.

- Execution of a contract for the sale of electric energy or capacity from the facility.

- Application for air, water, or land use permits.

\section{SPP's Proposed Revisions to the Queue Process ${ }^{4}$}

In early 2008, SPP formed the Generation Queuing Task Force (GQTF) whose mission is to accelerate the processing of large generator interconnection requests. The GQTF consists of transmission owners, renewable developers and marketers, and SPP staff. The group began meeting monthly, both in-person and via conference call, in March 2008. The existing queue process will be revised to consist of milestones that generators will have to meet before moving forward; essentially moving away from a first come, first served approach to a queue management approach. In addition, SPP plans to propose significant increases in required deposits and other associated fees. These proposed reforms are currently in the final approval phases at SPP, and SPP plans to submit a proposed tariff amendment to FERC by March 2009.

\footnotetext{
${ }^{4}$ Information in this section from: SPP Generation Queuing Task Force Documents, accessed December 3, 2008. http://www.spp.org/section.asp?group=1227\&pageID=27
} 
The proposed interconnection procedure contains a Pre-Application Phase, an Application Review Phase that contains sets of milestones and three different queues depending on which study stage the project is in, and a final Facilities Study Phase.

1. Pre-Application Phase

This is an optional phase where SPP will provide all the required information to an IC that wishes to perform their own feasibility study. A non-disclosure agreement will be required.

2. Application Review Phase

This phase contains three different queues and depending on which set of milestones an IC meets, the IC will be placed in one of the following three queues:

(1) Feasibility Study/Screening Process

An IC may submit a request for an optional feasibility study. Feasibility studies will be performed once every three months for the requests received during a three-month window. The IC does not receive a binding queue number but will be assigned to the Feasibility Queue. ICs must meet Milestone Set 1: $\$ 10,000$ deposit and basic study materials.

(2) Preliminary Impact Study

ICs will be able to submit a request during a six-month window and will be assigned a Preliminary Planning Queue number. ICs must meet Milestone Set 2:

- Deposit based on project size:

$\circ$ Less than $100 \mathrm{MW}-\$ 40,000$

- Between $100 \mathrm{MW}$ and $800 \mathrm{MW}-\$ 60,000$

○ Greater than $800 \mathrm{MW}-\$ 90,000$

- Documentation of site control.

- Detailed study data.

(3) Definitive Planning Process

ICs that are able to meet a more inclusive set of milestones can proceed straight to this stage that will begin every six months. Under this process, ICs will be assigned to the Definitive Planning Queue. ICs must be able to meet Milestone Set 3 as listed below:

- Study Deposit based on project size:

- Less than $75 \mathrm{MW}-\$ 75,000$

- Greater than $75 \mathrm{MW}-\$ 150,000$

- Definitive point of interconnection. 
- Definitive plant size in MW. No decrease in plant capacity is allowed after the study is completed.

- Site control.

- Detailed study materials.

- Additionally, one of the following milestones must be met:

- Security equal to $\$ 2,000 / \mathrm{MW}$ of the plant size (refundable at a commercial operation or withdrawal).

- A power purchase agreement or similar hedge type agreement, or a signed statement attesting that the project is included in an applicable state resource plan, or other information to indicate the project will qualify as a designated network resource in SPP.

- A purchase order for generating equipment specific to project in the queue position (not a blanket order) or a signed statement attesting the facility is included to be supplied with turbines.

- Application for an air permit.

- Application for a Federal Aviation Administration permit.

3. Facility Study Phase

An IC must have progressed through to the Definitive Planning Phase to be eligible for a facilities study. The IC has 30 days after receiving the definitive impact study results to meet one of the milestones in Milestone Set 4. If this cannot be accomplished, the request will be withdrawn and the IC must re-enter the process at the next Definitive Planning window. The list of milestones in Milestone Set 4 is as follows:

- Letter of credit or payment for estimated network upgrades.

- A power purchase agreement or similar hedge type agreement, or a signed statement attesting that the project is included in applicable state resource plan, or other information to indicate the project will qualify as a designated network resource in SPP.

- A purchase order for generating equipment specific to the project in the queue position (not a blanket order) or a signed statement attesting the facility is included to be supplied with turbines.

- Application for an air permit.

- Application for a Federal Aviation Administration permit.

Upon completion of the Facility Study Phase, the IC is provided a draft standard LGIA with appendices, at which time it has 60 days to negotiate with SPP and the transmission owner(s). SPP plans to continue to allow ICs to suspend processing of their queue application for a cumulative period of up to 18 months after completion of the Facility Study Phase, but ICs will still be required to pay for their allocated cost of shared network upgrades. 


\section{WESTERN AREA POWER ADMINISTRATION}

Western Area Power Administration is a Federal agency that markets and delivers reliable, cost-based hydroelectric power and related services within a 15-state region of the central and western U.S. Its role is to transmit electricity from multi-use water projects, which includes 57 power plants operated by the Bureau of Reclamation, U.S. Army Corps of Engineers and the International Boundary and Water Commission. Together, these plants have an installed capacity of 10,395 megawatts.

In order to fulfill its role, Western owns and operates more than 17,000 miles of transmission lines that are used to deliver federal power on a project-specific basis to preference customers throughout its 1.3 million square mile region. Some of Western's transmission facilities are interconnected to project-specific transmission and distribution facilities, for example large federal facilities, and others are interconnected to third party transmission lines, for example utility transmission systems that step down to distribution lines for delivery of retail power.

Western's transmission system overlays nine of the 10 windiest states in the nation, leading to increased interconnection requests by wind power developers. As of January 2008, Western had already interconnected $305 \mathrm{MW}$ of wind, with more than 69 additional study requests in the queue, totaling more than 14,000 $\mathrm{MW}$ of renewable generation. Representative projects include an 8.3 MW wind farm in Wyoming to a $50 \mathrm{MW}$ wind farm in South Dakota. Western also receives two to three interconnection requests from larger fossil fuel-fired facilities each year. As with other transmission providers, recent increases in interconnection requests have strained Western's system planning resources. Western is currently evaluating its interconnection process.

Western is not a public utility subject to FERC jurisdiction under Sections 205 and 206 of the Federal Power Act. ${ }^{1}$ It is therefore not subject to the open access requirement of Order Nos. 888 and 2003, which are broadly applicable to public utilities. Western does voluntarily file an OATT with the FERC under the safe harbor reciprocity conditions provided through Order No. 888. Under this procedure, Western may voluntarily submit to FERC a transmission tariff and a request for a declaratory order that the tariff meets the FERC comparability (nondiscrimination) standards. If FERC finds that such a tariff contains terms and conditions that substantially conform or are superior to those in the pro forma OATT contained in Order No. 888, and the LGIA and LGIP pro forma tariffs provided in Order No. 2003, FERC will deem it to be an acceptable reciprocity tariff and will require public utilities to provide open-access transmission service upon request to that particular non-public utility. This reciprocity is necessary to deliver power to some federal power customers without a direct interconnection to Western's system.

While not a public utility subject to FERC Order 888 , Western is a transmitting utility subject to Sections 211-213 of the Federal Power Act which grants authority to FERC regarding the interconnection and wheeling of electric power. Order No. 2003 provides that nonjurisdictional utilities (such as Western) that wish to maintain safe-harbor open access tariffs

\footnotetext{
${ }^{1}$ Sections 205 and 206 are specific to issues related to rates and charges and the power of FERC to regulate rates and charges.
} 
must adopt an LGIP and an LGIA that "substantially conforms to or are superior to" FERC's pro forma documents. Subsequently, on January 26, 2005, Western filed revisions to its nonjurisdictional open access transmission tariff to incorporate changes to the LGIP and LGIA to conform, as much as possible, to the pro forma tariffs provided in FERC Order No. 2003. However, as a federal government entity subject to the laws and provisions that regulate the operation and administration of government agencies, Western is not able to comply with 100 percent of the pro forma tariffs. Included with their January 26, 2005 filing of the LGIA and LGIP documents, Western provided a cover letter that lists the exceptions and proposed modifications to the pro forma documents. The more significant modifications proposed by Western are listed below:

1. Any language referencing compliance under Sections 205 and 206 of the Federal Power Act were deleted.

2. As a non-profit federal power marketing agency subject to Executive and Congressional oversight regarding staffing, funding, and authorization limits, Western may not have sufficient resources to meet the timeframes proposed in the pro forma LGIA. Western proposed modifying the LGIA and LGIP to include language saying that Western may meet all deadlines using "reasonable efforts."

3. Western has added language to the LGIP that allows the Interconnection Customer additional flexibility in locating the point of interconnection.

4. The pro forma LGIP has a provision whereby the Interconnection Customer may only be charged the amount of the construction cost estimates provided by the Transmission Provider, even if the costs to interconnect are higher, leaving the Transmission Provider to pay the difference. However, a key requirement of the Federal Anti-Deficiency Act restricts Western from obligating funds that have not yet been congressionally appropriated or authorized for expenditure. Consequently, Western added language stating that, regardless of the provided estimates, Western will charge the Interconnection Customer for all actual amounts and if Western overestimates the charges, it will refund the dollars against actual dollars spent. Similarly, Western added language that requires Interconnection Customers to pay for the cost of negotiations, and revised articles referring to payment of "liquidated damages."

5. Western is required by law to conduct a mandatory environmental analysis. Thus, the LGIP was revised to condition Western's offering of an Engineering and Procurement Agreement or a final LGIA upon Western's determination that it may proceed with construction under the National Environmental Protection Act.

6. The pro forma LGIA allows the LGIA to remain in effect for a period of 10 years from the effective date or a longer (indefinite) period at the request of the Interconnection Customer. Western found that this language could obligate the federal government to rebuild aging Interconnection Facilities without prior Congressional appropriations or authorization to expend funds. This section was subsequently modified to limit the maximum term of the LGIA to 40 years, at the written request of the customer. 
7. Western revised the LGIP and LGIA to reflect its general requirement to comply with Department of Energy standards and directives related to physical infrastructure security, as well as "Good Utility Practices."

8. The pro forma LGIA allows Western to inspect any facilities being constructed by the Interconnection Customer, but does not pass the costs of those inspections on to the other party as required by longstanding Western policy. Accordingly, Western modified the LGIA (Article 5.2) to require the Interconnection Customer to pay Western's costs for inspection.

9. As a Federal entity, Western does not, as a general rule, pay taxes. Language in that regard has been removed from the tariff.

10. The 20-year network upgrade crediting period limit set forth in Order No. 2003-B could obligate Western to make a balloon payment at the end of the 20-year period without having first obtained the necessary Congressional appropriations or authorization for expenditure of funds. Western clarified that it will provide credits for network upgrades under the LGIA without any restriction as to the period of time so that there is no risk of having to make a balloon payment to repay the balance for network upgrades.

11. The LGIA was revised to require advanced payment for all work related to network upgrades. As written, the pro forma LGIA would have required Western to accept a guarantee, a surety bond, letter of credit or other form of security in lieu of actual payment for procuring, constructing, and installing Network Upgrades. However, Western does not accept a provision of security to perform such services; rather, it requires advance payment to do so consistent with the Federal Contributed Funds Act.

12. Western modified the invoice provisions to clarify that Western will not pay interest on money owed to the Interconnection Customer except as expressly provided for in the LGIA.

FERC issued a declaratory order in August 2005 that found Western's LGIA and LGIP tariff provisions acceptable with the exception of one modification. The one exception was changes made to termination language under Attachment J, Section 1 that allowed the transmission customer to terminate the agreement upon ninety days' notice of a rate change. Western states that, when it filed its original OATT, it had not yet developed separate rates for transmission and ancillary services that would require Western to adjust its rates on a routine basis. Western found the blanked termination clause to add too much risk of violating federal provisions and requested that the termination be allowed only in instances where Western changes the formula through which rates are set. With some modifications to terminology and definitions, this provision was later accepted by FERC and the Western LGIA and LGIP were accepted for under safe harbor granting Western reciprocity that is necessary for Western's role as a power marketer and in wheeling power. 


\section{REPORT DOCUMENTATION PAGE}

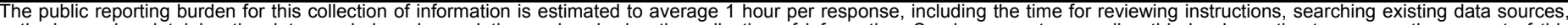

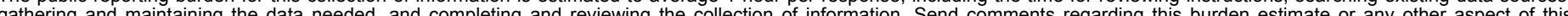

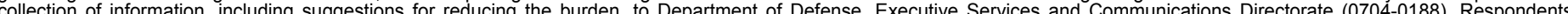

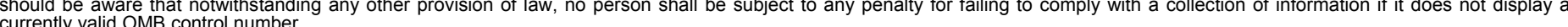

PLEASE DO NOT RETURN YOUR FORM TO THE ABOVE ORGANIZATION.

\begin{tabular}{l|l|l|l} 
1. REPORT DATE $(D D-M M-Y Y Y Y)$ & 2. REPORT TYPE & 3. DATES COVERED (FrOm - TO)
\end{tabular} January 2009

Subcontract Report

4. TITLE AND SUBTITLE

Generation Interconnection Policies and Wind Power: A Discussion

of Issues, Problems, and Potential Solutions

6. AUTHOR(S)

K. Porter, S. Fink, C. Mudd, and J. DeCesaro 5a. CONTRACT NUMBER

DE-AC36-08-GO28308

5b. GRANT NUMBER

5c. PROGRAM ELEMENT NUMBER

5d. PROJECT NUMBER

NREL/SR-550-44508

5e. TASK NUMBER

WER9.6501

5f. WORK UNIT NUMBER

7. PERFORMING ORGANIZATION NAME(S) AND ADDRESS(ES)

Exeter Associates, Inc., 5565 Sterrett Place, Suite 310, Columbia, MD

21044

8. PERFORMING ORGANIZATION REPORT NUMBER

LAM-8-77548-01

9. SPONSORING/MONITORING AGENCY NAME(S) AND ADDRESS(ES)

National Renewable Energy Laboratory

10. SPONSOR/MONITOR'S ACRONYM(S)

NREL

1617 Cole Blvd.

Golden, CO 80401-3393

11. SPONSORING/MONITORING AGENCY REPORT NUMBER NREL/SR-550-44508

12. DISTRIBUTION AVAILABILITY STATEMENT

National Technical Information Service

U.S. Department of Commerce

5285 Port Royal Road

Springfield, VA 22161

13. SUPPLEMENTARY NOTES

NREL Technical Monitor: David Corbus

14. ABSTRACT (Maximum 200 Words)

This report describes the adoption and implementation of FERC Order 2003 and the reasons for the sharp rise in generation interconnection filings in recent years.

\section{SUBJECT TERMS}

Wind; FERC; regulation; grid integration; system integration; interconnection; utilities; power generators; ISO; capacity.

\begin{tabular}{l}
\hline 16. SECURITY CLASSIFICATION OF: \\
\begin{tabular}{|l|l|l|}
\hline a. REPORT & b. ABSTRACT & c. THIS PAGE \\
Unclassified & Unclassified & Unclassified \\
& & \\
\hline
\end{tabular} \\
\hline
\end{tabular}

\begin{tabular}{|c|c|}
\hline $\begin{array}{l}\text { 17. LIMITATION } \\
\text { OF ABSTRACT }\end{array}$ & $\begin{array}{l}\text { 18. } \text { NUMBER } \\
\text { OF PAGES }\end{array}$ \\
\hline UL & \\
\hline
\end{tabular}

19a. NAME OF RESPONSIBLE PERSON

19b. TELEPHONE NUMBER (Include area code) 